\title{
A Comparison of Ground Motion Characteristics from Induced Seismic Events in Alberta with those in Oklahoma
}

Krista M. Kaski, The University of Western Ontario

Supervisor: Dr. Gail M. Atkinson, The University of Western Ontario

A thesis submitted in partial fulfillment of the requirements for the Master of Science degree in Geophysics

(c) Krista M. Kaski 2017

Follow this and additional works at: https://ir.lib.uwo.ca/etd

Part of the Geophysics and Seismology Commons

\section{Recommended Citation}

Kaski, Krista M., "A Comparison of Ground Motion Characteristics from Induced Seismic Events in Alberta with those in Oklahoma" (2017). Electronic Thesis and Dissertation Repository. 5063.

https://ir.lib.uwo.ca/etd/5063

This Dissertation/Thesis is brought to you for free and open access by Scholarship@Western. It has been accepted for inclusion in Electronic Thesis and Dissertation Repository by an authorized administrator of Scholarship@Western. For more information, please contact wlswadmin@uwo.ca. 


\begin{abstract}
Ground motions from potentially-induced seismic events in Alberta of magnitude (M) > 3, recorded within $100 \mathrm{~km}$, are empirically characterized in terms of their response spectral shapes and amplitudes. Ground motions are compared statistically to those from induced events in Oklahoma, as well as to three benchmark ground motion prediction equations (GMPEs), derived from natural events. Discrepancies between Alberta and Oklahoma events appear to be magnitude-dependent, and distance-independent. For events greater than $\mathbf{M} \sim 4$, the ground motions appear equivalent in the two regions. Highfrequency motions from $\mathbf{M}<3.5$ events in Alberta are weaker than those of natural events, even those at shallow focal depths. For larger magnitudes, the residuals between the Alberta motions and benchmark GMPEs (Yenier and Atkinson, 2015; Atkinson, 2015; Abrahamson et al., 2014) suggest that observations are in reasonable accord with the models. These results provide a further understanding of ground motions from induced events in Alberta.
\end{abstract}

\title{
Keywords
}

Induced seismicity, Ground motion characteristics, Ground motion prediction equations, Seismic hazard, Alberta, Oklahoma. 


\section{Co-Authorship Statement}

This thesis is prepared in integrated-article format and includes the following manuscript written by Krista Kaski and the co-author. Krista is the first author on this study of ground motion characteristics from induced seismic events in Alberta. Krista performed the analyses described in this thesis and authored the article below with assistance from the co-author.

1) Kaski, K. M. and G. M. Atkinson (2017). A Comparison of Ground Motion Characteristics from Induced Seismic Events in Alberta with those in Oklahoma, Seismological Research Letters, 88, no. 6, 1570-1585.

The thesis and the composed article were completed under the supervision of Dr. Gail M. Atkinson. 


\section{Acknowledgements}

Firstly, I would like to whole-heartedly thank my supervisor Dr. Gail Atkinson for her guidance and encouragement throughout the course of my Masters, and her insightful leadership and contribution to this project. I have always admired Dr. Atkinson's leadership, organization, and her expertise in her field. She has helped me to grow as a researcher and geoscientist, and I plan to take all that she has taught with me to my future research and career endeavors.

Secondly, I would like to thank Dr. Karen Assatourians for his tireless work processing and compiling all the data used in this study, and Mark Novakovic for compiling the data and calculating the event magnitudes. Their efforts are greatly appreciated and of course this wouldn't have been possible with them. Additionally, I would like to thank Dr. Hadi Ghofrani for his kind words and encouragement throughout this process.

Lastly, I would like to of course thank my incredibly supportive and loving parents for their strength, wisdom, and never-wavering advocacy of myself and my educational pursuits. 


\section{Table of Contents}

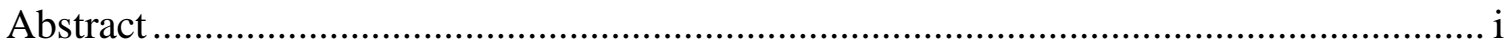

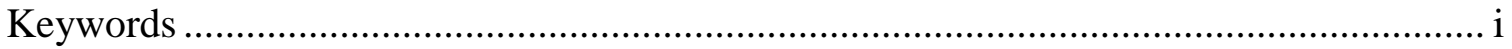

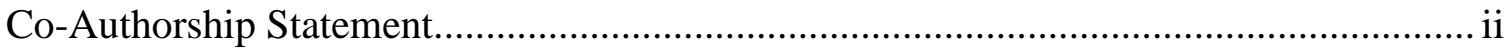

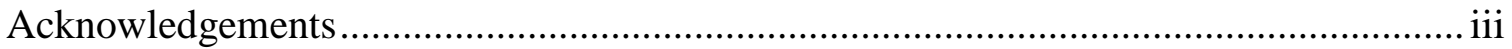

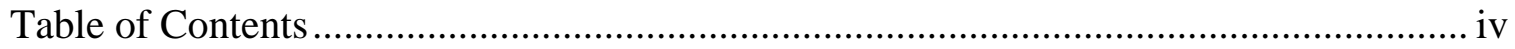

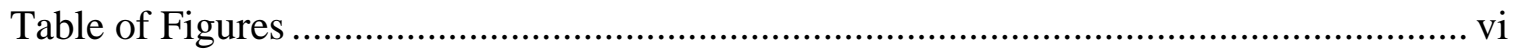

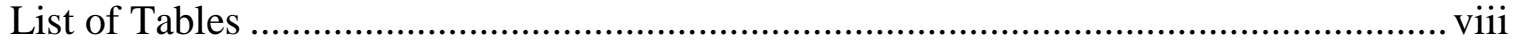

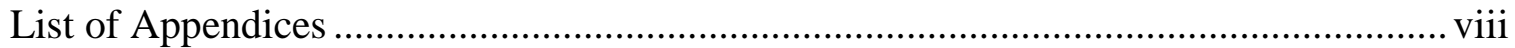

Table of Supplementary Figures provided in the Appendices ......................................... ix

List of Abbreviations and Symbols......................................................................... xiii

Chapter 1. Introduction ..................................................................................... 1

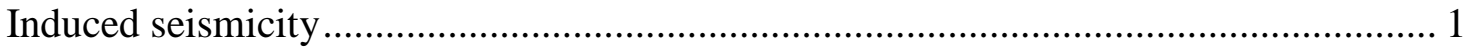

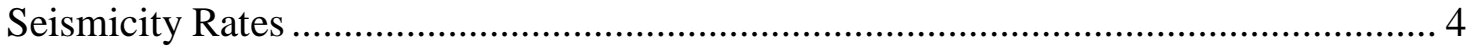

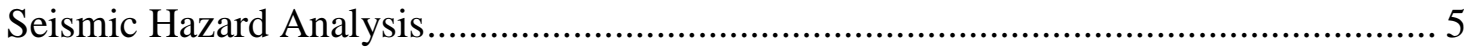

Components of a Ground Motion Prediction Equation................................................... 7

Impact of Induced Seismicity on Seismic Hazard .................................................... 11

Chapter 2. Literature Review ................................................................................ 12

Ground Motions from Induced Earthquakes ………….............................................. 12

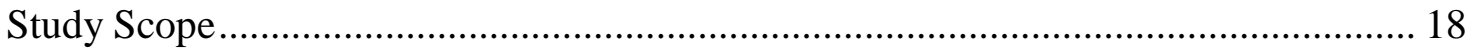

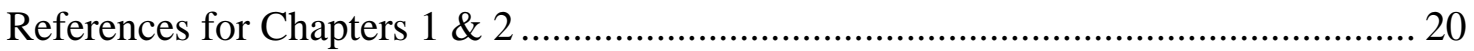

Chapter 3. A Comparison of Ground Motion Characteristics from Induced Seismic Events in Alberta with those in Oklahoma .................................................................. 25

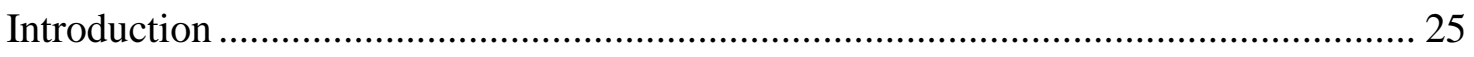

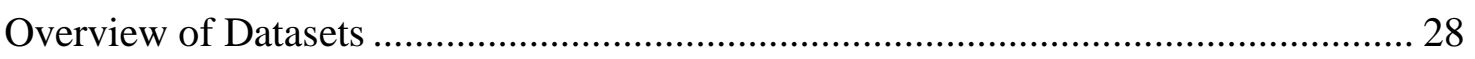

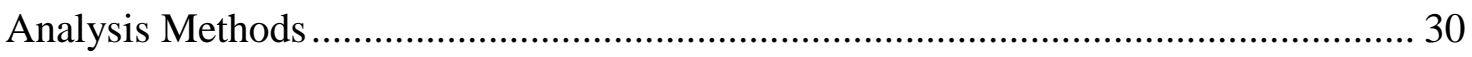

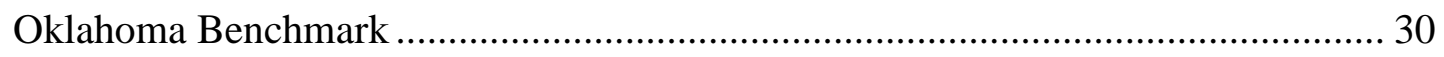

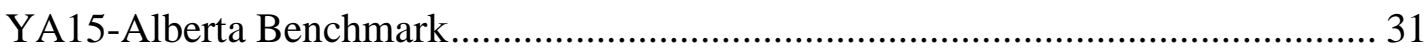

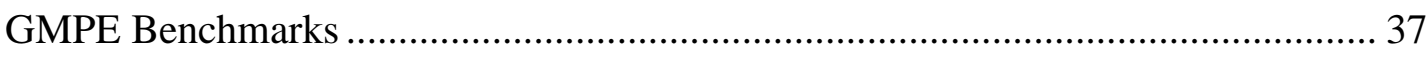

Ground Motions for Typical Events Compared to the Benchmarks ............................. 42

Residuals of Alberta Motions with Respect to the Benchmarks ................................... 50

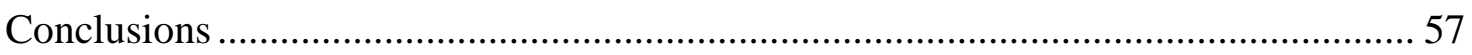

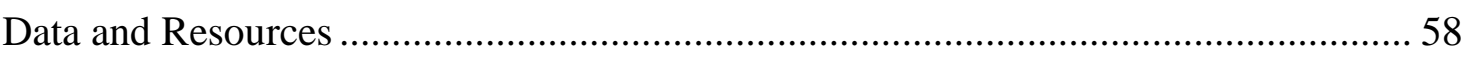

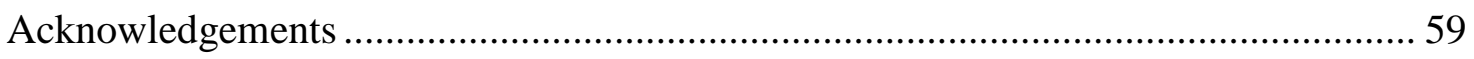




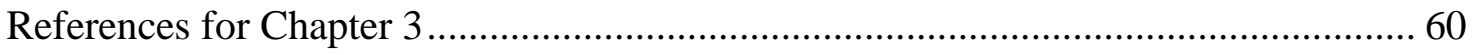

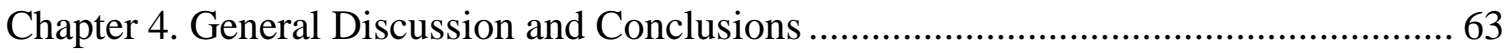

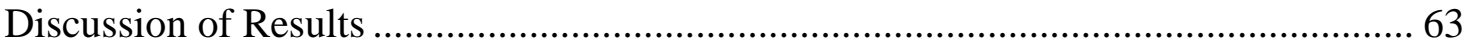

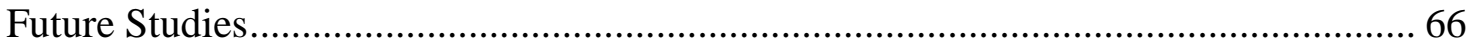

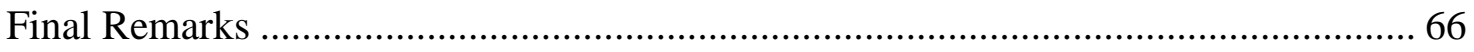

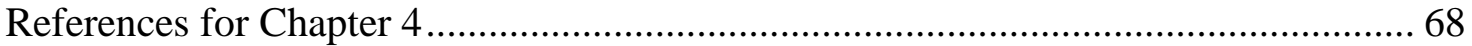

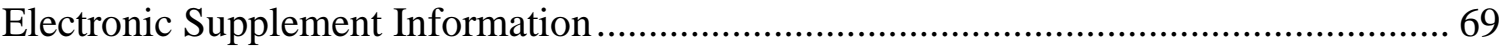

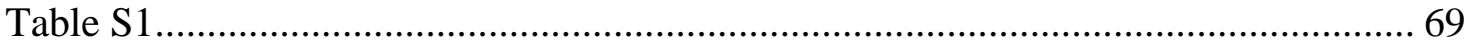

Appendix A. Vertical Ground Motions - Supplementary Figures ................................... 70

Appendix B. Horizontal Ground Motions - Supplementary Figures ................................ 81

Appendix C. Residuals - Supplementary Figures ………………………………….... 92

Curriculum Vitae - Krista Kaski ........................................................................... 103 


\section{Table of Figures}

Figure 1. Location of stations and study events in Alberta (left) and Oklahoma (right). 29

Figure 2. Distribution of the study databases in terms of moment magnitude (M) and hypocentral distance $\left(\mathrm{R}_{\text {hypo }}\right)$

Figure 3. Stress parameters $(\Delta \sigma)$ calculated from PSA amplitudes at 5, 10, and $20 \mathrm{~Hz}$. $\Delta \sigma$ is calculated using vertical-component PSAs at the specified frequency with the YA15 model (averaging its value over all stations within $100 \mathrm{~km}$ recording the event). The value of $\Delta \sigma$ calculated using the $10 \mathrm{~Hz}$ amplitudes is chosen.

Figure 4. Average Alberta empirical calibration factor $\mathrm{C}_{\mathrm{AB}}$ with frequency to calibrate YA15 to Alberta ground motions. Error bars denote the standard error around the mean. The model for the calibration factor of YA15 for CENA is plotted for comparison........ 39

Figure 5. YA15 $\mathrm{AB}$ (vertical component) evaluated at 4 magnitudes and distances compared to YA15 $\mathrm{CENA}$. YA15 ${ }_{\mathrm{CENA}}$ amplitudes are plotted for stress parameters $\Delta \sigma$ corresponding to focal depths of $0.5,5$, and $8 \mathrm{~km}$. Note the amplitudes of the Alberta motions are low (across all frequencies) because of the value of the overall Alberta calibration constant, not the stress parameter.

Figure 6. Vertical-component 5\% damped Alberta PSAs (circles) for an M3.0 event in Rocky Mountain House (RMH), Alberta. The average binned Oklahoma PSA for equivalent magnitude-distance range is plotted along with \pm 1 standard deviation (std) around the mean (shaded region). YA15 $\mathrm{AB}$ and YA15event are represented by light solid and dashed lines. $\Delta \sigma_{\text {best }}$ is 15 bars. California GMPEs A15 (black dotted) and ASK14 (dot-dashed) are shown.

Figure 7. Horizontal-component (geometric mean) Alberta PSAs (squares) for an M3.0 event in RMH, AB. See Figure 6 caption for Oklahoma PSA and GMPE descriptions. . 46

Figure 8. Vertical-component Alberta PSAs (circles) for an M4.0 event in RMH, AB. See Figure 6 caption for Oklahoma PSA and GMPE descriptions. $\Delta \sigma_{\text {best }}$ is 29 bars. ...... 47

Figure 9. Horizontal-component Alberta PSAs (squares) for an M4.0 event in RMH, AB. See Figure 6 caption for Oklahoma PSA and GMPE descriptions. 48

Figure 10. Vertical (top; circles) and horizontal (bottom; squares) component Alberta PSAs compared to mean Oklahoma PSA \pm 1 std for an M4.2 event in Fox Creek, Alberta. See Figure 6 caption for GMPE descriptions. $\Delta \sigma_{\text {best }}$ is 67 bars.

Figure 11. Average $\log _{10}$ residuals versus magnitude for vertical-component Alberta PSAs (all records) with respect to Oklahoma binned-average vertical-component PSA at 1, 5, 10, and $20 \mathrm{~Hz}$. Marker sizes indicate magnitude bins of Alberta events. Error bars denote the standard deviation of the residuals for each event.

Figure 12. Average log 10 residuals versus magnitude for horizontal-component Alberta PSAs (all records) with respect to Oklahoma binned-average horizontal-component PSA at 1, 5, 10, and $20 \mathrm{~Hz}$. Marker sizes indicate magnitude bins of Alberta events. Error bars denote the standard deviation of the residuals for each event. 
Figure 13. Average $\log _{10}$ residuals versus magnitude for vertical-component Alberta PSAs (all records) with respect to YA $15_{\mathrm{CENA}}$ (focal depth $=2 \mathrm{~km}$ ) predicted PSA at 1,5 , 10, and $20 \mathrm{~Hz}$. Marker sizes indicate magnitude bins of Alberta events. Error bars denote the standard deviation of the residuals for each event. Residuals for horizontal-component PSAs are provided in Appendix C.

Figure 14. Average $\log _{10}$ residuals versus magnitude for vertical-component Alberta PSAs (all records) with respect to PSA predicted by A15 at 1, 5, 10, and $20 \mathrm{~Hz}$. Marker sizes indicate magnitude bins of Alberta events. Error bars denote the standard deviation of the residuals for each event. Residuals for horizontal-component PSAs are provided in Appendix C. 55

Figure 15. Average $\log _{10}$ residuals versus magnitude for vertical-component Alberta PSAs (all records) with respect PSA predicted by ASK14 (with depth to rupture modification for induced events) at 1, 5, 10, and $20 \mathrm{~Hz}$. Marker sizes indicate magnitude bins of Alberta events. Residuals are calculated in log base 10. Residuals for horizontal- 


\section{List of Tables}

Table 1. NEHRP Site Classifications for use in the 2015 National Building Code of Canada (NBCC). Developed using time-averaged shear wave velocity of the upper $30 \mathrm{~m}$

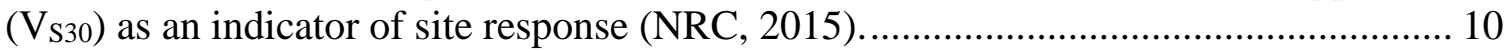

Table 2. Dates, locations, $\mathrm{M}$, and calculated $\Delta \sigma_{\text {best }}$ for study events in Alberta. .............. 34

Table S1. Horizontal- and vertical-component 5\% damped PSA $\left(\mathrm{cm} / \mathrm{s}^{2}\right)$ calculated at 28 frequencies for each of 25 seismic events recorded in Alberta. Table data included are: event number, hypocentral distance $(\mathrm{km})$, moment magnitude $(\mathbf{M})$, event date and location, station name, sample rate, component recorded ( $\mathrm{HH} 1, \mathrm{HH} 2, \mathrm{HHZ}$ representing two horizontal and one vertical component, respectively), station location and PSA calculated from 0.1 to $50 \mathrm{~Hz}$, as well as PGA, in $\mathrm{cm} / \mathrm{s}^{2}$ and PGV $(\mathrm{cm} / \mathrm{s})$. (Provided as an electronic supplement to this thesis).

\section{List of Appendices}

Appendix A. Vertical Ground Motions - Supplementary Figures.................. 70

Appendix B. Horizontal Ground Motions - Supplementary Figures................. 81

Appendix C. Residuals - Supplementary Figures.............................. 92 


\title{
Table of Supplementary Figures provided in the Appendices
}

\author{
Appendix A. Vertical Ground Motions - Supplementary Figures
}

Figure A1. Vertical-component 5\% damped Alberta PSAs (circles) for M 3.2 event in Alberta. The average binned vertical-component Oklahoma PSA for equivalent magnitude-distance range is plotted along with \pm 1 standard deviation around the mean (shaded region). YA15AB and YA15event are represented by light solid and dashed lines. California GMPEs A15 (black dotted) and ASK14 (dot-dashed) are shown.

Figure A2. Vertical-component PSAs for M 3.1 event in Alberta. See Figure A1 caption for graphical description. 70

Figure A3. Vertical-component PSAs for M 3.1 event in Alberta. See Figure A1 caption for graphical description. .71

Figure A4. Vertical-component PSAs for M 3.0 event in Alberta. See Figure A1 caption for graphical description. .71

Figure A5. Vertical-component PSAs for M 3.0 event in Alberta. See Figure A1 caption for graphical description.

Figure A6. Vertical-component PSAs for M 3.1 event in Alberta. See Figure A1 caption for graphical description.

Figure A7. Vertical-component PSAs for M 3.5 event in Alberta. See Figure A1 caption for graphical description.

Figure A8. Vertical-component PSAs for M 3.6 event in Alberta. See Figure A1 caption for graphical description.

Figure A9. Vertical-component PSAs for M 3.1 event in Alberta. See Figure A1 caption for graphical description.

Figure A10. Vertical-component PSAs for M 3.1 event in Alberta. See Figure A1 caption for graphical description.

Figure A11. Vertical-component PSAs for M 3.3 event in Alberta. See Figure A1 caption for graphical description.

Figure A12. Vertical-component PSAs for M 3.8 event in Alberta. See Figure A1 caption for graphical description.

Figure A13. Vertical-component PSAs for M 3.4 event in Alberta. See Figure A1 caption for graphical description.

Figure A14. Vertical-component PSAs for M 3.9 event in Alberta. See Figure A1 caption for graphical description.

Figure A15. Vertical-component PSAs for M 4.0 event in Alberta. See Figure A1 caption for graphical description.

Figure A16. Vertical-component PSAs for M 3.4 event in Alberta. See Figure A1 caption for graphical description.

Figure A17. Vertical-component PSAs for M 3.3 event in Alberta. See Figure A1 caption for graphical description..... 
Figure A18. Vertical-component PSAs for M 4.0 event in Alberta. See Figure A1 caption for graphical description.

Figure A19. Vertical-component PSAs for M 3.1 event in Alberta. See Figure A1 caption for graphical description.

Figure A20. Vertical-component PSAs for M 3.0 event in Alberta. See Figure A1 caption for graphical description.

Figure A21. Vertical-component PSAs for M 3.0 event in Alberta. See Figure A1 caption for graphical description.

Figure A22. Vertical-component PSAs for M 3.0 event in Alberta. See Figure A1 caption for graphical description.

Figure A23. Vertical-component PSAs for M 3.0 event in Alberta. See Figure A1 caption for graphical description.

Figure A24. Vertical-component PSAs for M 3.1 event in Alberta. See Figure A1 caption for graphical description.

Figure A25. Vertical-component PSAs for M 3.2 event in Alberta. See Figure A1 caption for graphical description.

Appendix B. Horizontal Ground Motions - Supplementary Figures

Figure B1. Horizontal-component 5\% damped Alberta PSAs (squares) for M 3.2 event in Alberta. The average binned horizontal-component Oklahoma PSA for equivalent magnitude-distance range is plotted along with \pm 1 standard deviation around the mean (shaded region). YA $15_{\mathrm{AB}}$ and YA15 $5_{\text {event }}$ are represented by light solid and dashed lines. California GMPEs A15 (black dotted) and ASK14 (dot-dashed) are shown.

Figure B2. Horizontal-component PSAs for M 3.1 event in Alberta. See Figure B1 caption for graphical description.....

Figure B3. Horizontal-component PSAs for M 3.1 event in Alberta. See Figure B1 caption for graphical description.....

Figure B4. Horizontal-component PSAs for M 3.0 event in Alberta. See Figure B1 caption for graphical description.

Figure B5. Horizontal-component PSAs for M 3.0 event in Alberta. See Figure B1 caption for graphical description.

Figure B6. Horizontal-component PSAs for M 3.1 event in Alberta. See Figure B1 caption for graphical description...

Figure B7 Horizontal-component PSAs for M 3.5 event in Alberta. See Figure B1 caption for graphical description.

Figure B8. Horizontal-component PSAs for M 3.6 event in Alberta. See Figure B1 caption for graphical description...

Figure B9. Horizontal-component PSAs for M 3.1 event in Alberta. See Figure B1 caption for graphical description.

Figure B10. Horizontal-component PSAs for M 3.1 event in Alberta. See Figure B1 caption for graphical description.

Figure B11. Horizontal-component PSAs for M 3.3 event in Alberta. See Figure B1 caption for graphical description. 
Figure B12. Horizontal-component PSAs for M 3.8 event in Alberta. See Figure B1 caption for graphical description.

Figure B13. Horizontal-component PSAs for M 3.4 event in Alberta. See Figure B1 caption for graphical description.

Figure B14. Horizontal-component PSAs for M 3.9 event in Alberta. See Figure B1 caption for graphical description.

Figure B15. Horizontal-component PSAs for M 4.0 event in Alberta. See Figure B1 caption for graphical description.

Figure B16. Horizontal-component PSAs for M 3.4 event in Alberta. See Figure B1 caption for graphical description.

Figure B17. Horizontal-component PSAs for M 3.3 event in Alberta. See Figure B1 caption for graphical description.

Figure B18. Horizontal-component PSAs for M 4.0 event in Alberta. See Figure B1 caption for graphical description.

Figure B19. Horizontal-component PSAs for M 3.1 event in Alberta. See Figure B1 caption for graphical description.

Figure B20. Horizontal-component PSAs for M 3.0 event in Alberta. See Figure B1 caption for graphical description.

Figure B21. Horizontal-component PSAs for M 3.0 event in Alberta. See Figure B1 caption for graphical description.

Figure B22. Horizontal-component PSAs for M 3.0 event in Alberta. See Figure B1 caption for graphical description.

Figure B23. Horizontal-component PSAs for M 3.0 event in Alberta. See Figure B1 caption for graphical description.

Figure B24. Horizontal-component PSAs for M 3.1 event in Alberta. See Figure B1 caption for graphical description.

Figure B25. Horizontal-component PSAs for M 3.2 event in Alberta. See Figure B1 caption for graphical description.

\section{Appendix C. Residuals - Supplementary Figures}

Figure $\mathrm{C} 1$. Average $\log _{10}$ residuals versus magnitude for horizontal-component Alberta PSAs (all records) with respect to PSA predicted by A15 at 1, 5, 10, and $20 \mathrm{~Hz}$. Marker sizes indicate magnitude bins of Alberta events. Error bars denote the standard deviation of the residuals for each event.

Figure C2. Average $\log _{10}$ residuals versus magnitude for horizontal-component Alberta PSAs (all records) with respect to PSA predicted by YA15 ${ }_{\mathrm{CENA}}$ (focal depth $=2 \mathrm{~km}$ ) at $1,5,10$, and $20 \mathrm{~Hz}$. Marker sizes indicate magnitude bins of Alberta events. Error bars denote the standard deviation of the residuals for each event.

Figure C3. Average $\log _{10}$ residuals versus magnitude for horizontal-component Alberta PSAs (all records) with respect to PSA predicted by ASK14 at 1, 5, 10, and $20 \mathrm{~Hz}$. Marker sizes indicate magnitude bins of Alberta events. Error bars denote the standard deviation of the residuals for each event. 
Figure C4. Log (base 10) residuals versus hypocentral distance for vertical-component Alberta PSAs (all records) with respect to Oklahoma binned-average vertical-component PSAs at 1, 5, 10, and $20 \mathrm{~Hz}$. Marker sizes indicate magnitude bins of Alberta events.

Figure C5. Log (base 10) residuals versus hypocentral distance for vertical-component Alberta PSAs (all records) with respect PSA predicted by A15 at 1, 5, 10, and $20 \mathrm{~Hz}$. Marker sizes indicate magnitude bins of Alberta events.

Figure C6. Log (base 10) residuals versus hypocentral distance for vertical-component Alberta PSAs (all records) with respect to PSA predicted by YA15 ${ }_{\text {CENA }}$ (focal depth $=2 \mathrm{~km}$ ) at $1,5,10$, and $20 \mathrm{~Hz}$. Marker sizes indicate magnitude bins of Alberta events.

Figure C7. Log (base 10) residuals versus hypocentral distance for vertical-component Alberta PSAs (all records) with respect to PSA predicted by ASK14 (with depth to rupture modification for induced events) at 1,5,10, and $20 \mathrm{~Hz}$. Marker sizes indicate magnitude bins of Alberta events.

Figure C8. Log (base 10) residuals versus hypocentral distance for horizontal-component Alberta PSAs (all records) with respect to Oklahoma binned-average horizontal-component PSAs at 1, 5, 10, and $20 \mathrm{~Hz}$. Marker sizes indicate magnitude bins of Alberta events. 99

Figure C9. Log (base 10) residuals versus hypocentral distance for horizontal-component Alberta PSAs (all records) with respect PSA predicted by A15 at 1, 5, 10, and $20 \mathrm{~Hz}$. Marker sizes indicate magnitude bins of Alberta events.

Figure C10. Log (base 10) residuals versus hypocentral distance for vertical-component Alberta PSAs (all records) with respect to PSA predicted by YA15 ${ }_{\text {CENA }}$ (focal depth $=2 \mathrm{~km}$ ) at 1, 5, 10, and $20 \mathrm{~Hz}$. Marker sizes indicate magnitude bins of Alberta events.

Figure C11. Log (base 10) residuals versus hypocentral distance for horizontal-component Alberta PSAs (all records) with respect to PSA predicted by ASK14 (with depth to rupture modification for induced events) at 1,5,10, and $20 \mathrm{~Hz}$. Marker sizes indicate magnitude bins of Alberta events. 


\section{List of Abbreviations and Symbols}

A15

AGY14

ASK14

$\mathrm{BC}$

C

CASC

CENA

CNSN

CUREE

$\mathrm{D}_{\text {rup }}$

$f$

GMPE

$h_{\text {eff }}$

$\mathrm{Hz}$

M

MMI

MRSN

NBCC
Atkinson (2015) model

Atkinson, Greig, and Yenier (2014) model

Abrahamson, Silva, and Kamai (2014)

model

British Columbia

Empirical calibration factor

Composite Alberta Seismicity Catalogue

Central and Eastern North America

Canadian National Seismograph Network

Consortium of Universities for Research

in Earthquake Engineering

Rupture distance

Frequency

Ground motion prediction equation

Effective-depth parameter

Hertz

Moment magnitude

Modified Mercalli Intensity

Montana Regional Seismic Network

National Building Code of Canada 
U.S

YA15

YA15 $5_{\text {CENA }}$

$\mathrm{Z}_{\mathrm{TOR}}$

$\Delta \sigma$
United States

Yenier and Atkinson (2015) model

Yenier and Atkinson (2015) model

calibrated to CENA

Depth to top of rupture

Stress parameter 


\section{Chapter 1. Introduction}

The rate of seismicity associated with oil and gas activity in Alberta has increased markedly since 2010, as the technology to extract hydrocarbons from unconventional shale reservoirs using hydraulic fracturing in long horizontal wellbores has become widespread (Atkinson et al., 2016). The increased rate of seismicity has important implications for seismic hazard assessment in Alberta (Atkinson et al., 2015a). It is important to understand the potential ground motions from these events in order to determine their potential impact on seismic hazard. This thesis aims to improve our understanding of ground motions from induced events in Alberta, and in particular how they compare to the large induced-ground motion database derived from events in Oklahoma.

\section{Induced seismicity}

It has been known since the 1960's that earthquakes can be triggered by the injection of fluids into the subsurface (Davies et al., 2013). This induced seismicity, however, has become a more commonly discussed and pertinent topic for study in recent years due to a significant increase in the number of earthquakes occurring in previously seismically-quiescent regions. Regions such as the Central and Eastern United States (Keranen et al., 2014; Ellsworth 2013) and the Western Canadian Sedimentary Basin (WCSB) (Atkinson et al., 2016), have experienced a steep rise in earthquake occurrence since approximately 2010, which has been attributed to practices involved with unconventional hydrocarbon extraction in North America. 
There are many practices that induce earthquakes, however this study will focus on ground motions from events that occur most-likely due to hydraulic fracturing (in Alberta) and by deep disposal of co-produced wastewater (in Oklahoma). The basic mechanism by which an earthquake is triggered, involves the release of stored and built up strain energy, through a fault slip. In the case of induced earthquakes, this slip tends to occur along pre-existing faults. A fault will remain stable as long as the shear stress $(\tau)$ acting on it is less than the resistance to slip (shear resistance) (National Research Council (NRC), 2013). Shear resistance $\left(\mathrm{R}_{\mathrm{S}}\right)$ is characterized by the difference between the applied normal stress $(\sigma)$ and the permeating pore-fluid pressure $(\rho)$, as well as the coefficient of friction $(\mu)$ such that $R_{S}=\mu(\sigma-\rho)$ (NRC, 2013). An earthquake is triggered when the shear stress surpasses the shear resistance such that $\tau>R_{S}$ (NRC, 2013). This can be achieved through an increase in pore-fluid pressure and/or a change in state of normal stress, causing existing faults to reactivate (Healy et al., 1968; Raleigh et al., 1976). Shear rupture occurs when a failure condition is achieved through either: an increase in shear stress, a reduction of the applied normal stress, and/or an elevation in pore pressure (Ellsworth, 2013).

Hydraulic fracturing is commonly performed by drilling into tight-shale formations and injecting fluids under pressure to enable the production of oil and gas from previously unproductive formations (Ellsworth, 2013); recent advances in this technology have led to the widespread use (since 2010) of long horizontal wellbores. Hydraulic fracturing commonly involves changes in both the shear and tensile stress of the subsurface, and pressure propagated through hydraulically conductive paths can induce slip by reducing normal stress, as well as increasing pore pressure (Ellsworth, 
2013). Much of the induced seismicity in western Alberta and northeastern B.C., Canada, appears to be related to hydraulic fracturing in long horizontal wellbores (Atkinson et al., 2016). The total volume of fluids injected in such operations, over multiple stages, is of the order of 10,000 to over 50,000 $\mathrm{m}^{3}$ (Schultz et al., 2017).

Dewatering plays involve extracting large amounts of water from the subsurface along with the targeted hydrocarbons. This can involve the production of up to 200 times the amount of water produced per barrel of oil when compared with conventional oil extraction (Keranen et al., 2014; Ellsworth, 2013). These types of plays are more common in central and eastern states in the United States, such as Texas, Arkansas, Colorado, and Oklahoma (Keranen et al., 2014). The disposal of this produced wastewater typically involves injecting high volumes at high rates (up to $10,000 \mathrm{~m}^{3}$ per day, often for several years) into subsurface reservoirs, and thus involves larger volumes, over a larger area, in comparison to hydraulic fracturing. Wastewater disposal can cause extensive pressure perturbations, which may lead to the onset of fault rupture and induce an earthquake (Walters et al., 2015). These pressure perturbations can affect the stress regime along a pre-existing fault. Additionally, water that has traveled from the injection site can increase the fluid pore pressure at a fault and decrease its resistance to slip. Induced events can occur proximally or distally to the source of perturbation and can occur at the onset of industry activity, or up to five years after production concludes (due to the time required for pore pressure to travel to faults) (Ellsworth, 2013).

Although it can be difficult to determine the origin of an event and conclusively define it as natural or induced, several studies (Atkinson et al., 2016; Ghofrani and Atkinson, 2016; Schultz et al., 2015; Schultz et al., 2016) have used statistical methods to 
correlate hydraulic fracturing wells to seismic events in the WCSB both spatially and temporally. Additionally, some events in Alberta have also been correlated with wastewater disposal wells, as well as poroelastic effects due to reservoir depletion (Atkinson et al., 2016; Baranova et al., 1999; Wetmiller, 1986). By contrast, in the central U.S., most of the induced seismicity is believed to be related to wastewater disposal (Ellsworth, 2013; Keranen et al., 2014), perhaps due to the prevalence of large dewatering plays in those regions.

\section{Seismicity Rates}

Induced seismicity has become a more frequent topic of discussion in recent years due to a significant increase in the number of earthquakes occurring in previously seismically-quiescent regions. There were 2528 moment magnitude $(\mathbf{M})>3$ earthquakes between June 2008 and February 2017 (United States Geological Survey Composite Catalog, 2017), compared with an average of $21 \mathbf{M}>3$ earthquakes per year in the central and eastern United States from 1967 to 2000 (Ellsworth, 2013). Seismic swarms correlated with injection wells in Oklahoma dominate central and eastern United States seismicity and were responsible for $45 \%$ of nation-wide earthquakes between 2008 and 2013 (Keranen et al., 2014). In Canada, development of shale gas and shale oil resources is focused within the WCSB, where seismic activity has been increasing since 2010 (Atkinson et al., 2016). Most observed events in the WCSB with $\mathbf{M} \geq 3$ have been associated with oil and gas activity since 1985, and Atkinson et al. (2016) determined that from 2010 to 2015 more than half of all $\mathbf{M} \geq 3$ events correlated spatially and temporally with hydraulic fracturing operations. It was determined that only $\sim 0.3 \%$ of all hydraulic 
fracturing operations are associated with $\mathbf{M} \geq 3$ events, but as the number of these operations grows in Alberta and eastern British Columbia, the cumulative risk of inducing earthquakes becomes greater (Atkinson et al., 2016). Determination of seismic hazard from these injection-induced events in Alberta is important as oil and gas operations have become widespread throughout this region; an area in which hazard from seismicity has been considered insignificant, and so seismic design has been minimal (Atkinson et al., 2016).

\section{Seismic Hazard Analysis}

Regional seismic hazard maps in Canada are developed for use in the National Building Code of Canada (NBCC) and are consistently updated to reflect new seismic hazard models generated through enhanced understanding of seismicity and ground motions in Canada, as well as advanced methodologies to evaluate seismic hazard (Adams and Atkinson, 2003). Seismic hazard is generally evaluated for engineering design practice (Adams and Atkinson, 2003), in that structures are designed to withstand a potential ground shaking that could occur, and is based on a probabilistic approach (Cornell 1968; McGuire 1977; Basham et al., 1982, 1985). To summarize this approach succinctly: seismic source zones are defined either by a geographic area or by proximity to a known fault system; a magnitude-recurrence relationship is determined from historical seismicity based on the recurrence law developed by Gutenberg and Richter (1944); typical ground motions for the source zones are calculated as a function of magnitude and distance; hazard contributions are integrated over all magnitude and distances, for all source zones, according to the total probability theorem (Adams and 
Atkinson, 2003). Hazard is defined as the probability of exceeding a specified intensity of ground shaking, at various frequencies, in a given time period. Building codes are then designed based on these probabilities, with varying acceptable probabilities of exceedance for different building uses or for critical infrastructure. The reliability of the final models is highly dependent on the reliability of the input ground motion prediction equations (GMPEs), which specify expected peak or median ground shaking amplitudes as a function of magnitude, distance, and other variables (Adams and Atkinson, 2003; Atkinson and Adams, 2013). It should be noted that national seismic hazard maps for the NBCC do not yet consider the contributions of induced seismicity to hazard. The results of this study will facilitate including such hazards in future NBCC editions, by improving our knowledge of the ground-motion effects.

As seismic hazard is calculated for engineering design purposes, the ground shaking is specified in a format that is relevant for engineered structures. Buildings are designed based on a design spectrum that specifies the level of seismic design force (or displacement) as a function of the natural period of vibration of that building with some level of damping (Consortium of Universities for Research in Earthquake Engineering (CUREE), 1997). In terms of seismic response, structures can be idealized as a single degree of freedom (SDOF) linear oscillator with viscous damping, typically taken as $~ 5 \%$ of critical (Trifunac, 1971). Ground motions from an earthquake can then be modeled as a response spectrum, which illustrates the maximum or median shaking response of several oscillators, with varying natural frequencies, to a given accelerogram or "input shaking" (CUREE, 1997). These response spectra represent ground motions from earthquakes as pseudo-spectral accelerations (PSA) with 5\% damping. PSA is calculated 
at each frequency $(f)$ of interest from the measured peak ground displacement (PGD) of an oscillator at that frequency such that $P S A(f)=P G D \times(2 \pi f)^{2}$. GMPEs output their predicted ground motions as intensity measures such as peak ground acceleration (PGA), peak ground velocity (PGV) or PSA values for a range of frequencies of engineering interest (often 0.1 to $50 \mathrm{~Hz}$ ). These are known as the response variables (Boore and Atkinson, 2008). The horizontal component is generally of most interest as it is larger than the vertical component. Moreover, structures have greater inherent capacity to resist vertical loads, therefore, focus is placed on the more damaging horizontal components of motion.

\section{Components of a Ground Motion Prediction Equation}

GMPEs predict ground shaking amplitudes as a function of magnitude and distance. These models can be developed empirically using regional ground motion observations. Alternatively, as many regions worldwide lack the available data needed to develop these equations, GMPEs are instead developed through simulations of earthquakes to determine characteristic ground shaking (Yenier and Atkinson, 2015a). The simulations are based on a seismological model of the source, path, and site functions that define the ground motion behaviours expected from seismic waves from an earthquake of a particular magnitude that have traveled through a subsurface medium, and are recorded at a site with specific soil properties. An example of a functional-form GMPE is shown (simplified from Yenier and Atkinson, 2015a).

$$
\ln (P S A)=F_{E}(\mathbf{M}, \Delta \sigma)+F_{Z}\left(Z, \mathbf{M}, R_{\text {hypo }}\right)+F_{\gamma}(\gamma)+F_{S}\left(V_{S 30}, P G A_{r}\right)+C(f)
$$


This GMPE outputs ground motion intensity as 5\%-damped PSAs. The earthquake source function $F_{E}$ is a function of moment magnitude $\mathbf{M}$, and the stress parameter $\Delta \sigma$, which controls the behaviour of ground motion amplitudes at high frequencies (Yenier and Atkinson, 2015b). The stress parameter, sometimes referred to as the stress drop, is a measure of the difference in fault shear stress before and after an earthquake. Higher stress drops correspond to stronger high-frequency ground motions, for a given seismic moment (Hanks, 1979; Boore, 1983). The stress parameter referred to in this thesis is related to the corner frequency of a Brune source model (Brune, 1970;1971). The Brune model represents the spectral shape of earthquake ground motions at the source, which scales with the seismic moment and the corner frequency. For the Brune model, the displacement spectrum is constant (flat) at low frequencies (below the corner frequency), and is proportional to the seismic moment. The corner frequency represents the frequency at which ground motions begin to decay at a rate of approximately $1 / f^{2}$, where $f$ is frequency (Madariaga, 2006; Brune, 1970;1971). The Brune source model can be expressed as

$$
\Omega(\omega)=\frac{M_{0}}{1+\left(\frac{\omega}{\omega_{0}}\right)^{2}}
$$

where $\Omega$ is the amplitude of the displacement spectrum, $M_{0}$ is the seismic moment, $\omega$ is the angular frequency and $\omega_{0}$ is the angular corner frequency (Madariaga, 2006). The stress parameter $\Delta \sigma$ can be calculated from the corner frequency $\omega_{0}$, where $\omega_{0}=2 \pi f_{0}$ such that (Boore, 2003):

$$
f_{0}=4.9 \times 10^{6} \beta\left(\frac{\Delta \sigma}{M_{0}}\right)^{\frac{1}{3}}
$$


In equation 1.3 above, $\beta$ is the shear wave velocity in $\mathrm{km} / \mathrm{s}$, seismic moment is expressed in dyne-cm and stress is given in bars.

The geometrical spreading function $F_{Z}$ in equation 1.1 is a function of $Z, \mathbf{M}$ and hypocentral distance $\left(R_{\text {hypo }}\right)$. $Z$ represents the geometrical attenuation of seismic wave Fourier amplitudes due to the spreading of seismic wave energy. $Z$ is commonly modeled as a bi-linear decay with different rates of attenuation at different distances; this is based on the transition of spreading direct waves at distances of less than $50 \mathrm{~km}$, and surface waves spreading at greater distances (Yenier and Atkinson, 2015a). The function $F_{\gamma}$ models the anelastic attenuation or loss of seismic wave energy through frictional losses. $\gamma$ is commonly defined for a specific tectonic environment (for example, different attenuation coefficients exist for California and for Central and Eastern North America (CENA)).

The function $F_{S}$ provides a site-correction that models amplification at a site, commonly based on its time-averaged shear wave velocity in the upper $30 \mathrm{~m}\left(V_{S 30}\right)$. Site amplification refers to the change in ground motion amplitudes due to amplification effects from site geology. For example, vertically-propagating shear waves traveling through high-shear-wave-velocity bedrock will exhibit an increase in seismic wave amplitude in the horizontal direction of motion when they encounter a lower-velocity soil layer above. The amount of amplification depends on the stiffness (proportional to shearwave velocity) and thickness of the soil layer. Sites are classified based their average shear-wave velocity by the National Earthquake Hazard Reduction Program (NEHRP) and the NBCC and are described in Table 1 below. Horizontal-component motions are more amplified compared with the vertical component, which are assumed to undergo 
minimal amplification due to site geology. Comparing the ratio of horizontal ground motions to vertical at a site can give an idea of the level of site amplification. GMPEs are developed as ground motions for a reference site condition or soil stiffness, and so a site correction is applied if the GMPE is applied to other site conditions.

Table 1. NEHRP Site Classifications for use in the 2015 National Building Code of Canada (NBCC). Developed using time-averaged shear wave velocity of the upper $30 \mathrm{~m}$ $\left(V_{S 30}\right)$ as an indicator of site response (NRC, 2015).

Class

\begin{tabular}{|c|c|c|}
\hline A & Hard rock & $>1500$ \\
\hline B & Rock & $760-1500$ \\
\hline C & Dense soil/ soft rock & $360-760$ \\
\hline D & Stiff soil & $180-360$ \\
\hline E & Soft soil & $<180$ \\
\hline F & N/A & $\begin{array}{c}\text { Soils requiring specific } \\
\text { study }\end{array}$ \\
\hline
\end{tabular}

Finally, GMPEs will often include an empirical calibration factor $C$, which takes into account the average residual differences between simulations used to derive the GMPE and empirical data (Yenier and Atkinson, 2015a). GMPEs have historically been derived through simulations and empirical calibrations of ground motions from natural events. For example, several ground motion models have been derived from the Pacific Earthquake Engineering Research Center (PEER) Next Generation Attenuation (NGA) database or its subsets NGA-East (representing more stable continent earthquakes) and NGA-West2 (comprised of earthquakes near or on plate boundaries). 
Impact of Induced Seismicity on Seismic Hazard

Moderate induced earthquakes from both wastewater injection (Ellsworth, 2013; Keranen et al., 2014) and hydraulic fracturing (Atkinson et al., 2015a) have significant damage potential at near-epicentral distances (Hough, 2014; Atkinson, 2015; Yenier et al., 2017). Although this is understood, it is currently less clear how induced earthquakes affect the calculation of seismic hazard for an entire region. Many guidelines and regulations that address induced earthquakes are prescriptive and reactionary (Walters et al., 2015). One solution proposed by Walters et al. (2015) is a site-specific and adaptable hazard risk assessment and traffic-light protocol for each injection project. Performing pre-injection assessments of natural seismicity in the region, operation factors, and the exposure of nearby critical facilities and infrastructure can inform operations and allow for a more conservative approach (Walters et al., 2015). The traffic-light protocol specifically addresses the possibility of a variable seismic risk over time and allows for real-time risk management, as injection projects are recommended to either continue (green), modify due to increased risk (amber), or cease/suspend operations due to severe risk (red). Such protocols are in effect today in Alberta, as exemplified by the 12 January 2016 M4.2 event in Fox Creek that resulted in an order from the Alberta Energy Regulator to cease oil and gas operations at the site in response (Alberta Energy Regulator and Alberta Geological Survey, 2016). These site-specific protocols and assessments are useful for operations, but the question remains as to how the increasing rate and magnitudes of induced events will affect future assessments of seismic hazard in Canada. The USGS recently produced probabilistic seismic hazard assessment for the 
central and eastern United States that included contributions from both induced and natural earthquakes, and spanned only one year (2016). They assume that short-term seismicity rates in this region (between 2014 and 2015) would remain relatively stable over short time periods (Petersen et al., 2016). A case study by Atkinson et al. (2015b) determined that in low-to-moderate seismicity environments, such as Fox Creek, Alberta, hazard from induced seismicity proximal to a site can greatly surpass the pre-existing hazard from natural sources and background seismicity in the region. The study specifically looked at the hazard at Fox Creek and determined the hazard in the region is greatly increased from induced seismicity for probabilities of engineering interest and at PGA, PGV, and frequencies $>1 \mathrm{~Hz}$. These results were heavily conditional upon the relatively low level of natural background seismicity in Fox Creek, and they note that in areas of higher background seismicity, the effect of increased triggered earthquakes on the hazard would be less apparent. They also note that the induced seismicity affected the hazard more at higher frequencies, because induced events at relatively low magnitude and short distances dominate the contributions to hazard.

\section{Chapter 2. Literature Review}

\section{Ground Motions from Induced Earthquakes}

Hough (2014) considered ground motions from 11 injection-induced earthquakes in the central and eastern United States. These earthquakes were moderate in magnitude (ranging from M3.9 to M5.7) and all occurred between 2011 and 2013. An intensity prediction is a prediction of the felt intensity of ground shaking. The study used the 
United States Geological Survey (USGS) "Did You Feel It" responses to systematically calculate Modified Mercalli Intensities (MMI) from the 11 induced earthquakes as well as several benchmark tectonic earthquakes, and then compared the datasets to an intensity prediction equation developed by Atkinson and Wald (2007). This comparison was made by determining a magnitude value that would optimize the fit between the measured MMIs and the intensity predictions of Atkinson and Wald (2007). These estimated magnitudes were found to be on average 0.82 magnitude units lower than the actual event magnitudes, leading to the conclusion that shaking levels from the moderate induced events correspond with those expected from events with considerably lower magnitudes. The lower equivalent magnitudes were driven by low shaking mainly at distances greater than approximately $10 \mathrm{~km}$. Furthermore, it was found that tectonic (natural) events considered were well characterized by Atkinson and Wald (2007) intensity predictions. It was therefore inferred that there is a significant systematic discrepancy in source properties between natural and induced events (Hough, 2014). From the scaling relationships of Boore (1983) and Hanks and Johnston (1992), we know that high frequency ground motions depend strongly on the stress parameter and weakly on the moment magnitude. Hough (2014) determined that if the intensity predictions were to match the observed dataset from the induced events, the stress parameters of those events would have to be $\sim 2-10$ times lower than the corresponding values for natural earthquakes. Other studies have examined the nature of high-frequency ground motions and have also determined that induced earthquakes have systematically lower stress parameters than natural earthquakes. This has been attributed this to a "focal depth effect", in which the stress parameter scales with focal depth, and will inherently be 
lower for shallower events (Yenier and Atkinson, 2014; Atkinson, 2015; Novakovic and Atkinson, 2015; Yenier et al., 2017).

To better understand their likely ground motion characteristics, Atkinson (2015) developed a GMPE specifically designed for the magnitude and distance range of induced seismic events. This GMPE was developed from a database of California earthquakes with magnitudes of M 3-6 at distances of less than $40 \mathrm{~km}$, as these tend to be the magnitudes and distances at which these events can be felt. The GMPE uses hypocentral distance as the distance metric, which is more appropriate for induced events than fault-based distances as it allows for a functional GMPE that will correctly model point-source scaling attributes that apply to small events. The GMPE implicitly accounts, at least in part, for the effect of focal depth on the stress parameter, in that deeper events will have inherently larger stress parameters than shallow events (Yenier and Atkinson, 2014). The resulting GMPE produces horizontal-component 5\%-damped PSAs for frequencies between 0.2 and $33 \mathrm{~Hz}$. The results illustrate a lack of saturation (attenuation) of ground motions at 2-10 km distances, which suggests that moderate induced events can produce strong ground motions at short distances, which could be potentially damaging. This is in alignment with the finding of Hough (2014) that induced events displayed smaller intensities than predicted except for at distances less than $10 \mathrm{~km}$. Atkinson (2015) notes that the potential for strong shaking is essentially due to the shallow focal depths, as bringing the earthquake closer to the epicentre will cause stronger shaking at closer distances. Epistemic or "modeling" uncertainty is the uncertainty associated with predictions due to an uncertain median estimate of the proposed model (Atkinson et al., 2014a). The Atkinson (2015) ground motion model has 
large epistemic uncertainty (up to a factor of 2) in PSA amplitudes at close distances (3-5 $\mathrm{km}$ ), and so motions of events $\mathbf{M} \sim 4$ near source could be higher or lower than predicted by a factor of 2. Douglas et al. (2013) developed a GMPE for induced earthquake motions in geothermal areas in Europe and California using $\mathbf{M}<4.5$ events with more data at close hypocentral distances than the Atkinson (2015) GMPE. Comparisons between the two suggest that they are in good agreement with each other in regions of overlap (i.e. California). Both studies point to the potential for large ground motion amplitudes at close distances from shallow events; at near-epicentral distances, amplitudes were far greater than those expected from NGA-West2 GMPEs (models derived using the PEER NGA-West2 database of natural earthquakes near or on plate boundaries). GMPEs developed from the NGA-West2 database tend to be optimized to model data from large events rather than small/moderate events.

A preliminary evaluation of ground motions in Alberta (Novakovic and Atkinson, 2015) looked at PSA values from vertical and horizontal components of motion between 0.2 and $50 \mathrm{~Hz}$ and compared observed amplitudes to the Western North America (WNA) prediction equation of the Atkinson, Greig, and Yenier (2014b; AGY14) model and to the Atkinson (2015) GMPE. They found that motions are in qualitative agreement with expected amplitude and attenuation trends, although some refinement of the attenuation model is needed. They also found that overall amplitudes were about $0.2 \log$ units (factor of 1.6) greater on the horizontal than on the vertical component, and that the horizontal to vertical component amplitude ratios peaked around $2-5 \mathrm{~Hz}$, suggestive of an amplification of motions due to site response. When looking at the ground motions corrected to the source, this study determined that for high frequencies $(>10 \mathrm{~Hz})$ there 
was more scatter in the data than for lower frequencies $(1 \mathrm{~Hz})$. This indicated variability in the stress parameter, possibly due to smaller stress parameters for induced events, or an effect from the event type. Stress parameters tend to be smaller for shallow $(<5 \mathrm{~km}), \mathbf{M}$ 3-5 events in Western North America than for events in Central and Eastern North America, and events with depths greater than $10 \mathrm{~km}$ have stress parameters approximately 10 times higher than shallow events in both regions (Novakovic and Atkinson, 2015; Yenier and Atkinson, 2015a; 2015b).

Atkinson et al. (2015a) examined ground motions from three M 4 events in Alberta and BC; two of which were known to be induced by hydraulic fracturing, and a third of ambiguous origin. These events were widely felt and had the potential to cause damage to infrastructure if located in close proximity. They found that ground motions from these three events at frequencies up to $2 \mathrm{~Hz}$ were in agreement with predictions from applicable GMPEs (those that were developed from empirical small-magnitude close distance earthquake data, such as Atkinson, 2015, or from simulation data, such as Yenier and Atkinson, 2014) as well as with observational data from similar-sized events in California. However, it was noted that amplitudes at higher frequencies were much lower than predicted, suggesting an effect due to a low stress parameter. They again assert the findings of Yenier and Atkinson (2014) that suggest that low stress parameters of induced events relative to that of natural events is considered the result of a focal depth effect, in which events at shallow depths have lower stress parameters than deep events. Furthermore, they conclude that, based on their amplitudes, moderate events (M 4-5) from induced seismicity may be damaging to nearby infrastructure due to localized strong ground motions. 
An investigation of the region-specific source and attenuation attributes from an injection-induced seismic sequence in Prague, Oklahoma was conducted by Yenier et al. (2017). The study analysed motions from three main shocks on 5, 6 and 8 November 2011 of magnitudes M 5.0, M 5.7, and M 5.0 respectively, as well as their aftershocks. Thousands of records were used as Oklahoma has good seismographic coverage. The study refined the regionally-adjustable GMPE of Yenier and Atkinson (2015a; YA15), to represent the induced earthquake ground motions recorded in Oklahoma, at least in the Prague region. They adopted a generic bilinear geometric spreading model, in which the rate of decay of amplitudes changes from -1.3 to -0.5 at a transition distance of $50 \mathrm{~km}$, and anelastic attenuation behaviour derived from CENA. They assumed that, on average, the sites in Oklahoma are characterized by a $V_{S 30}$ of approximately $430 \mathrm{~m} / \mathrm{s}$, which corresponds to a site classification of class C (see Table 1), as defined by NEHRP. It should be noted, however, that site characterization in the region is limited and this assumption was based on preliminary work. They determined a stress parameter for each event by matching its spectral shape to a Brune $(1970,1971)$ point-source model (equivalent to finding the corner frequency). The three large events had stress parameters of 130 to 265 bars consistent with those observed for natural CENA events with focal depths from 5-10 km, but the aftershocks were characterized by a lower mean stress drop, $\sim 30$ bars on average over all magnitudes. This is lower than the mean stress parameters observed for shallow ( $<5 \mathrm{~km}$ depth) CENA events by factor of 1.5 . The study also concluded that if ground motions from induced events are compared to those from deeper natural events, the induced motions will appear higher (i.e. stronger shaking) at close 
distances and lower at further distances, due to the competing effects of shallow focal depth and stress parameter scaling on the ground-motion amplitudes.

\section{Study Scope}

The study presented in Chapter 3 of this thesis aims to characterize ground motions from moderate $(\mathbf{M}>3)$ induced events in Alberta (including some parts of eastern British Columbia and northern Montana) at hypocentral distances of less than 100 $\mathrm{km}$. Induced seismicity rates in Alberta are rising as more hydraulic fracturing wells are being implemented every year (Atkinson et al., 2016). Increased rates of seismicity, in otherwise stable and quiet regions with low rates of background seismicity, greatly increases hazard in a probabilistic seismic hazard analysis (Adams and Atkinson, 2003; Ellsworth, 2013; Keranen et al., 2014). As hazard increases, it is paramount that we work to quantify the effects, and, if needed, to reduce the exposure of nearby local structures and critical facilities. Understanding ground motion behaviours and amplitudes from hydraulic fracturing and injection-induced earthquakes in Alberta will help to tune existing GMPEs and hazard models to these specific conditions. The study uses empirical ground-motion data from earthquakes in Alberta, as well as parametric representations of the ground motions using an existing GMPE (Yenier and Atkinson, 2015a), to compare ground motion amplitude response spectra to those from induced events in Oklahoma. This comparison allows for an evaluation of ground motions recorded in Alberta with the largest database of ground motions from induced seismic events yet known, minimizing potential bias. Additionally, recorded ground motions are compared to existing GMPEs that have the potential to represent induced earthquake ground motions (Atkinson, 2015; 
Yenier and Atkinson, 2015a, calibrated to CENA; and Abrahamson et al., 2014). The study aims to make meaningful comparisons in order to better understand ground motions from moderate events in Alberta at close hypocentral distances, and to contribute to the field of seismic hazard analysis in Canada for engineering design and risk mitigation purposes. 
References for Chapters $1 \& 2$

Abrahamson, N. A., W. J. Silva, and R. Kamai (2014). Summary of the Abrahamson, Silva, and Kamai NGA-West2 ground-motion relations for active crustal regions, Earthquake Spectra 30, 1025-1056.

Adams, J., and G. Atkinson (2003). Development of seismic hazard maps for the proposed 2005 edition of the National Building Code of Canada, Canadian Journal of Civil Engineering, 30, 255-271.

Alberta Energy Regulator (AER) and the Alberta Geological Survey (AGS) (26 January 2016). Introduction to the induced seismicity study in the Fox Creek Area, Presentation to the Fox Creek Town Council, powerpoint.

Atkinson, G. (2015). Ground-motion prediction equation for small-to moderate events at short hypocentral distances, with application to induced seismicity hazards, Bulletin of the Seismological Society of America 105, doi: 10.1785/0120140142.

Atkinson, G. M. and J. Adams (2013). Ground motion prediction equations for application to the 2015 Canadian national seismic hazard maps, Canadian Journal of Civil Engineering, 40, 988-998.

Atkinson, G., and K. Assatourians (2017). Are ground-motion models derived from natural events applicable to the estimation of expected motions for induced earthquakes? Seismological Research Letters 88, no. 2A, doi: $10.1785 / 0220160153$.

Atkinson, G.M. and D. J. Wald (2007). "Did You Feel It?" intensity data: A surprisingly good measure of earthquake ground motion, Seismological Research Letters 78, 362-368.

Atkinson, G., J. Bommer, N. A. Abrahamson (2014a). Alternative approaches to modeling epistemic uncertainty in ground motions in probabilistic seismic-hazard analysis, Seismological Research Letters 85, no. 6, doi: 10.1785/0220140120.

Atkinson, G., D. W. Greig, and E. Yenier (2014b). Estimation of moment magnitude for small events $(\mathrm{M}<4)$ on local networks, Seismological Research Letters 85, no. 5, 1116-1124.

Atkinson, G., K. Assatourians, B. Cheadle, and W. Greig (2015a). Ground motions from three recent earthquakes in western Alberta and northeastern British Columbia and their implications for induced-seismicity hazard in eastern regions, Seismological Research Letters 86, no. 3, 1022-1031, doi: 10.1785/0220140195. 
Atkinson, G. M., H. Ghofrani, and K. Assatourians (2015b). Impact of induced seismicity on the evaluation of seismic hazard: Some preliminary considerations, Seismological Research Letters, 86, 1116-1124.

Atkinson, G., D. Eaton, H. Ghofrani, D. Walker, B. Cheadle, R. Schultz, R. Shcherbakov, K. Tiampo, J. Gu, R. Harrington, Y. Liu, M. van der Baan, and H. Kao (2016). Hydraulic fracturing and seismicity in the Western Canada Sedimentary Basin, Seismological Research Letters 87, no. 3, doi: 10.1785/0220150263.

Basham, P., D. Weichert, F. Anglin, and M. Berry (1982). New probabilistic strong seismic ground motion maps of Canada - a compilation of earthquake source zones, methods and results, Energy, Mines and Resources Canada, Earth Physics Branch, Open-file Report 82-33.

Basham, P., D. Weichert, F. Anglin, and M. Berry (1985). New probabilistic strong seismic ground motion maps of Canada, Bulletin of the Seismological Society of America, 75, 563-595.

Baranova, V., A. Mustaqeem, and S. Bell (1999). A model for induced seismicity caused by hydrocarbon production in the Western Canada sedimentary basin, Canadian Journal of Earth Science 36, 47-64.

Boore, D. M. (1983). Stochastic simulation of high-frequency ground motions based on seismological models of radiated spectra, Bulletin of the Seismological Society of America, 73, 1865-1894.

Boore, D. and G. Atkinson (2008). Ground-motion prediction equations for the average horizontal component of PGA, PGV and 5\%-damped PSA at spectral periods between $0.01 \mathrm{~s}$ and $10 \mathrm{~s}$, Earthquake Spectra, 24, no. 1, 99-138.

Brune, J. (1970). Tectonic stress and the spectra of seismic shear waves from earthquakes, Journal of Geophysical Research 75, 4997-5009.

Brune, J. (1971). Correction, Journal of Geophysical Research 76, 5002.

Consortium of Universities for Research in Earthquake Engineering (1997). Historic Developments in the Evolution of Earthquake Engineering.

Cornell, C. (1968). Engineering seismic risk analysis, Bulletin of the Seismological Society of America, 58, 1583-1606.

Davies, R., G. Foulger, A. Bindley, and P. Styles (2013). Induced seismicity and hydraulic fracturing for the recovery of hydrocarbons, Marine and Petroleum Geology, 45, 171-185. 
Douglas, J., B. Edwards, V. Convertito, N. Sharma, A. Tramelli, D. Kraaijpoel, B. Cabrera, N. Maercklin, and C. Troise (2013). Predicting ground motion from induced earthquakes in geothermal areas. Bulletin of the Seismological Society of America, 103, 1875-1897.

Ellsworth, W. (2013). Injection-induced earthquakes, Science 341, 1225942.

Ghofrani, H., and G. Atkinson (2016). A preliminary statistical model for hydraulic fracture-induced seismicity in the Western Canada Sedimentary Basin, Geophysical Research Letters, 43, no. 10, 164-172, doi: 10.1002/2016GL070042.

Gutenberg, R. and C.F. Richter (1944). Frequency of earthquakes in California, Bulletin of the Seismological Society of America, 34, 185-188.

Hanks, T. C. (1979). $b$ values and $\omega^{-\gamma}$ seismic source models: Implications for tectonic stress variations along active crustal fault zones and the estimation of highfrequency strong ground motion, Journal of Geophysical Research 84 (B5), 22352242.

Hanks, T. C. and A. C. Johnston (1992). Common features of the excitation and propagation of strong ground motion for North American earthquakes, Bulletin of the Seismological Society of America, 82, 1-23.

Healy, J. H., W. W. Rubey, D. T. Griggs, and C. B. Raleigh (1968). The Denver earthquakes, Science, 161, 1301.

Hough, S. (2014). Shaking from injection-induced earthquakes in the central and eastern United States, Bulletin of the Seismological Society of America 104, 2619-2626.

Keranen, K., M. Weingarten, G. Abers, B. Bekins, and S. Ge (2014). Sharp increase in central Oklahoma seismicity since 2008 induced by massive wastewater injection, Science 345, 448-451.

Madariaga, R. (2006). Seismic source theory, chapter 2 in volume 4 Earthquake Seismology, Treatise on Geophysics (H. Kanamori ed.).

McGuire, R. (1977). Seismic design spectra and mapping procedures using hazard analysis based directly on oscillator response, International Journal of Earthquake Engineering and Structural Dynamics, 5, 211-234.

National Research Council (NRC; 2013). 2 types and causes of induced seismicity, Induced Seismicity Potential in Energy Technologies. Washington, DC: The National Academies Press. doi: 10.17226/13355.

National Research Council (NRC; 2015). National Building Code of Canada 2015, Volume 1, Division B, Part 4. 
Novakovic, M., and G. Atkinson (2015). Preliminary evaluation of ground motions from earthquakes in Alberta, Seismological Research Letters, 86, no. 4, doi: $10.1785 / 0220150059$.

Petersen, M. D., C. S. Mueller, M. P. Moschetti, S. M. Hoover, A. L. Llenos, W. L. Ellsworth, A. J. Michael, J. L. Rubinstein, A. F. McGarr, and K. S. Rukstales (2016). 2016 One-year seismic hazard forecast for the Central and Eastern United States from induced and natural earthquakes: U.S. Geological Survey Open-File Report

Raleigh, C.B. J. H. Healy, and J. D. Bredehoeft (1976). An experiment in Earthquake Control at Rangely, Colorado, Science, 191, 1230-1237.

Schultz, R., V. Stern, M. Novakovic, G. Atkinson, and Y. J. Gu (2015). Hydraulic fracturing and the Crooked Lake sequences: insights cleaned from regional seismic networks, Geophysical Research Letters, 42, doi: 10.1002/2015GL063455.

Schultz, R., H. Corlett, K. Haug, K. Kocon, K. MacCormack, V. Stern, and T. Shipman (2016), Linking fossil reefs with earthquakes: Geologic insight to where induced seismicity occurs in Alberta, Geophysical Research Letters, 43, 2534-2542, doi:10.1002/2015GL067514.

Schultz, R., R. Wang, Y. J. Gu, K. Haug, and G. Atkinson (2017). A seismological overview of the induced earthquakes in the Duvernay play near Fox Creek, Alberta, Journal of Geophysical Research: Solid Earth, 122, 492-505, doi:10.1002/2016JB013570.

Trifunac, M. D. (1971). Response envelope spectrum and interpretation of strong earthquake ground motion, Bulletin of the Seismological Society of America, 61, no. 2, 343-356.

Walters, R. J., M. D. Zoback, J. W. Baker, and G. C. Beroza (2015). Characterizing and responding to seismic risk associated with earthquakes potentially triggered by fluid disposal and hydraulic fracturing, Seismological Research Letters, 86, no. 4, doi: $10.1785 / 0220150048$.

Wetmiller, R. J. (1986). Earthquakes near Rocky Mountain House, Alberta, and their relationship to gas production facilities, Canadian Journal of Earth Sciences, 23, no. $2,172-181$.

Yenier, E., and G. Atkinson (2014). Point source modeling of moderate to large magnitude earthquakes and associated ground motion saturation effects, Bulletin of the Seismological Society of America 105, 1435-1455. 
Yenier, E., and G. Atkinson (2015a). Regionally adjustable generic ground-motion prediction equation based on equivalent point-source simulations: application to Central and Eastern North America, Bulletin of the Seismological Society of America 105, 1989-2009.

Yenier, E., and G. Atkinson (2015b). An equivalent point source model for stochastic simulation of earthquake ground motions in California, Bulletin of the Seismological Society of America 105, 1435-1455.

Yenier, E., G. Atkinson, and D. F. Sumy (2017). Ground motions for induced earthquakes in Oklahoma, Bulletin of the Seismological Society of America 107, no. 1, doi: 10.1785/0120160114. 


\section{Chapter 3. A Comparison of Ground Motion Characteristics from Induced Seismic Events in Alberta with those in Oklahoma}

Note: This chapter has been published in Seismological Research Letters, August 2017, as an article by Kaski and Atkinson.

Introduction

The rate of seismicity associated with oil and gas activity in Alberta has increased markedly since 2010, as the technology to extract hydrocarbons from unconventional shale reservoirs using hydraulic fracturing in long horizontal wellbores has become widespread (Atkinson et al., 2016). The increased rate of seismicity has important implications for seismic hazard assessment in Alberta (Atkinson et al., 2015). It is therefore important to understand the potential ground motions from these events.

Ground motion prediction equations (GMPEs) for induced events can be used to characterize peak amplitudes and response spectra as a function of magnitude, hypocentral distance, and other variables, for use in seismic hazard analysis (e.g. Atkinson, 2015; Yenier et al., 2017; Atkinson and Assatourians, 2017). Such GMPEs are not yet well-developed for induced events, due to the limitations imposed by publiclyavailable observational data and their magnitude-distance range (Atkinson and Assatourians, 2017). Atkinson (2015) developed a preliminary GMPE model, using data from moderate natural events in California recorded at short hypocentral distances, under the assumption that induced events have source and attenuation parameters that are broadly similar to those of natural earthquakes. Atkinson et al. (2015) examined ground motions from three $\mathbf{M} \sim 4$ (where $\mathbf{M}$ is moment magnitude) events in Alberta, two of which were known to have been induced by hydraulic fracturing practices, the third of ambiguous origin. These events were all widely felt and may have had the potential to 
cause damage to vulnerable infrastructure located in close proximity to the earthquake source. They found that ground motions from these three events at frequencies up to $2 \mathrm{~Hz}$ were in agreement with predictions from applicable GMPEs as well as with observational data from similar-sized events (of comparable magnitude and distance) in California. However, it was noted that ground motion amplitudes at higher frequencies were lower than predicted, suggesting an effect due to a low stress parameter (where stress parameter is based on the corner frequency of a Brune $(1970 ; 1971)$ source model, and controls the high-frequency amplitudes; see Boore, 2003); regional site effects may also have played a role. A low stress parameter relative to that of natural events results in low PSA energy at high frequencies, and is considered the result of a focal depth effect, such that events at shallow depths have lower stress parameters than deeper events (Yenier and Atkinson, 2015). Atkinson et al. (2015) found that moderate induced events (M 4-5) may be potentially damaging to nearby infrastructure due to their shallow focal depths, as this brings the earthquake source closer to surface, and could possibly result in localized strong ground motions. A lower stress parameter for such shallow events would be a mitigating factor; in essence, the very close distance is counterbalanced by a weak source process.

Whilst induced-event GMPEs are being more fully developed, GMPEs developed from natural earthquake databases have been used as proxies for induced events, with some modifications. In particular, GMPEs derived from natural events in California have been found to make good proxy estimates of ground motions from moderate induced events in central and eastern North America (CENA) as the result of an apparent trade-off between effects on the stress parameter due to source depth and those due to tectonic 
setting (Atkinson and Assatourians, 2017). A recent GMPE model developed using observational data from the 2011 induced earthquake sequence in Prague, Oklahoma (Yenier et al., 2017) appears to support this contention. However, the GMPE developed from the Prague database considers only a single sequence of earthquakes, and may not be fully representative of the behavior of ground motions from induced events. To date, there are no GMPEs derived from induced earthquakes in Alberta.

In this study, we aim to characterize ground motions from moderate induced seismic events in Alberta, Canada, through an examination of spectral shapes and amplitudes of 5\% damped pseudo-spectral acceleration (PSA) records. We focus on moderate $(\mathbf{M} \geq 3)$ earthquakes at hypocentral distances $\left(R_{\text {hypo }}\right)$ of less than $100 \mathrm{~km}$, as this typically represents ground shaking levels that are strong enough to be felt (Atkinson et al., 2014a). We compare ground motions from induced Alberta events to several benchmarks, including: (i) induced events in Oklahoma; (ii) natural events in CENA; and (iii) GMPEs proposed as induced-event proxies. We seek to isolate the ground motion factors that influence any disparities between Alberta motions and our benchmarks, and determine the relative significance of each factor. An interesting aspect of this study is that the induced events in Alberta are dominated by hydraulic fracturing (Atkinson et al., 2016), whilst those in Oklahoma and the central U.S. are mostly related to wastewater disposal (Ellsworth, 2013; Keranen et al., 2014). The type of anthropogenic source may have an effect on the ground motions through source effects, due to a dependency of the stress parameter on focal depth (Yenier and Atkinson, 2015) since hydraulic fracturing practices commonly induce smaller events at or near the depth of the fracture, which is often shallower than larger wastewater disposal-induced events that occur in deeper 
basement rock (Ellsworth, 2013; Keranen et al., 2014). Additionally, differences in ground motions between Alberta and Oklahoma induced events may be attributed to potential differences in site conditions in the two regions.

\section{Overview of Datasets}

The Alberta ground motion dataset consists of seismic events recorded by several broadband seismograph networks including: the Canadian National Seismograph Network (CNSN), the Regional Alberta Observatory for Earthquake Studies Network (RAVEN), TransAlta's Dam Monitoring Network (TD), the Montana Regional Seismic Network (MRSN), as well as the Pacific Northwest Seismic Network (PNSN). The data were processed as described in Assatourians and Atkinson $(2010 ; 2017)$ to obtain response spectra and peak amplitudes. Moment magnitudes are estimated using the PSAbased algorithm of Atkinson et al. (2014b) as described by Novakovic and Atkinson (2015). Quarry blasts and mining-related events are identified based on an "event-type" flag provided as part of the Composite Alberta Seismicity Catalogue (CASC) (Fereidoni and Cui, November 2015; Fereidoni and Atkinson, 2017; www.inducedseismicity.ca). Blasts were removed from the dataset, whilst events flagged as an earthquake, or for which there is insufficient information available to determine it a blast, were kept for analysis. The focus in this study is on ground motion characteristics near the earthquake source, where the effects of attenuation on spectral shape are minimal. Therefore, we consider only those events with at least two records within $100 \mathrm{~km}$. The calculated response spectra for all Alberta records used in this analysis are available in Table S1 in the electronic supplement. For each station within $100 \mathrm{~km}$, the geometric mean of the 
horizontal components is calculated and used as the horizontal record. There is a total of 306 records (geomean horizontal and vertical components) from 28 events of $\mathbf{M} \geq 3$ in Alberta from September 2013 through December 2016 within $100 \mathrm{~km}$. While some events are located in eastern British Columbia and northern Montana (see Figure 1), the majority of events are located in Alberta, and so the events and their ground motions are referred to as the Alberta dataset.
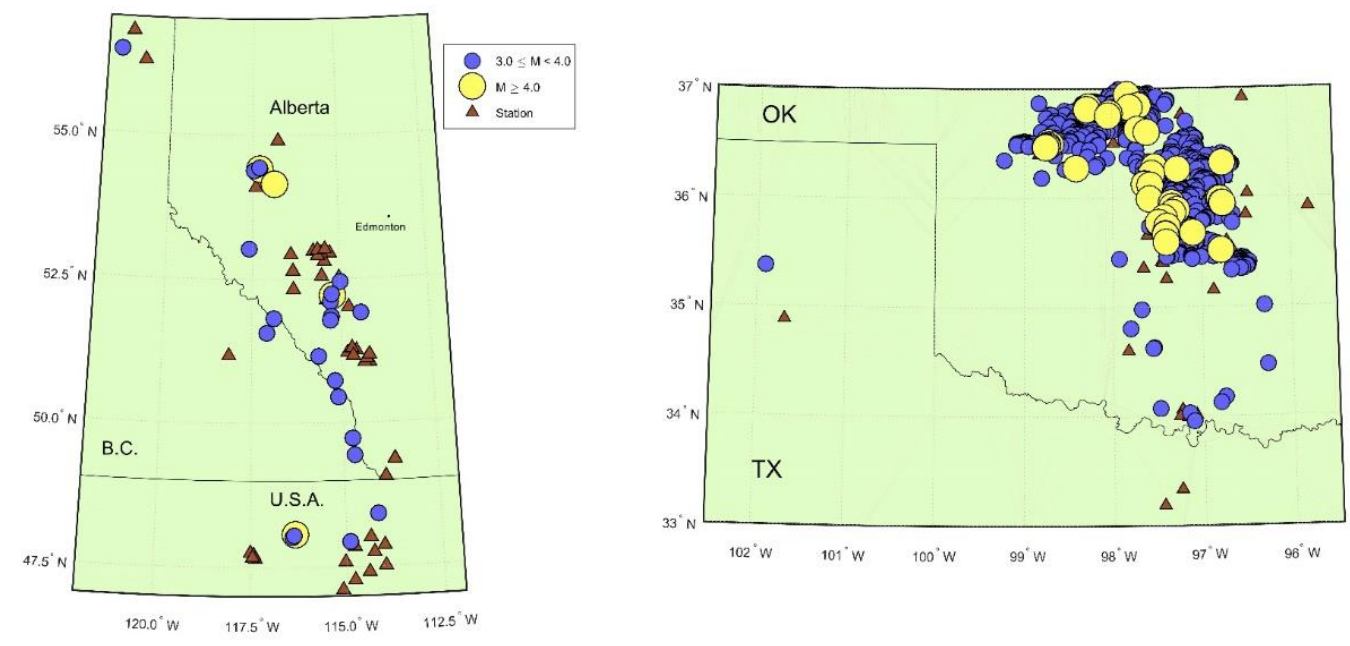

Figure 1. Location of stations and study events in Alberta (left) and Oklahoma (right).

We utilize the richer Oklahoma ground-motion database as a benchmark, in order to make non-parametric comparisons of high-frequency ground motions from induced events in the two regions. The Oklahoma database is an expanded version of that compiled by Assatourians and Atkinson (2017), with moment magnitudes computed by Novakovic (personal communication, 2017) (see Data and Resources). The comparisons cover the range of magnitudes from M2.9 to $\mathbf{M} 4.3$ and $R_{h y p o}<110 \mathrm{~km}$ (where $R_{h y p o}$ is hypocentral distance). For the Oklahoma records, only those with a minimum sample rate of 100 samples/sec are considered. Moreover, we retain only the accelerometer 
records for events of $\mathbf{M} \geq 4$ and only the broadband records for events of $\mathbf{M}<4$. This balances the better low-frequency characteristics of broadband records for smaller events against the possibility of clipping for larger events. We bin the Oklahoma records into magnitude and distance slices that are comparably equivalent with each Alberta record. Figure 1 shows the approximate earthquake locations and Figure 2 illustrates the magnitude-distance distributions of our two databases.
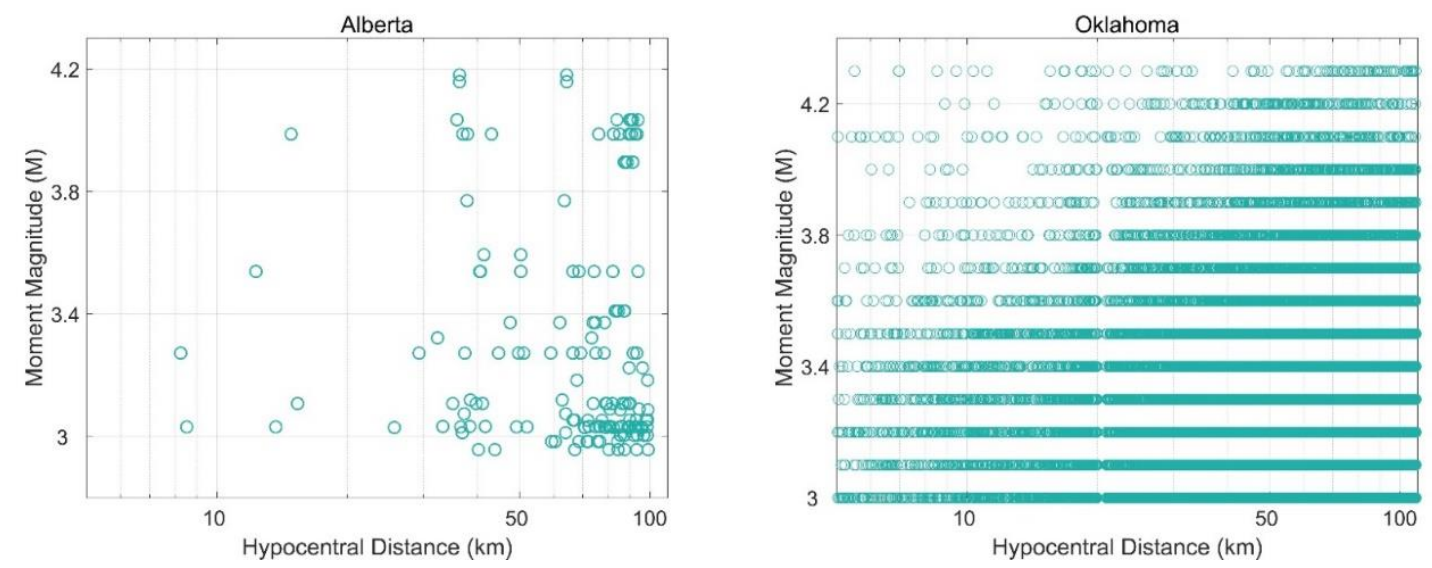

Figure 2. Distribution of the study databases in terms of moment magnitude (M) and hypocentral distance $\left(R_{\text {hypo }}\right)$.

Analysis Methods

Oklahoma Benchmark

In order to characterize the spectral behavior of ground motions from induced events in Alberta, we focus on the comparison of Alberta ground motions to several benchmarks. The primary benchmark is the rich dataset of ground motions for induced earthquakes in Oklahoma (see Data and Resources). These records are plentiful in the magnitude-distance range of our Alberta dataset, allowing us to compare individual Alberta records to statistical measures of comparable records in Oklahoma. Oklahoma 
records are binned based on available magnitude and $R_{\text {hypo }}$ of the Alberta records, so that we can compare records having:

$$
\mathbf{M}_{O K}=\mathbf{M}_{A B} \pm 0.15 \mathbf{M}
$$

and

$$
R_{\text {hypo }_{O K}}=R_{\text {hypo }_{A B}} \pm R_{\text {bin }} \mathrm{km}
$$

where $R_{\text {bin }}=5$ for $R_{\text {hypo }_{A B}} \leq 50 \mathrm{~km}, 8$ for $50<R_{\text {hypo }_{A B}} \leq 70 \mathrm{~km}$ and 10 for $70<$ $R_{\text {hypo }_{A B}} \leq 100 \mathrm{~km}$. The magnitude and distance bin sizes were chosen as a reasonable compromise between larger and smaller bin sizes. The bins are small enough to see the effects of different magnitudes and distances on ground motions but large enough to contain sufficient data points for comparison with single Alberta records. The final results are not considered to be significantly sensitive to the size of the bins. We take the geometric mean of all records within each bin, computing the standard deviation, as well as the standard error. We retain the magnitude-distance bins with standard error $<0.1 \log$ units for further analysis; these are the magnitude-distance bins having plentiful data in Oklahoma, allowing us to assess the significance of observed differences of Alberta motions versus those of Oklahoma.

\section{YA15-Alberta Benchmark}

We can characterize motions for our induced events in the context of a stochastic point-source model using the Yenier and Atkinson (2015; hereafter referred to as YA15) regionally-adjustable generic GMPE. The GMPE describes the 5\% damped pseudospectral acceleration (PSA) response spectra for the geometric mean of the horizontal component for a reference site condition of $\mathrm{B} / \mathrm{C}$ site class as defined by the 
National Earthquake Hazards Reduction Program (NEHRP; corresponding to a shear wave velocity in the upper $30 \mathrm{~m}\left(V_{S 30}\right)$ of $\left.760 \mathrm{~m} / \mathrm{s}\right)$. The model developed by Yenier and Atkinson (2015) parameterizes a stochastic point-source model that can be calibrated to regional ground motion observations. The functional form of the YA15 model is well suited for this study as it decouples the effects of the earthquake source and attenuation parameters and allows for regional adjustments by modifying a few key parameters (Yenier and Atkinson, 2015). The functional form of the YA15 model is given as

$$
\ln Y=F_{E}+F_{Z}+F_{\gamma}+F_{S}+C,
$$

in which $\ln Y$ is the natural logarithm of the predicted PSAs. $F_{E}, F_{Z}, F_{\gamma}$, and $F_{S}$, are functions that describe earthquake source, geometrical spreading, anelastic attenuation, and site effects, respectively, and the $C$ term is a frequency-dependent empirical calibration factor that adjusts the model based on the residuals between the predicted and observed amplitudes. The earthquake source function $F_{E}$ is used to describe the effect of both magnitude $\left(F_{M}\right)$ and stress parameter $\left(F_{\Delta \sigma}\right)$ on the ground-motion amplitudes:

$$
F_{E}=F_{M}+F_{\Delta \sigma} .
$$

The stress parameter reflects the relative high-frequency content, through the corner frequency of a Brune point-source model (Boore, 2003).

We use the YA15 model to determine the best stress parameter $(\Delta \sigma)$ to represent the ground motions for each event in Alberta. This evaluation is based on the verticalcomponent PSAs so that we can neglect site effects, which are less pronounced on the vertical than on the horizontal component. The stress parameter function $F_{\Delta \sigma}$ is

$$
F_{\Delta \sigma}=e_{\Delta \sigma} \ln \left(\frac{\Delta \sigma}{100}\right),
$$


where $e_{\Delta \sigma}$ is a frequency and magnitude dependent coefficient that controls the rate of ground motion scaling with the stress parameter $(\Delta \sigma)$ (see Yenier and Atkinson, 2015). We rearrange equation 3 to express $F_{E}=\ln Y_{A B}-F_{Z}-F_{\gamma}-F_{S}$, where $Y_{A B}$ are the recorded vertical PSAs, ignoring for now the calibration constant. We set $F_{S}=0$ as we assume that there is no significant site amplification (relative to $\mathrm{B} / \mathrm{C}$ reference conditions) for the vertical component. $F_{Z}$ represents the effect of geometrical spreading. We use the hinged bilinear model adopted in YA15, which accounts for a transition from direct-wave spreading to surface-wave spreading of reflected and refracted waves at a transition distance of $50 \mathrm{~km}$ (Yenier and Atkinson, 2014). $F_{\gamma}$ is the anelastic attenuation function, assumed to match the empirically-derived CENA attenuation coefficients, $\gamma_{C E N A}$, determined in Yenier and Atkinson (2015):

$$
F_{\gamma}=\gamma_{C E N A} D_{\text {rup }}
$$

in which we assume that the rupture distance $D_{\text {rup }}=R_{\text {hypo }}$ for small to moderate events.

We calculate the apparent source spectrum $F_{E}$ for each record and average over station records within $100 \mathrm{~km}$ to determine the average source spectrum for each event. Rearranging equations $2.3,2.4$ and 2.5, we are able to derive a value for the best-fit stress parameter $\Delta \sigma_{\text {best }}$, such that $\Delta \sigma_{\text {best }}=100 \exp \left(\left(F_{E}-F_{M}\right) / e_{\Delta \sigma}\right)($ See Table 2$)$. This "best-fit" value is determined in order to model the induced ground motions using YA15, and represents a rough estimate of the stress parameters for these events. The values in Table 2 are not taken into account when comparing the stress parameters between events in Alberta and Oklahoma. 
Table 2. Dates, locations, $\boldsymbol{M}$, and calculated $\Delta \sigma_{\text {best }}$ for study events in Alberta.

\begin{tabular}{|c|c|c|c|c|}
\hline $\begin{array}{l}\text { Date } \\
(\mathrm{mm} / \mathrm{dd} / \mathbf{y y y y})\end{array}$ & Latitude $\left(^{\circ}\right)$ & Longitude $\left(^{\circ}\right)$ & $\begin{array}{l}\text { Magnitude } \\
\text { (M) }\end{array}$ & $\begin{array}{l}\Delta \sigma_{\text {best }} \\
\text { (bars) }\end{array}$ \\
\hline $8 / 26 / 2014$ & 51.78 & -115.29 & 3.0 & 6 \\
\hline $1 / 23 / 2016$ & 50.73 & -115.20 & 3.0 & 22 \\
\hline $6 / 17 / 2016$ & 50.45 & -115.12 & 3.0 & 7 \\
\hline $4 / 23 / 2016$ & 54.42 & -117.29 & 3.0 & 28 \\
\hline $9 / 22 / 2014$ & 51.91 & -114.43 & 3.0 & 14 \\
\hline $2 / 21 / 2016$ & 52.10 & -115.28 & 3.0 & 15 \\
\hline $10 / 3 / 2015$ & 51.84 & -115.26 & 3.0 & 14 \\
\hline $6 / 17 / 2015$ & 49.44 & -114.72 & 3.1 & 3 \\
\hline $10 / 16 / 2014$ & 51.16 & -115.64 & 3.1 & 34 \\
\hline $9 / 22 / 2016$ & 54.42 & -117.31 & 3.1 & 27 \\
\hline $1 / 13 / 2015$ & 51.56 & -117.08 & 3.1 & 21 \\
\hline $2 / 21 / 2014$ & 53.02 & -117.59 & 3.1 & 25 \\
\hline $7 / 13 / 2014$ & 52.23 & -115.24 & 3.1 & 25 \\
\hline $1 / 7 / 2015$ & 54.43 & -117.30 & 3.1 & 43 \\
\hline $2 / 13 / 2014$ & 51.82 & -116.88 & 3.2 & 22 \\
\hline $9 / 29 / 2016$ & 49.73 & -114.76 & 3.2 & 16 \\
\hline $6 / 2 / 2015$ & 52.45 & -114.99 & 3.3 & 25 \\
\hline $1 / 15 / 2015$ & 54.38 & -117.46 & 3.3 & 53 \\
\hline 4/11/2015 & 48.41 & -114.15 & 3.4 & 28 \\
\hline $4 / 24 / 2015$ & 48.02 & -116.40 & 3.4 & 47 \\
\hline
\end{tabular}




\begin{tabular}{|l|l|l|l|l|}
\hline $\mathbf{1 1 / 1 1 / 2 0 1 4}$ & 47.93 & -114.90 & 3.5 & 22 \\
\hline $\mathbf{1 2 / 1 7 / 2 0 1 4}$ & 56.44 & -121.60 & 3.6 & 23 \\
\hline $\mathbf{1 / 2 3 / 2 0 1 5}$ & 54.43 & -117.31 & 3.8 & 50 \\
\hline $\mathbf{4 / 2 4 / 2 0 1 5}$ & 48.05 & -116.36 & 3.9 & 56 \\
\hline $\mathbf{8 / 9 / 2 0 1 4}$ & 52.21 & -115.22 & 4.0 & 29 \\
\hline $\mathbf{4 / 2 4 / 2 0 1 5}$ & 48.07 & -116.33 & 4.0 & 86 \\
\hline $\mathbf{6 / 1 3 / 2 0 1 5}$ & 54.15 & -116.86 & 4.0 & 35 \\
\hline $\mathbf{1 / 1 2 / 2 0 1 6}$ & 54.41 & -117.29 & 4.2 & 66 \\
\hline
\end{tabular}

$F_{M}$ is determined based on the input magnitudes calculated as described by Novakovic and Atkinson (2015) using the PSA method developed by Atkinson et al. (2014b). These magnitudes are calibrated to those from regional moment tensors as in Atkinson and Babaie Mahani (2013); the moment calculation procedure is calibrated. We note some circularity in the determination of $\Delta \sigma_{\text {best }}$ through the event term based on PSAs, however, this circularity is desired for this application as it allows us to determine the value of $\Delta \sigma_{\text {best }}$ that reflects the ratio of high-frequency amplitudes to low frequency amplitudes. $e_{\Delta \sigma}$ is defined in Yenier and Atkinson (2015) for either $\Delta \sigma$ greater than or less than 100 bars, which can be determined based on the sign of the stress parameter function $F_{\Delta \sigma}$. For positive $F_{\Delta \sigma}$, we calculate $e_{\Delta \sigma}$ for $\Delta \sigma>100$ bars and if $F_{\Delta \sigma}$ is negative we calculate $e_{\Delta \sigma}$ for $\Delta \sigma \leq 100$ bars. Figure 3 shows the inferred value for $\Delta \sigma$, as calculated from PSA values at 5,10 , and $20 \mathrm{~Hz}$. We choose the value of $\Delta \sigma_{\text {best }}$ to be that calculated using PSA at $10 \mathrm{~Hz}$. We consider $10 \mathrm{~Hz}$ to be a high enough frequency that it allows us to capture the appropriate shape of the source spectrum without being overly 
affected by high-frequency attenuation, as the source spectrum is highly dependent on stress parameter at high frequencies (Yenier and Atkinson, 2015).

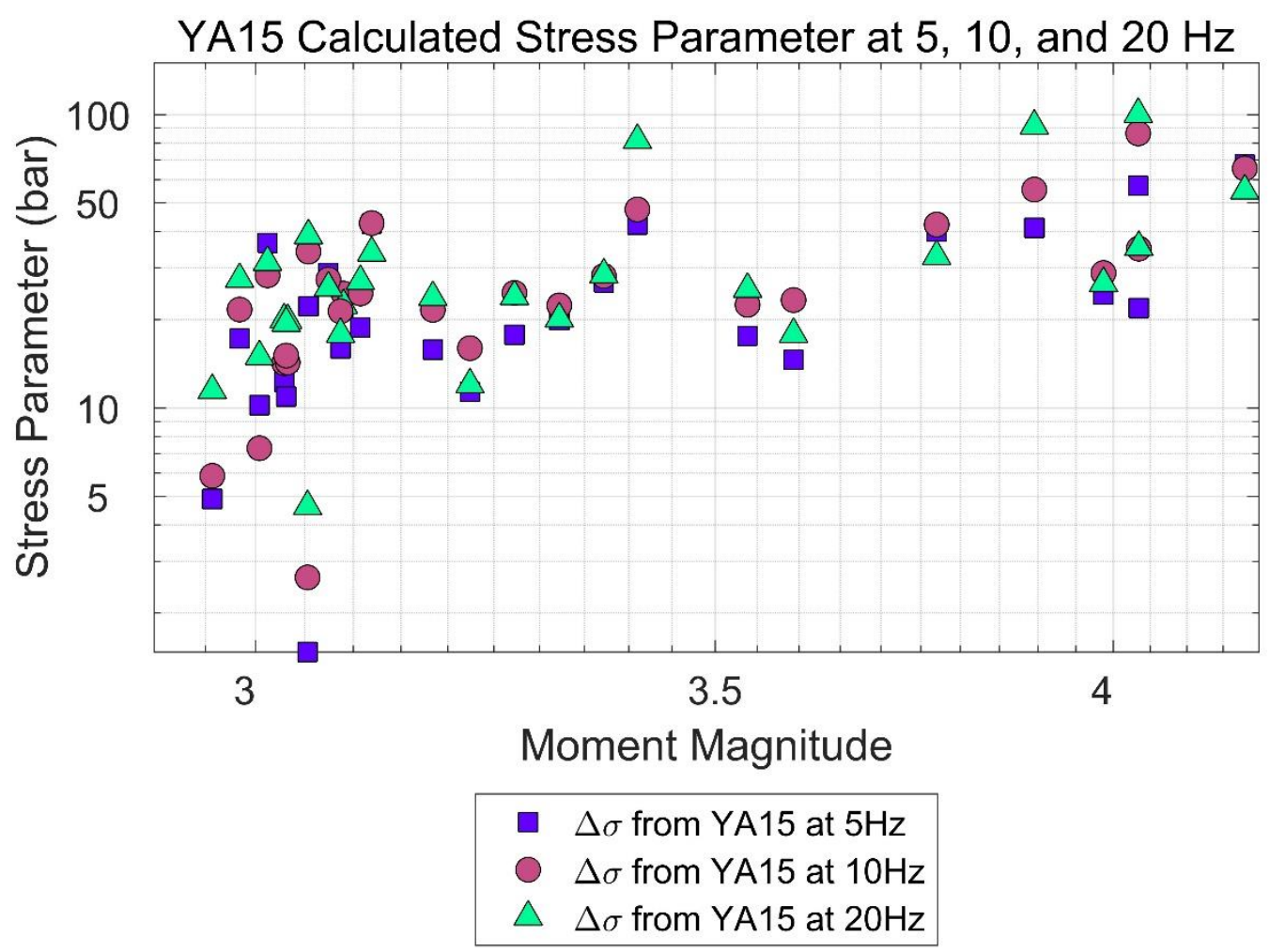

Figure 3. Stress parameters $(\Delta \sigma)$ calculated from PSA amplitudes at 5, 10, and $20 \mathrm{~Hz}$. $\Delta \sigma$ is calculated using vertical-component PSAs at the specified frequency with the YA15 model (averaging its value over all stations within $100 \mathrm{~km}$ recording the event). The value of $\Delta \sigma$ calculated using the $10 \mathrm{~Hz}$ amplitudes is chosen.

The calibration factor $C$ in equation 2.3 is defined by the natural $\log$ residuals between the predicted YA15 model (without calibration) for the Alberta ground motions and the observed vertical PSAs, averaged for each event, for each frequency. This is known hereafter as $C_{\text {event }}$. It implicitly includes both the event term and any average site term (for the vertical component, relative to the reference used by YA15, which is horizontal-component motions on $\mathrm{B} / \mathrm{C}$ site conditions). In addition to an event-specific $C$, 
an average calibration factor is calculated by taking the geometric mean of the residuals from all 28 events used in this study (as a function of frequency). This calibration factor is the Alberta average calibration factor, $C_{A B}$ (Figure 4), which is frequency dependent. Equation 2.3 becomes

$$
\ln Y=F_{E}\left(\boldsymbol{M}, \Delta \sigma_{\text {best }}\right)+F_{Z}+F_{\gamma(C E N A)}+C
$$

in which $C=C_{\text {event }}$ to represent an individual event, or $C_{A B}$ to represent the average over all Alberta events used in this study. We assume that attenuation and geometric spreading behaviours in Alberta are represented by CENA (a stable tectonic area). Through determinations of the event-specific stress parameters and both the event-specific and average regional calibration factors, in addition to the assumption that Alberta sites are characterized by a NEHRP B/C site condition, we are able to adjust the YA15 model to represent the Alberta dataset. We refer to this model as $\mathrm{YA} 15_{\mathrm{AB}}$ hereafter.

\section{GMPE Benchmarks}

We compare ground motion trends from induced events in Alberta with those from natural events in CENA by evaluating residuals for the Alberta ground motions against the predictions of the YA15 GMPE developed for CENA (YA15 ${ }_{\text {CENA }}$ hereafter). We choose the YA15 model to represent natural ground motions in CENA as it is the only model that is adjustable to a specific region (as shown in the previous section), and includes a focal depth effect; this allows us to evaluate ground motions from natural and induced events at shallow depths. This model was calibrated with the Next Generation Attenuation -East (NGA-East) database for CENA events of $\mathbf{M} \geq 3$ events within 600 $\mathrm{km}$. The functional form is as follows: 


$$
\ln Y_{C E N A}=F_{M}+F_{\triangle \sigma C E N A}+F_{Z}+\gamma_{C E N A} D_{r u p}+F_{S}+C_{e, C E N A}+C_{p, C E N A},
$$

in which $C_{e, C E N A}, C_{p, C E N A}$, are event-based and region-specific path-based calibration factors, respectively, and $F_{\triangle \sigma C E N A}$ is defined as

$$
F_{\triangle \sigma C E N A}=e_{\triangle \sigma} \ln \left(\frac{\sigma_{C E N A}}{100}\right),
$$

in which $\Delta \sigma_{C E N A}$ is defined based on the depth-scaling function:

$$
\ln \Delta \sigma_{C E N A}=5.704+\min [0,0.29(d-10)]+\min [0,0.229(\boldsymbol{M}-5)],
$$

where $d$ is focal depth in $\mathrm{km}$. The total calibration factor for CENA $\left(C_{e, C E N A}+C_{p, C E N A}\right)$ is plotted along with that for Alberta in Figure 4. We compare YA15 ${ }_{\mathrm{AB}}$, calibrated by the factor $C_{A B}$, with YA15 ${ }_{\text {CENA }}$ for four records in Figure 5. This is essentially a comparison of Alberta records with similar CENA records (same magnitude, distance and focal depth) within a common point-source model framework. 


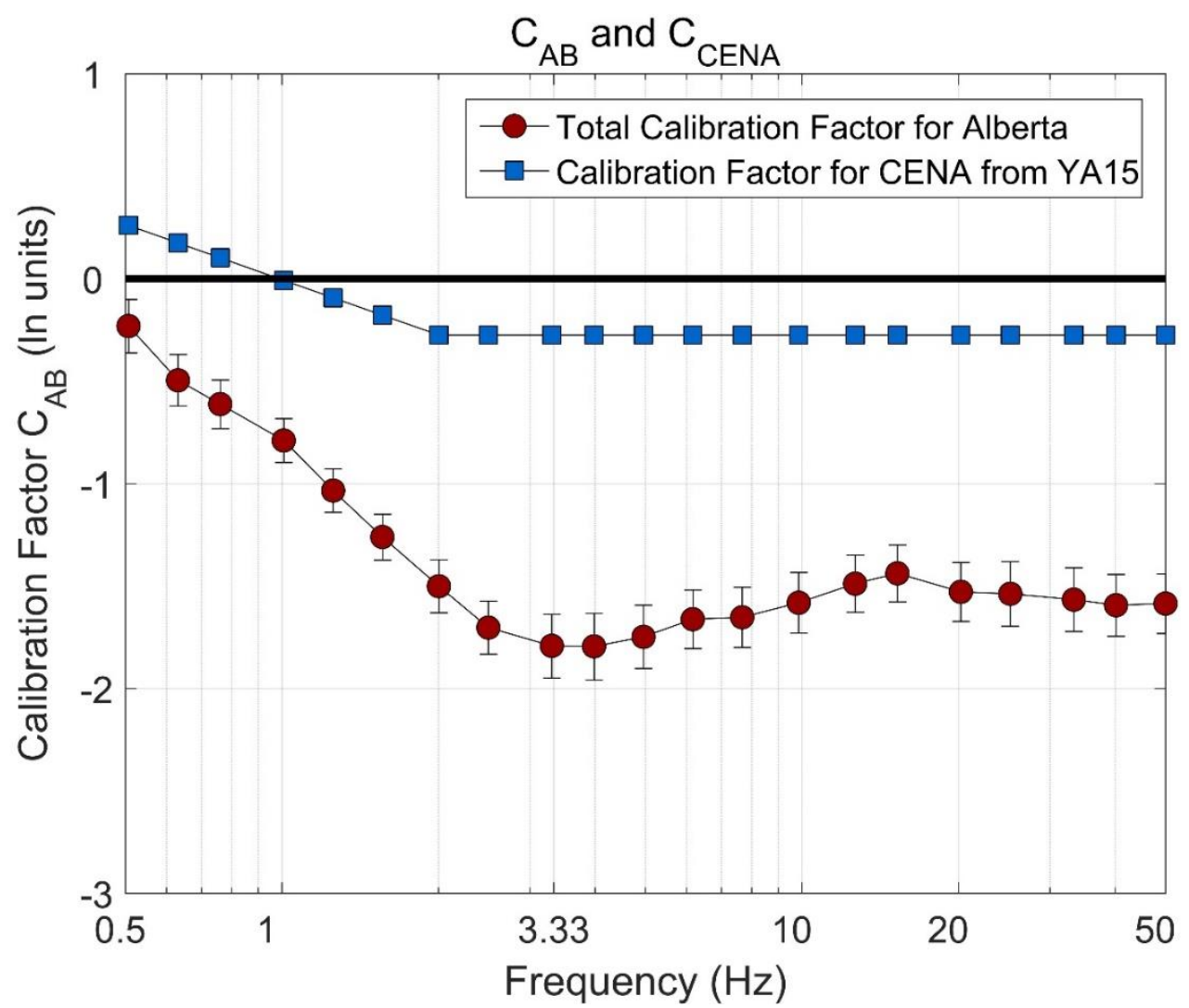

Figure 4. Average Alberta empirical calibration factor $C_{A B}$ with frequency to calibrate YA15 to Alberta ground motions. Error bars denote the standard error around the mean. The model for the calibration factor of YA15 for CENA is plotted for comparison. 

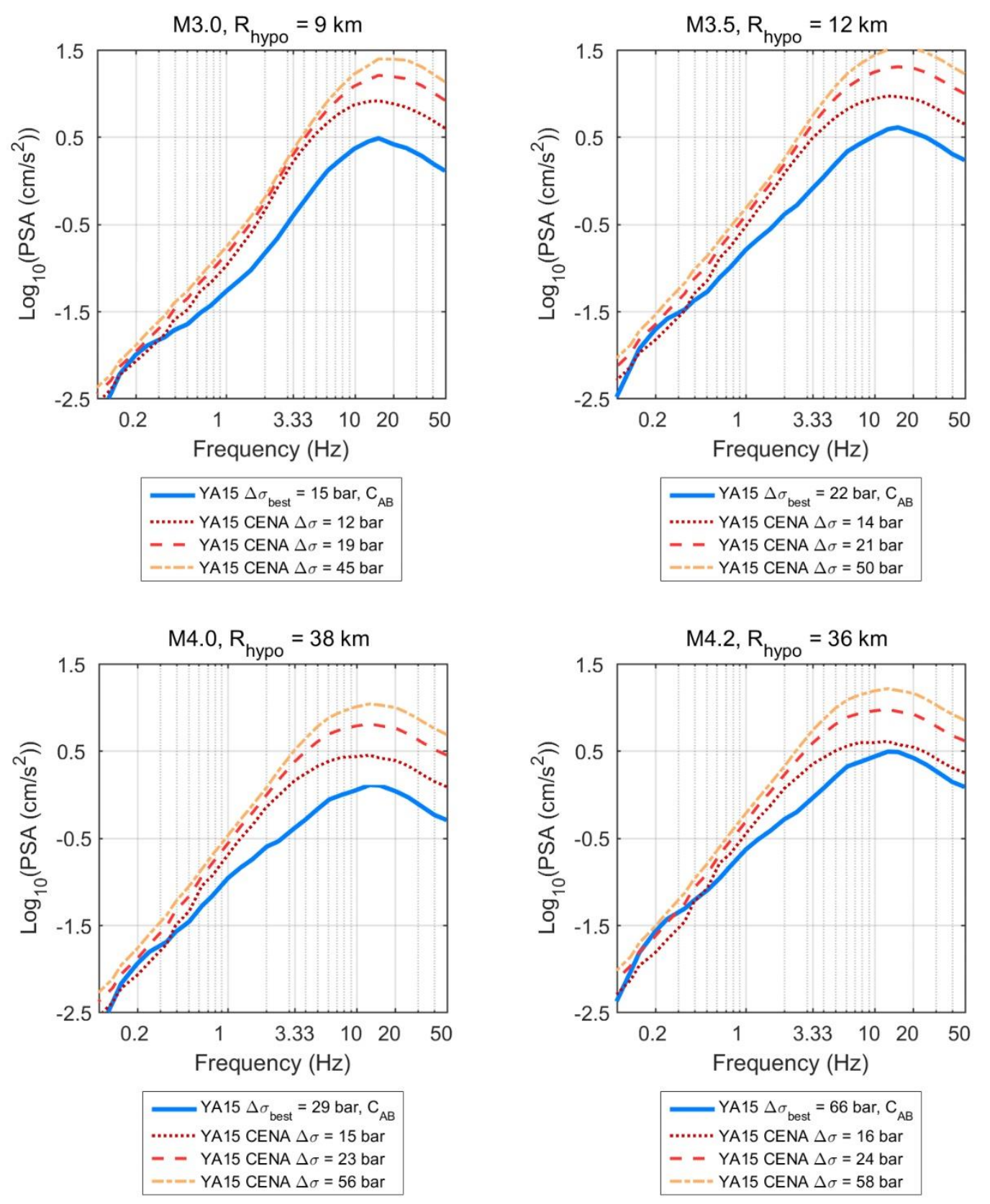

Figure 5. YA15 $A B$ (vertical component) evaluated at 4 magnitudes and distances compared to YA15 CENA. YA15 CENA amplitudes are plotted for stress parameters $\Delta \sigma$ corresponding to focal depths of 0.5, 5, and $8 \mathrm{~km}$. Note the amplitudes of the Alberta motions are low (across all frequencies) because of the value of the overall Alberta calibration constant, not the stress parameter. 
Two other GMPEs are used to evaluate induced Alberta events against natural events of similar magnitude (but greater depth) in California. These GMPEs, albeit developed from natural earthquakes, have been proposed as proxy models to represent induced earthquake ground motion behaviours (Atkinson and Assatourians, 2017). These particular models were proposed (along with the YA15 CENA model) due to their ability to better represent near-source scaling of induced ground motions, and their inclusion of ground motion-scaling with focal depth. These attributes aid in modeling induced ground motions, as induced earthquakes tend to be shallower and produce stronger ground motions within $\sim 10 \mathrm{~km}$ of the epicentre than natural earthquakes. The first GMPE is from Atkinson (2015; hereafter A15), which was developed from the Next Generation Attenuation (NGA) West2 database of California earthquakes, producing horizontalcomponent response spectra of M3-6 events at $R_{\text {hypo }}$ less than $40 \mathrm{~km}$. A15 has a simple functional form:

$$
\log Y=c_{0}+c_{1} \mathbf{M}+c_{2} \mathbf{M}^{2}+c_{3} \log R,
$$

where $Y$ represents the orientation-independent horizontal component 5\% damped PSAs at a given frequency, and logs are in base 10. The distance measure $R$ is an "effective point-source distance" as defined by

$$
R=\sqrt{R_{\text {hypo }}^{2}+h_{\text {eff }}^{2}} .
$$

This takes into account near-source saturation effects through the effective-depth parameter $h_{e f f}$, which is defined as

$$
h_{\text {eff }}=\max \left(1,10^{-1.72+0.43 \mathbf{M}}\right) .
$$

The effective depth parameter $h_{e f f}$, is as determined by Yenier and Atkinson (2014) and forces attenuation curves to saturate at close distances. 
The second GMPE used to represent median California ground motions for natural events is that of Abrahamson et.al. (2014; hereafter known as ASK14), also developed from the NGA-West2 database. The functional form contains many optional terms, but those most relevant here are the basic terms controlling the magnitude and distance dependence of motions for a reference site condition (the $f_{1}$ term), which provide a break in magnitude scaling for small magnitudes to accommodate point-source scaling ( $\mathbf{M}<5$; Abrahamson et. al, 2014), as well as the site-correction term $\left(f_{5}\right)$ through which we adjust the model to a $\mathrm{B} / \mathrm{C}$ reference site condition. The term for the depth to top of rupture $\left(f_{6}\right)$ is also relevant, because this term implicitly scales the stress parameter according to the earthquake focal depth. As is recommended by Atkinson and Assatourians (2017), we prescribe the depth to the top of the rupture $\left(Z_{T O R}\right)$ as unspecified. Specifying an unknown focal depth forces the spectral amplitudes to reflect an event of average depth in California $(\sim 8 \mathrm{~km})$ (see Atkinson and Assatourians for rationale).

Ground Motions for Typical Events Compared to the Benchmarks

We provide here an overview of response spectra from three events in Alberta, representing typical ground motion for events of $\mathbf{M}$ 3.0, $\mathbf{M} 4.0$ and $\mathbf{M} 4.2$, compared to the benchmarks described in the preceding section. The specific events occurred near Rocky Mountain House (RMH), Alberta (M 3.0; M 4.0), and Fox Creek, Alberta (M 4.2). Similar graphical comparisons for the remaining 25 events in our Alberta dataset are provided in Appendix A (vertical-components) and Appendix B (horizontalcomponents). 
The events near RMH are part of a seismic cluster that has had ongoing activity since the 1970s (Eaton and Mahani, 2015; Wetmiller, 1986). Events of this cluster have been interpreted to be induced by poroelastic stress changes associated with hydrocarbon production (Baranova 1999); this activity has not been directly linked to hydraulic fracturing practices (Eaton and Mahani, 2015). We showcase here the M 3.0 RMH earthquake that occurred on 21 February 2016, as it represents typical ground motions for an event of $\mathbf{M} \sim 3$, and was recorded over a good range of hypocentral distance. The $\mathbf{M} 4.0$ RMH event occurred on 9 August 2014. It is significant as it was the largest event to occur in the RMH cluster to date (Eaton and Mahani, 2015). This event also resulted in the shutdown of a nearby gas plant, leaving several hundred people without power for an extended period of time (Atkinson et al., 2015). It should be noted however, that this particular event has not yet been definitively classified as natural or induced (Eaton and Mahani, 2015; Atkinson et al., 2015; Ghofrani and Atkinson, 2016). Finally, the M 4.2 event on 12 January 2016 near Fox Creek was selected to represent ground motions from one of the largest events induced by hydraulic fracturing (Schultz et al., 2017). Hydraulic fracturing operations near Fox Creek have been deemed the cause of new earthquake sequences since December 2013 (Schultz et al., 2015, 2016). This particular event resulted in an order from the Alberta Energy Regulator to cease oil and gas operations at a site $35 \mathrm{~km}$ from Fox Creek in response to the event as per their regional traffic light protocol (Alberta Energy Regulator and Alberta Geological Survey, 2016).

Figure 6 provides an overview of vertical component PSAs from the M 3.02016 $\mathrm{RMH}$ event at hypocentral distances ranging from 9 to $92 \mathrm{~km}$; horizontal (geomean) component PSAs are shown in Figure 7. The motions are compared to the mean 
Oklahoma PSAs \pm 1 standard deviation benchmark, as well as the YA15 $5_{\mathrm{AB}}, \mathrm{YA} 15_{\mathrm{event}}$, A15, and ASK14 GMPEs. In these plots, YA15 ${ }_{\mathrm{AB}}$ is the generic GMPE as calibrated by

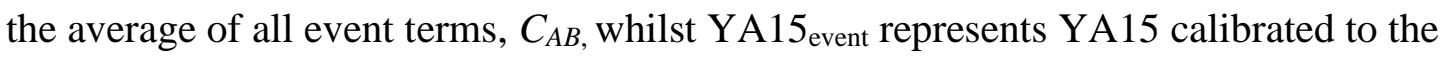
event-specific amplitudes, by $C_{\text {event }}$. Figures 8 and 9 show the same comparisons for the vertical and horizontal ground motions from the M 4.0 2014 RMH event at distances between 15 and $93 \mathrm{~km}$. Figure 10 shows the vertical and horizontal-motion comparisons from the M 4.22016 Fox Creek event at 36 and $64 \mathrm{~km}$.

It is important to recognize in viewing these graphical comparisons that discrepancies of observed motions with respect to the benchmarks may include both source and site effects. The site conditions of the stations in Alberta and Oklahoma are not yet well-documented (though studies are underway). thus we did not attempt to remove site effects. We believe that regional path effects are only a minor contributor to the observed differences, since the attenuation appears to be similar in the two regions (we do not observe any distance-dependent trends in the observed discrepancies). In general, then, any consistent trends seen across all events and stations should reflect the sum of regional differences in source amplitudes and average regional differences in site effects. Trends due to source effects may vary with both magnitude and frequency, while those due to site effects should vary with frequency only. 

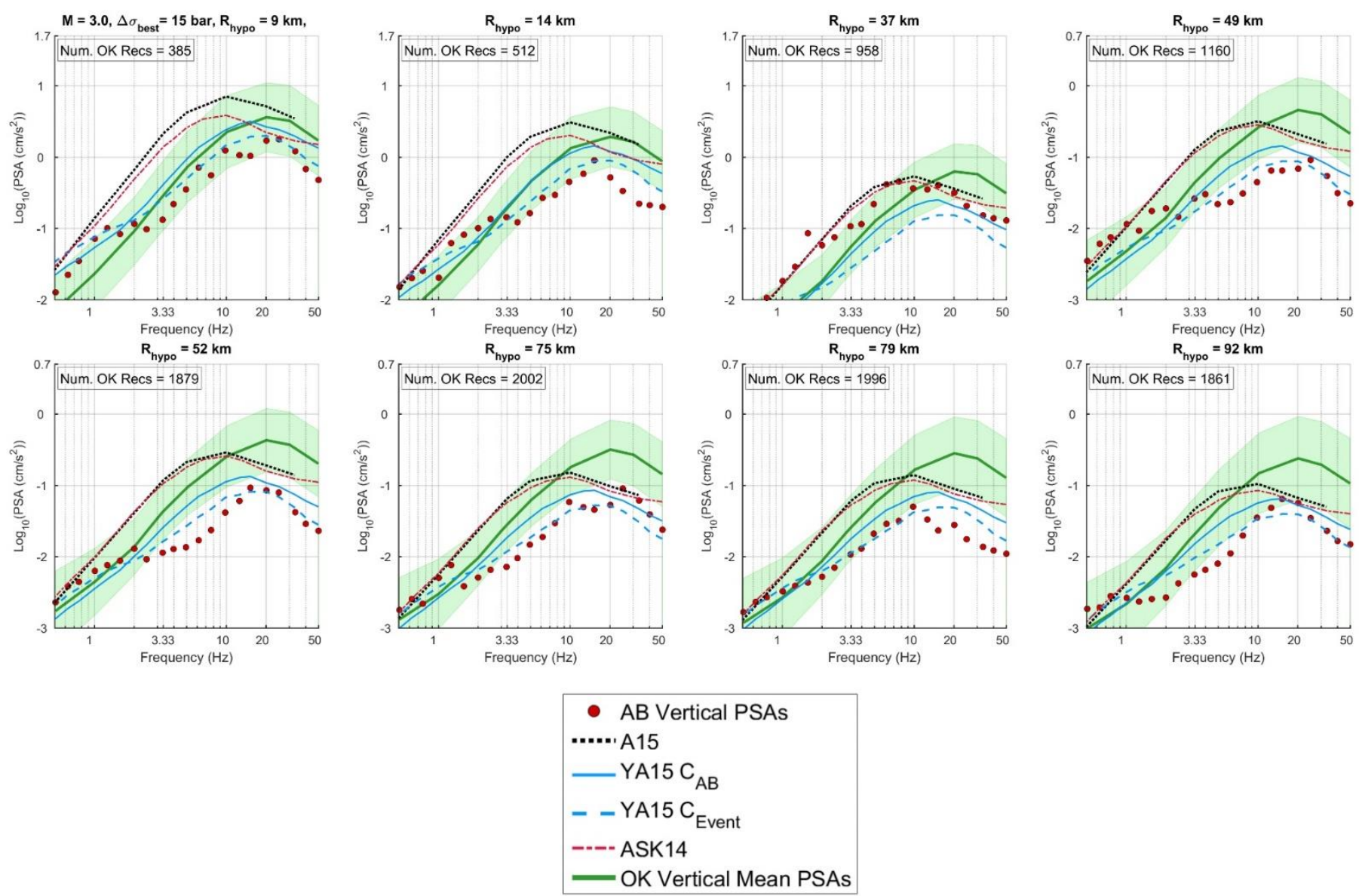

Figure 6. Vertical-component 5\% damped Alberta PSAs (circles) for an M3.0 event in Rocky Mountain House (RMH), Alberta. The average binned Oklahoma PSA for equivalent magnitude-distance range is plotted along with \pm 1 standard deviation (std) around the mean (shaded region). YA15 $5_{A B}$ and YA15 event are represented by light solid and dashed lines. $\Delta \sigma_{\text {best }}$ is 15 bars. California GMPEs A15 (black dotted) and ASK14 (dot-dashed) are shown. 

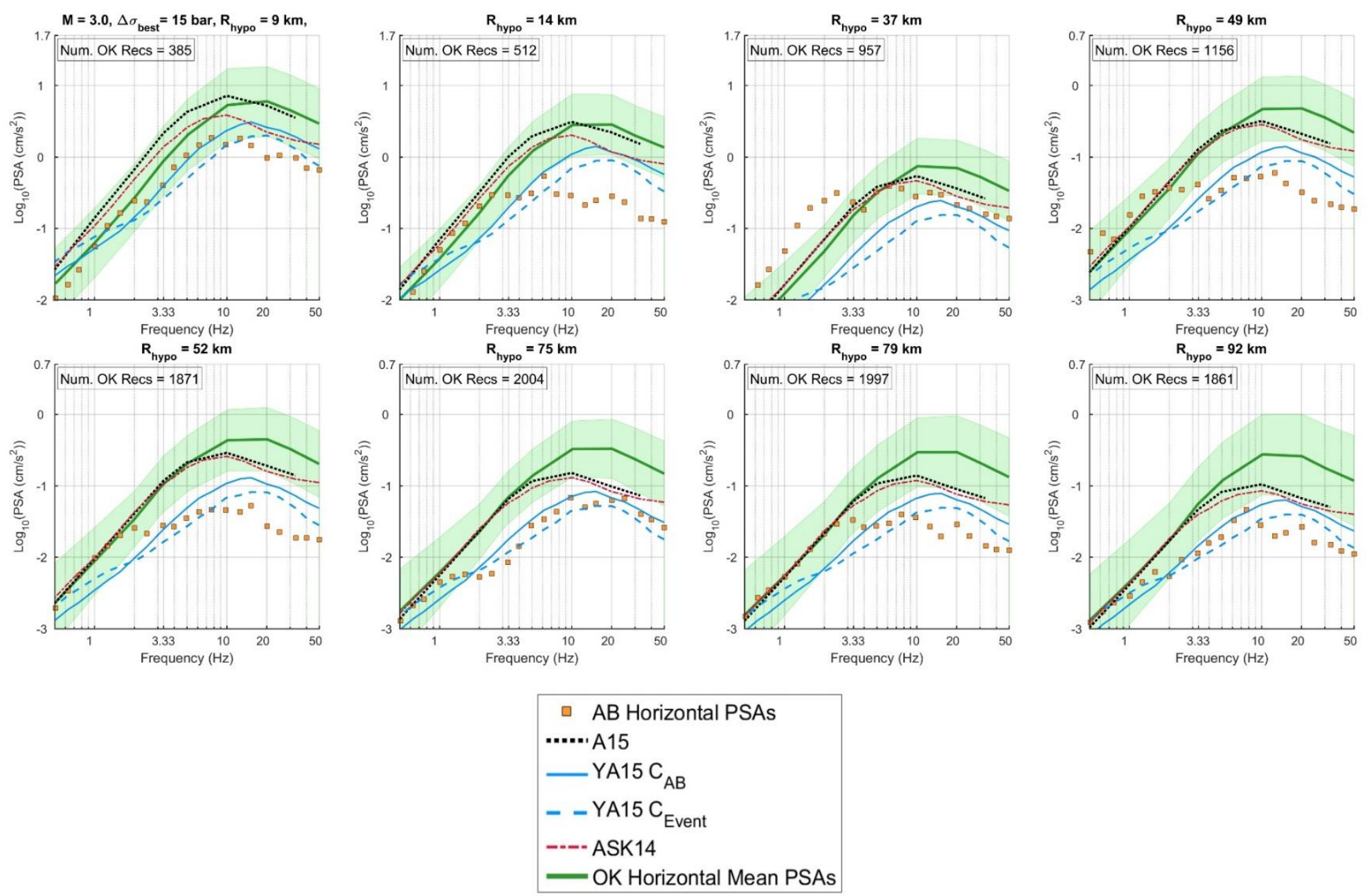

Figure 7. Horizontal-component (geometric mean) Alberta PSAs (squares) for an M3.0 event in RMH, AB. See Figure 6 caption for Oklahoma PSA and GMPE descriptions. 

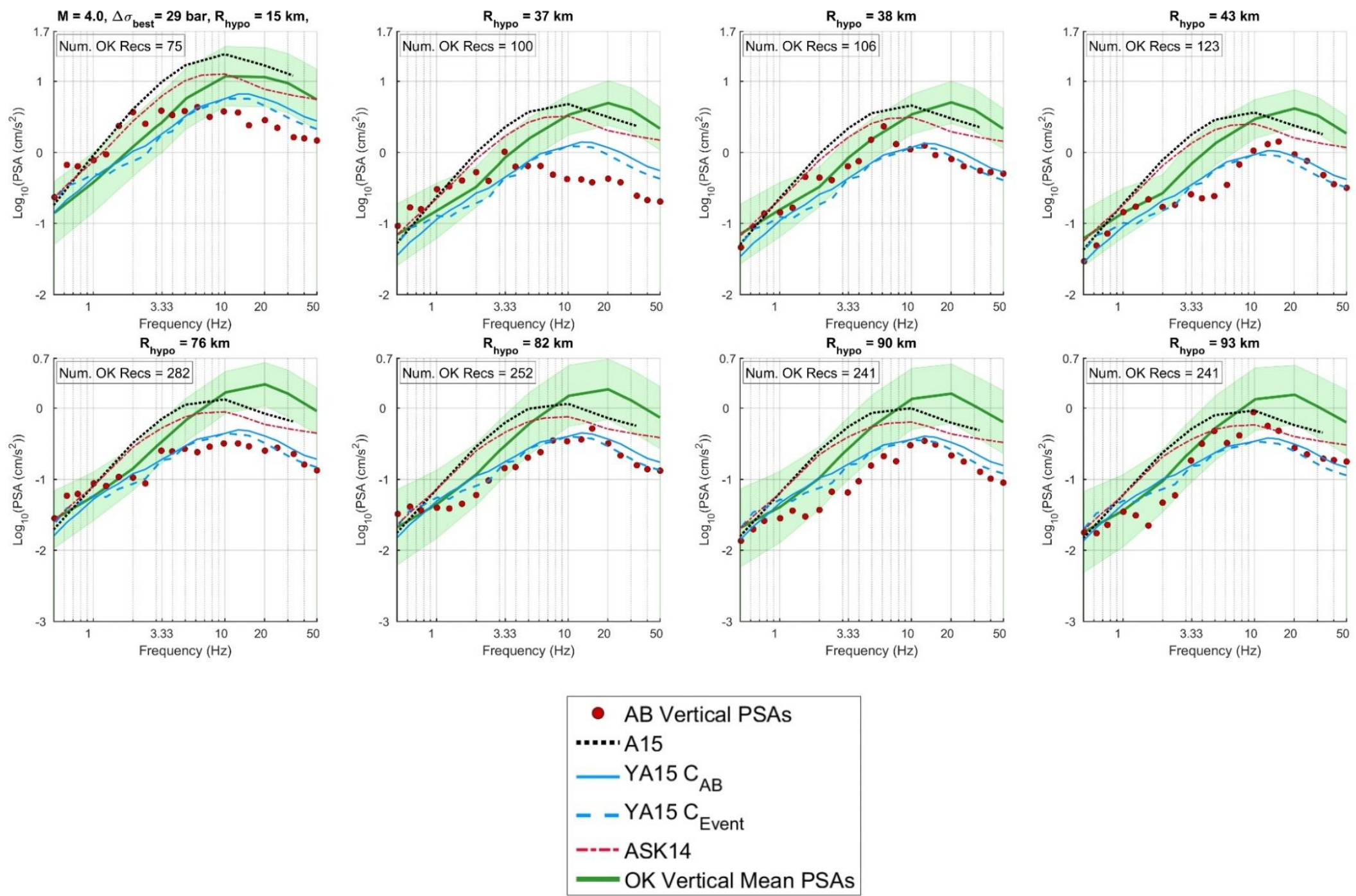

Figure 8. Vertical-component Alberta PSAs (circles) for an M4.0 event in RMH, AB. See Figure 6 caption for Oklahoma PSA and GMPE descriptions. $\triangle \sigma_{\text {best }}$ is 29 bars. 

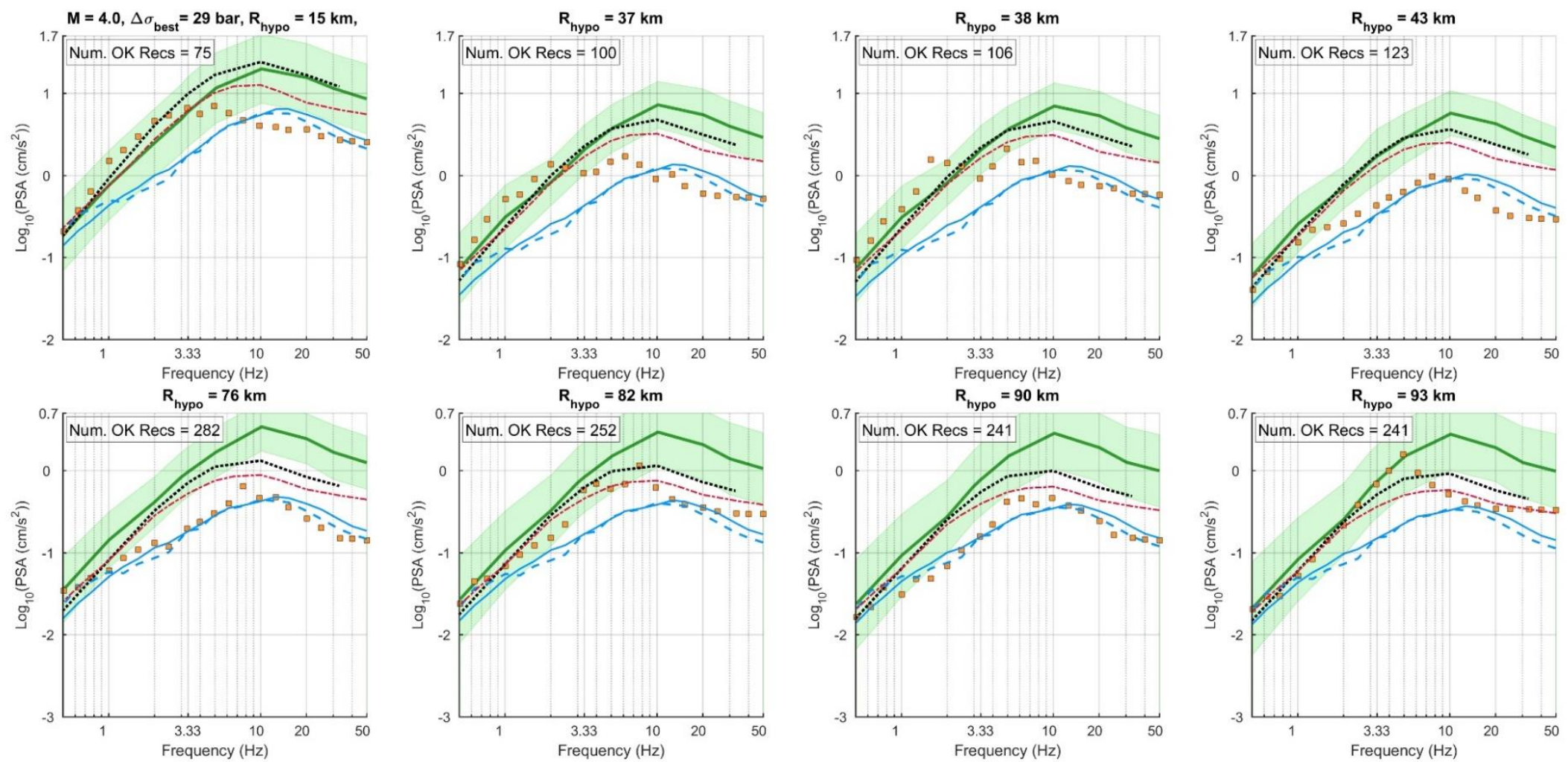

\begin{tabular}{|l|}
\hline AB Horizontal PSAs \\
$\cdots \cdot-\cdot \cdot \mathrm{A} 15$ \\
$-\mathrm{YA} 15 \mathrm{C}_{\mathrm{AB}}$ \\
$--\mathrm{YA} 15 \mathrm{C}_{\text {Event }}$ \\
---- ASK14 \\
- OK Horizontal Mean PSAs
\end{tabular}

Figure 9. Horizontal-component Alberta PSAs (squares) for an M4.0 event in RMH, AB. See Figure 6 caption for Oklahoma PSA and GMPE descriptions. 

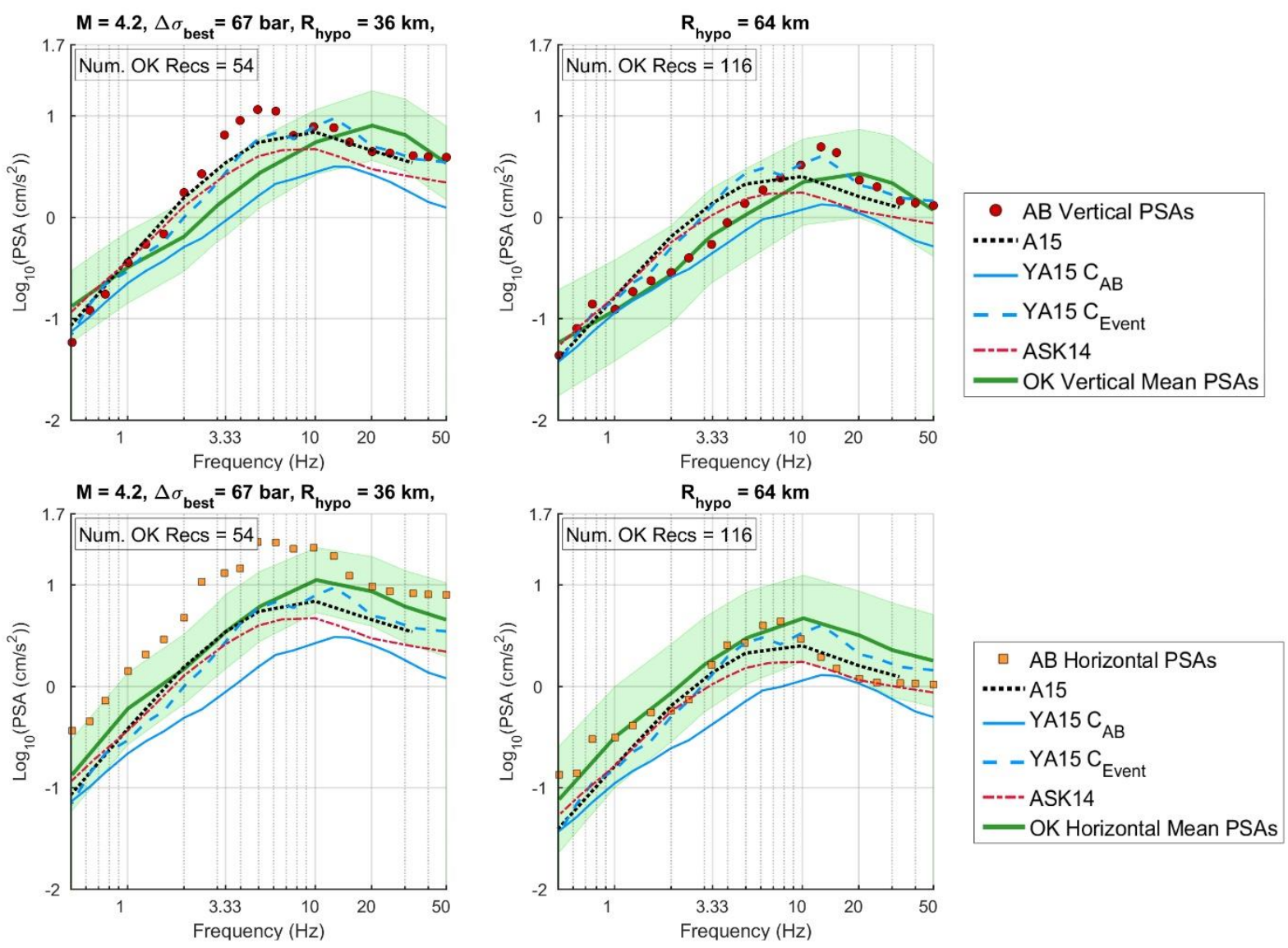

Figure 10. Vertical (top; circles) and horizontal (bottom; squares) component Alberta PSAs compared to mean Oklahoma PSA \pm 1 std for an M4.2 event in Fox Creek, Alberta. See Figure 6 caption for GMPE descriptions. $\triangle \sigma_{\text {best }}$ is 67 bars.

We observe a clear pattern in that the Alberta amplitudes are consistently lower than those of Oklahoma at frequencies greater than $\sim 3.3 \mathrm{~Hz}$. This is especially evident for the smallest event (M 3.0). Other small-magnitude events analyzed in this study, as presented in the electronic supplement, show similar trends. Because the discrepancies are more pronounced at small magnitudes than larger magnitudes, we speculate that they represent, at least in part, a source effect. There could also be a significant site effect. Preliminary information suggests that most Alberta sites are likely NEHRP Class D 
(Farrugia et al., 2017, unpublished manuscript), while Oklahoma sites are likely Class C on average (Yenier et al., 2017).

We observe some amplification of horizontal-component PSAs at low frequencies, relative to the vertical components. This is consistent with the preliminary results of ongoing site characterization and amplification studies in Alberta (Farrugia et al. 2017; unpublished manuscript). Horizontal-component motions in Alberta are, in general, amplified with respect to the vertical in the frequency range of 1-5 Hz (Farrugia et al., 2017; unpublished manuscript). We note that ground motions from the $\mathbf{M} 3.0$ event are lower than is expected from GMPEs. This is explored further using residual analysis.

\section{Residuals of Alberta Motions with Respect to the Benchmarks}

We calculate the log (base 10) residual at each frequency of Alberta PSAs with respect to the mean values for Oklahoma for the corresponding magnitude-distance bin as

$$
R s(f)=\log _{10}\left(P S A_{A B}(f)\right)-\log _{10}\left(P S A_{O K}(f)\right)
$$

Residuals of ground motions are presented in log scale as it is the log of the ground motions that is normally distributed. Hence, $\log _{10}$ or the natural logarithm of ground motions is used to create and evaluate ground motion models. Figure 11 plots these Alberta-Oklahoma log residuals, in magnitude-distance bins, for vertical-component amplitudes versus $\mathbf{M}$ at 1, 5, 10, and $20 \mathrm{~Hz}$. (Plots of the individual residuals for each Alberta record are provided in Appendix C.) Horizontal-component residuals are examined in Figure 12. 

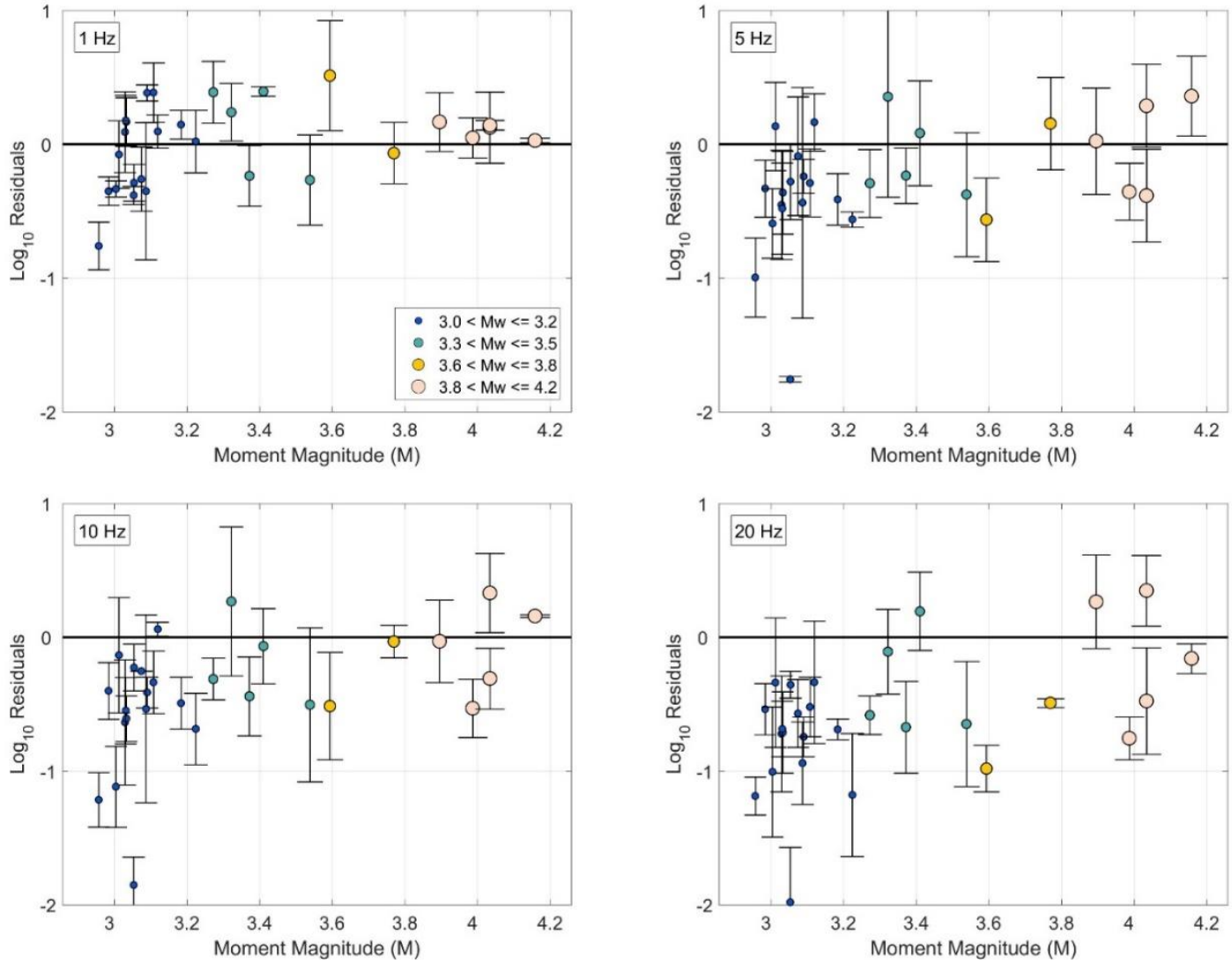

Figure 11. Average $\log _{10}$ residuals versus magnitude for vertical-component Alberta PSAs (all records) with respect to Oklahoma binned-average vertical-component PSA at 1, 5, 10, and $20 \mathrm{~Hz}$. Marker sizes indicate magnitude bins of Alberta events. Error bars denote the standard deviation of the residuals for each event. 

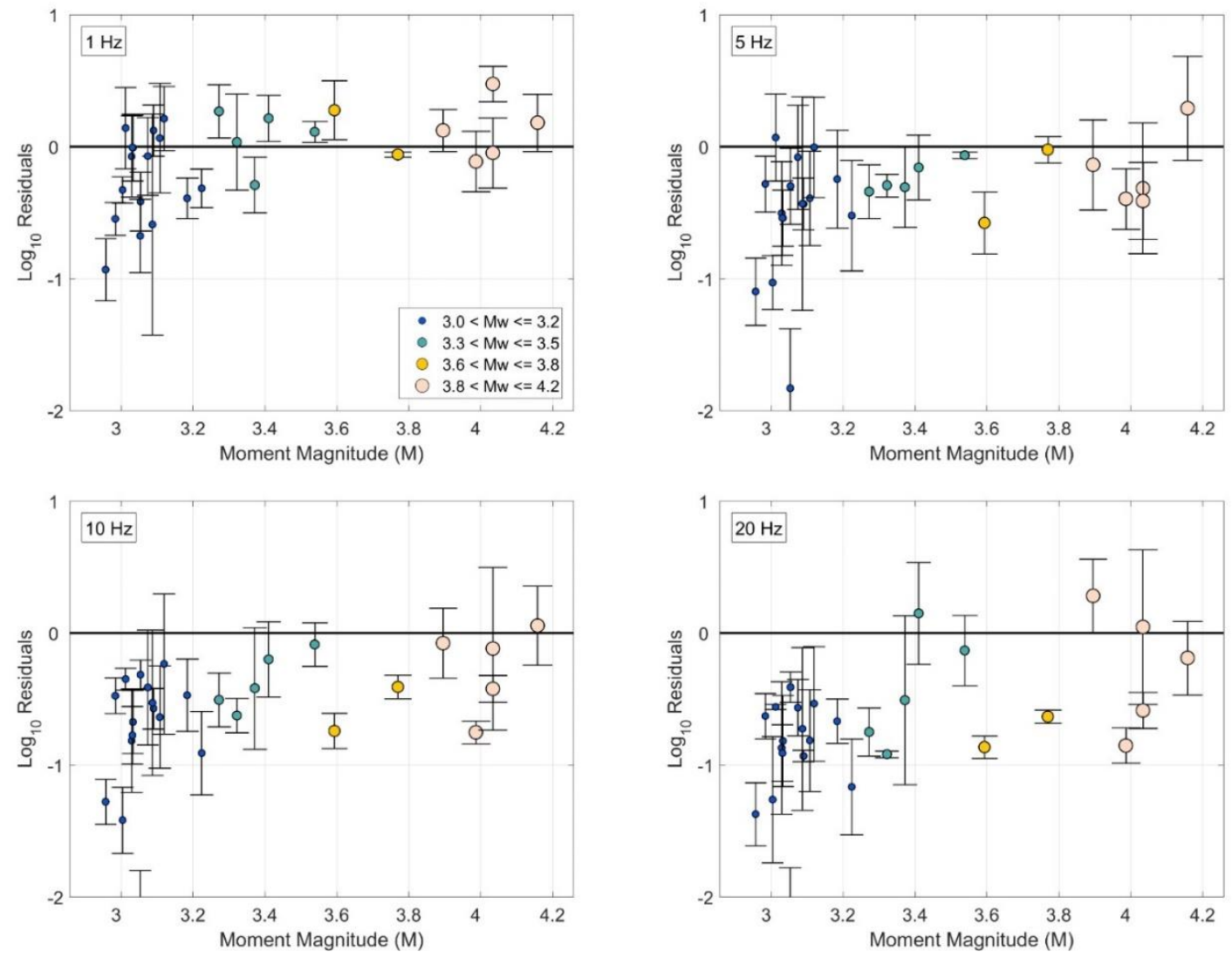

Figure 12. Average log10 residuals versus magnitude for horizontal-component Alberta PSAs (all records) with respect to Oklahoma binned-average horizontal-component PSA at 1, 5, 10, and $20 \mathrm{~Hz}$. Marker sizes indicate magnitude bins of Alberta events. Error bars denote the standard deviation of the residuals for each event.

Very clear and interesting trends are apparent in these figures. Smaller- magnitude events $(\mathbf{M}<3.8)$ in Alberta have notably lower amplitudes than do Oklahoma events at high frequencies $(f>\sim 3$ to $5 \mathrm{~Hz})$. However, the trend is not present for events of $\mathbf{M} \geq$ 3.8. These results suggest that the source parameters controlling smaller induced events in Alberta differ from those in Oklahoma, producing less high-frequency energy. However, once a critical size is reached $(\mathbf{M} \sim 4)$, perhaps corresponding to fault-controlled rupture processes, the source processes appear equivalent in the two regions - despite the different mechanisms for triggering the seismicity (hydraulic fracture versus wastewater 
injection). It is possible that focal depth also plays a role - the lower magnitude events in Alberta might be occurring at shallower depths, in crustal rocks of low strength.

However, we note that the PSA values in the two regions appear to be consistent at lower frequencies (i.e. on the moment magnitude-controlled end of the spectrum), and diverge at higher frequencies (controlled by the stress parameter).

The key earthquake source parameters in this study are moment magnitude, reflecting the low-frequency PSA, and stress parameter, reflecting the high-frequency PSA. Table 2 gives the stress parameter values obtained for the Alberta events of this study. For small events $(\mathbf{M}<3.8)$, these values are typically in the range from 5 to 30 bars, whilst for larger events they are in the range from 30 to 90 bars.

There does not appear to be a trend in the Alberta-Oklahoma residuals with $R_{\text {hypo }}$, (within any magnitude range) suggesting that our attenuation and path functions are applicable in both Alberta and Oklahoma. Therefore, we conclude that for $\mathbf{M}>\sim 3.8$ Alberta and Oklahoma median ground motion response spectra are comparable in terms of their spectral shapes and amplitudes, in spite of possible differences in average regional site conditions.

We compare vertical-component Alberta PSAs with expected ground motion amplitudes from our three benchmark GMPEs (YA15 $\mathrm{CENA}, \mathrm{A} 15$, and ASK14) through their log residuals. We assume that vertical-component amplitudes should have minimal site amplification and thus be comparable to GMPEs for the horizontal component for B/C site conditions (Atkinson et al. 2015). Figure 13 examines the log residuals between ground motions in Alberta and the YA15 ${ }_{\text {CENA }}$ prediction that represents natural earthquakes in CENA, at 1, 5, 10, and $20 \mathrm{~Hz}$, for a focal depth of $2 \mathrm{~km}$ (in CENA). We 
note that although the YA15 $\mathrm{CENA}$ model is for natural earthquakes, it implicitly accommodates induced events through the depth-dependence of the stress parameter. Thus, by assigning a focal depth of $2 \mathrm{~km}$, we are comparing very shallow natural events in CENA to induced events in Alberta, which are believed to occur near $2 \mathrm{~km}$ depth (Schultz et al., 2014; Schultz et al., 2015; Schultz et al., 2016).
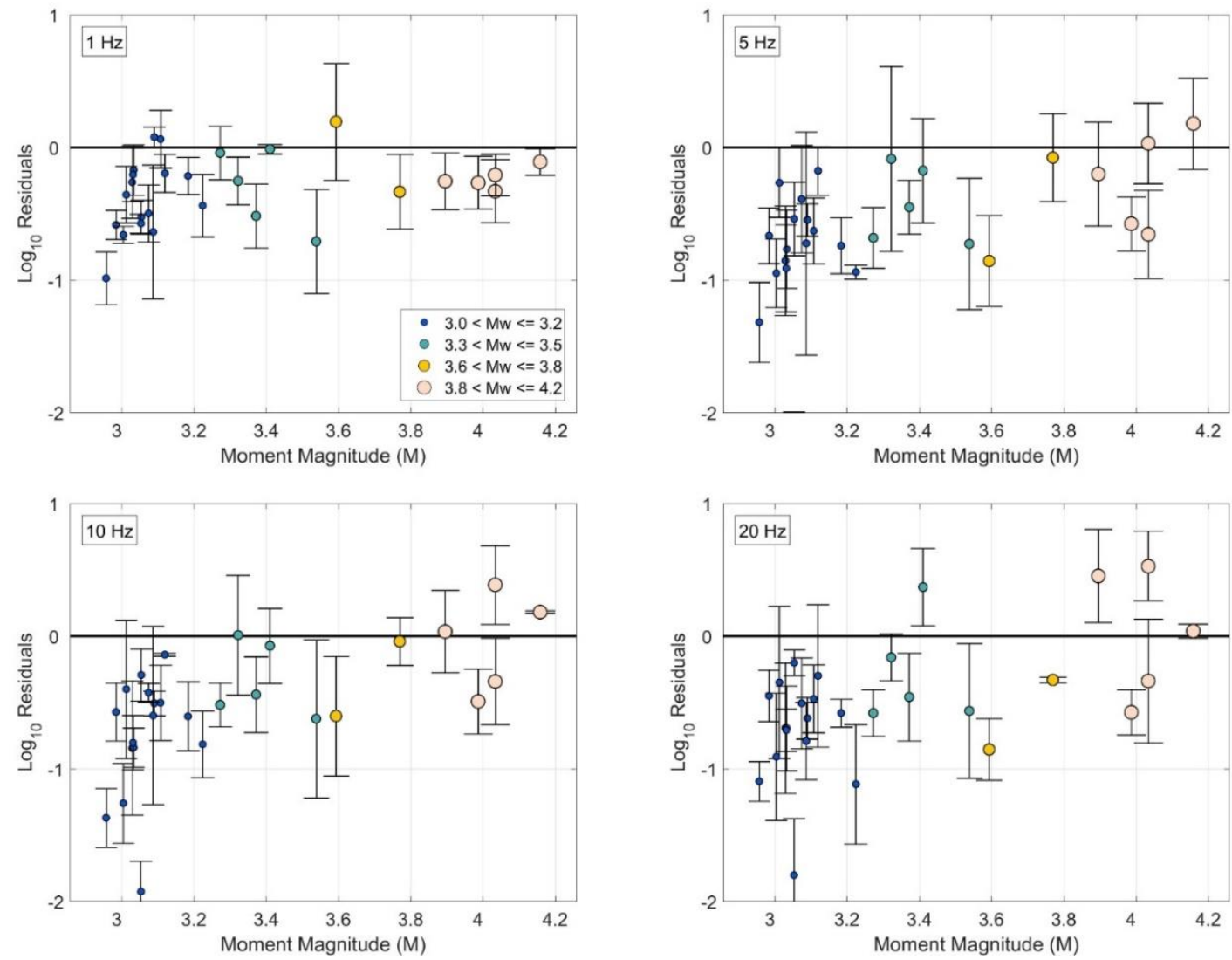

Figure 13. Average $\log _{10}$ residuals versus magnitude for vertical-component Alberta PSAs (all records) with respect to YA15 ${ }_{\text {CENA }}($ focal depth $=2 \mathrm{~km}$ ) predicted PSA at 1, 5, 10, and $20 \mathrm{~Hz}$. Marker sizes indicate magnitude bins of Alberta events. Error bars denote the standard deviation of the residuals for each event. Residuals for horizontalcomponent PSAs are provided in Appendix $C$.

This comparison also confirms that high-frequency motions from small events in Alberta, $\mathbf{M}<3.5$, appear to be weak, relative to natural CENA events, here represented by 
YA15 ${ }_{\text {CENA. }}$ However, at larger magnitudes, the induced Alberta events are consistent with the YA15 CENA predictions.

Figure 14 examines the residuals between Alberta ground motions and the A15 GMPE predictions. Note that the A15 GMPE (and the ASK14 GMPE) represents expected motions for California events that are deeper, $\sim 8 \mathrm{~km}$ on average.
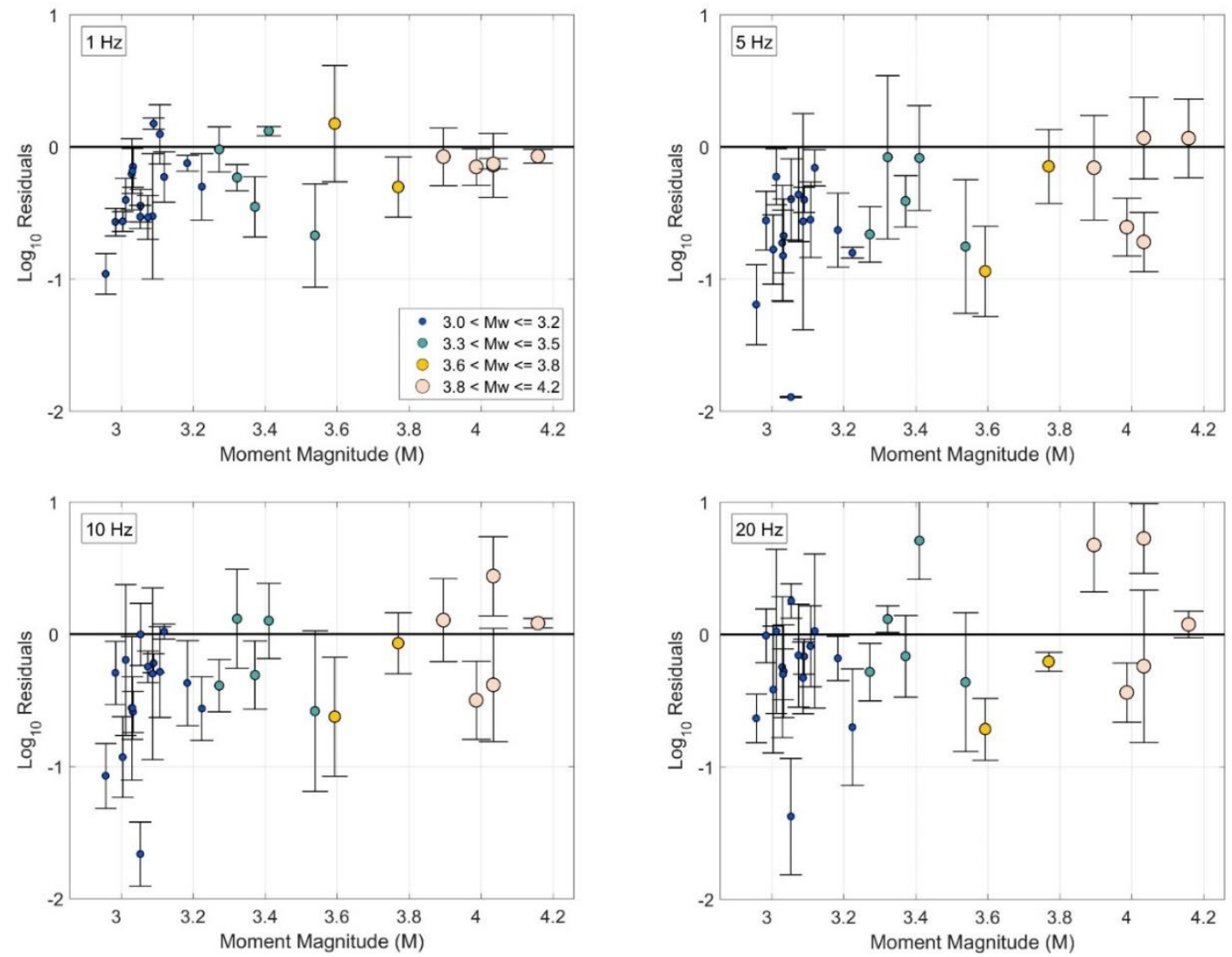

Figure 14. Average $\log _{10}$ residuals versus magnitude for vertical-component Alberta PSAs (all records) with respect to PSA predicted by A15 at 1, 5, 10, and $20 \mathrm{~Hz}$. Marker sizes indicate magnitude bins of Alberta events. Error bars denote the standard deviation of the residuals for each event. Residuals for horizontal-component PSAs are provided in Appendix $C$.

We find that overall this GMPE adequately captures the ground motion amplitudes; as was for the YA15 CENA model, there are negative residuals for small events, but these 
discrepancies are not observed for events of $\mathbf{M}>3.5$. The residuals around $f=5 \mathrm{~Hz}$ are slightly negative, suggesting that the Alberta motions are somewhat smaller than expected around this frequency. We see the same trends, overall agreement but with somewhat negative residuals around $f=5 \mathrm{~Hz}$, when comparing Alberta motions to those predicted by ASK14 in Figure 15.
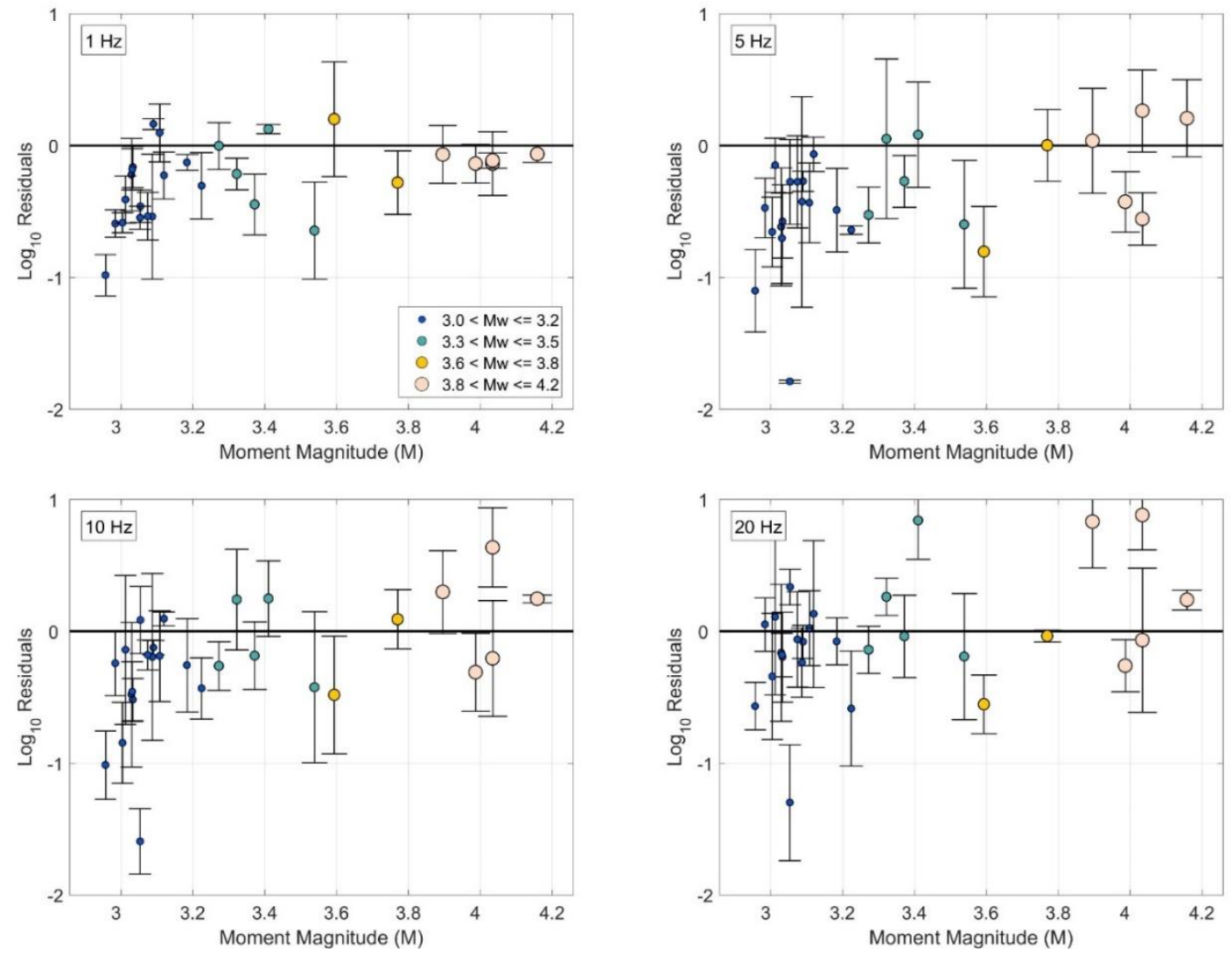

Figure 15. Average $\log _{10}$ residuals versus magnitude for vertical-component Alberta

PSAs (all records) with respect PSA predicted by ASK14 (with depth to rupture modification for induced events) at 1, 5, 10, and $20 \mathrm{~Hz}$. Marker sizes indicate magnitude bins of Alberta events. Residuals are calculated in log base 10. Residuals for horizontalcomponent PSAs are provided in Appendix $C$.

These analyses confirm that the A15 and ASK14 GMPEs are reasonable models to estimate ground motions from induced events in Alberta, despite their derivation from natural events in California. This is in agreement with similar findings of Atkinson and 
Assatourians (2017), who state that the A15 and ASK14 GMPEs (along with YA15 ${ }_{\text {CENA) }}$ are appropriate proxy GMPEs for predicting median ground motions from moderate induced events in CENA, due to their functional form and source and attenuation scaling attributes. Note that if ASK14 is to be applied to induced motions in Alberta, an unspecified depth to top of rupture $Z_{T O R}$ should be input to the model predictions.

\section{Conclusions}

Small-magnitude events $(\mathbf{M}<3.8)$ in Alberta have notably lower amplitudes than do Oklahoma events at high frequencies $(f>\sim 3$ to $5 \mathrm{~Hz})$. As these discrepancies are more pronounced for small-magnitude events compared to larger magnitudes, we venture that they are indicative of a source effect; there may also be some component of the observed differences that are attributable to regional differences in site effects. For events greater than $\mathbf{M} \sim 4$, the ground-motion amplitudes appear equivalent in the two regions despite the different mechanisms for triggering the seismicity. Moreover, there are no apparent trends in residuals with hypocentral distance. We conclude that for events of $\mathbf{M}$ > 3.8 Alberta and Oklahoma median ground motion response spectra are comparable in terms of their spectral shapes and amplitudes, in spite of possible differences in average regional site conditions. An important consequence is that studies of seismic hazard from induced seismicity can take advantage of the denser and more robust Oklahoma database to supplement the sparse Alberta database.

We also compared vertical-component Alberta PSAs with expected ground motion amplitudes from three benchmark GMPEs (YA15 $\mathrm{CENA}$, A15, and ASK14). The comparisons with YA15 ${ }_{\text {CENA }}$ confirm that high-frequency motions from $\mathbf{M}<3.5$ events 
in Alberta appear to be weak relative to natural CENA events, even those at shallow depth $(2 \mathrm{~km})$.

In comparison to GMPEs for California events at greater depths, we find that residuals between the Alberta PSAs and the A15 and ASK14 GMPEs are slightly negative (i.e. less than predicted by the GMPEs) around $f=5 \mathrm{~Hz}$, but are otherwise in reasonable agreement. This supports the conclusion of Atkinson and Assatourians (2017) that these GMPEs, although derived from natural events in California, are reasonable models to estimate ground motions from induced events in Alberta.

\section{Data and Resources}

The Alberta ground motion dataset consists of seismic events recorded by several broadband seismograph networks including: the Canadian National Seismograph Network (CNSN), the Regional Alberta Observatory for Earthquake Studies Network (RAVEN), TransAlta's Dam Monitoring Network (TD), the Montana Regional Seismic Network (MRSN), as well as the Pacific Northwest Seismic Network (PNSN). The data are processed as described in Assatourians and Atkinson (2010) to obtain response spectra and peak amplitudes. The Oklahoma database is that compiled by Assatourians and Atkinson (2017) but also including smaller events that are part of a larger database processed by Assatourians and Atkinson (unpublished manuscript, 2017). The moment magnitudes for each event in the Alberta database was computed by Novakovic (personal communication, 2017) as described in Novakovic and Atkinson (2015). NGA-West2 GMPEs were evaluated using the spreadsheet provided by www.peer.berkeley.edu (last 
accessed August 2016). Details of the NGA-East and NGA-West2 database compilations are provided at www.peer.berkeley.edu (last accessed November 2016).

Acknowledgements

This work was funded by the Natural Sciences and Engineering Research Council of Canada, TransAlta, and Nanometrics. Karen Assatourians compiled the response spectral databases used in the study. Mark Novakovic computed the moment magnitudes of study events. 


\section{References for Chapter 3}

Abrahamson, N. A., W. J. Silva, and R. Kamai (2014). Summary of the Abrahamson, Silva, and Kamai NGA-West2 ground-motion relations for active crustal regions, Earthquake Spectra 30, 1025-1056.

Alberta Energy Regulator (AER) and the Alberta Geological Survey (AGS) (26 January 2016). Introduction to the induced seismicity study in the Fox Creek Area, Presentation to the Fox Creek Town Council, powerpoint.

Assatourians, K., and G. Atkinson (2010). Database of processed time series and response spectra for Canada: An example application to the study of 2005 MN5.4 Riviere du Loup, Quebec earthquake, Seismological Research Letters 81, 10131031.

Atkinson, G. (2015). Ground-motion prediction equation for small-to moderate events at short hypocentral distances, with application to induced seismicity hazards, Bulletin of the Seismological Society of America 105, doi: 10.1785/0120140142.

Atkinson, G., and K. Assatourians (2017). Are ground-motion models derived from natural events applicable to the estimation of expected motions for induced earthquakes? Seismological Research Letters 88, no. 2A, doi: $10.1785 / 0220160153$.

Atkinson, G., and A. Babaie Mahani (2013). Estimation of moment magnitude from ground motions at regional distances, Bulletin of the Seismological Society of America 103, 107-116.

Atkinson, G., B. Worden, and D. Wald (2014a). Intensity prediction equations for North America, Bulletin of the Seismological Society of America 104, 3084-3093.

Atkinson, G., D. W. Greig, and E. Yenier (2014b). Estimation of moment magnitude for small events $(\mathrm{M}<4)$ on local networks, Seismological Research Letters 85, no. 5, $1116-1124$.

Atkinson, G., K. Assatourians, B. Cheadle, and W. Greig (2015). Ground motions from three recent earthquakes in western Alberta and northeastern British Columbia and their implications for induced-seismicity hazard in eastern regions, Seismological Research Letters 86, no. 3, 1022-1031, doi: 10.1785/0220140195.

Atkinson, G., D. Eaton, H. Ghofrani, D. Walker, B. Cheadle, R. Schultz, R. Shcherbakov, K. Tiampo, J. Gu, R. Harrington, Y. Liu, M. van der Baan, and H. Kao (2016). Hydraulic fracturing and seismicity in the Western Canada Sedimentary Basin, Seismological Research Letters 87, no. 3, doi: 10.1785/0220150263. 
Baranova, V., A. Mustaqeem, and S. Bell (1999). A model for induced seismicity caused by hydrocarbon production in the Western Canada sedimentary basin, Canadian Journal of Earth Science 36, 47-64.

Boore, D. M. (2003). Simulation of ground motion using the stochastic method, Pure and Applied Geophysics, 160, issue 3, 635-676.

Brune, J. (1970). Tectonic stress and the spectra of seismic shear waves from earthquakes, Journal of Geophysical Research 75, 4997-5009.

Brune, J. (1971). Correction, Journal of Geophysical Research 76, 5002.

Eaton D. and A. B. Mahani (2015). Focal mechanisms of some inferred induced earthquakes in Alberta, Canada, Seismological Research Letters 86, no. 4, doi: $10.1785 / 0220150066$

Ellsworth, W. (2013). Injection-induced earthquakes, Science 341, 1225942.

Farrugia, J., G. Atkinson, and S. Molnar (2017). Characterization of earthquake site amplification in Alberta, Canada, Manuscript submitted for review to Bulletin of the Seismological Society of America.

Fereidoni, A., and G. Atkinson (2017). Discriminating earthquakes from quarry blasts based on ShakeMap ground-motion parameters, Manuscript submitted for review to Bulletin of the Seismological Society of America.

Fereidoni, A., and L. Cui (2015). Composite Alberta Seismicity Catalogue (CASC), (www.inducedseismicity.ca).

Ghofrani, H., and G. Atkinson (2016). A preliminary statistical model for hydraulic fracture-induced seismicity in the Western Canada Sedimentary Basin, Geophysical Research Letters, 43, no. 10, 164-172, doi: 10.1002/2016GL070042.

Keranen, K., M. Weingarten, G. Abers, B. Bekins, and S. Ge (2014). Sharp increase in central Oklahoma seismicity since 2008 induced by massive wastewater injection, Science 345, 448-451.

Novakovic, M., and G. Atkinson (2015). Preliminary evaluation of ground motions from earthquakes in Alberta, Seismological Research Letters, 86, no. 4, doi: $10.1785 / 0220150059$.

Schultz, R., V. Stern, and Y. J. Gu (2014). An investigation of seismicity clustered near the Cordel Field, west central Alberta, and its relation to a nearby disposal well, Journal of Geophysical Research: Solid Earth, 119, 3410-3423, doi:10.1002/2013JB010836. 
Schultz, R., V. Stern, M. Novakovic, G. Atkinson, and Y. J. Gu (2015). Hydraulic fracturing and the Crooked Lake sequences: insights cleaned from regional seismic networks, Geophysical Research Letters, 42, doi: 10.1002/2015GL063455.

Schultz, R., H. Corlett, K. Haug, K. Kocon, K. MacCormack, V. Stern, and T. Shipman (2016), Linking fossil reefs with earthquakes: Geologic insight to where induced seismicity occurs in Alberta, Geophysical Research Letters, 43, 2534-2542, doi:10.1002/2015GL067514.

Schultz, R., R. Wang, Y. J. Gu, K. Haug, and G. Atkinson (2017). A seismological overview of the induced earthquakes in the Duvernay play near Fox Creek, Alberta, Journal of Geophysical Research: Solid Earth, 122, 492-505, doi:10.1002/2016JB013570.

Wetmiller, R. J. (1986). Earthquakes near Rocky Mountain House, Alberta, and their relationship to gas production facilities, Canadian Journal of Earth Sciences, 23, no. $2,172-181$.

Yenier, E., and G. Atkinson (2014). Point source modeling of moderate to large magnitude earthquakes and associated ground motion saturation effects, Bulletin of the Seismological Society of America 105, 1435-1455.

Yenier, E., and G. Atkinson (2015). Regionally adjustable generic ground-motion prediction equation base on equivalent point-source simulations: application to Central and Eastern North America, Bulletin of the Seismological Society of America 105, 1989-2009.

Yenier, E., G. Atkinson, and D. F. Sumy (2017). Ground motions for induced earthquakes in Oklahoma, Bulletin of the Seismological Society of America 107, no. 1 , doi: $10.1785 / 0120160114$. 


\section{Chapter 4. General Discussion and Conclusions}

\section{Discussion of Results}

Several results discussed in Chapter 2 of this study have important consequences for the understanding of ground motions from induced events in Alberta, and for future studies of seismic hazard from these events. We observed that ground motion amplitudes in Alberta for small-magnitude events $(\mathbf{M}<3.8)$ are consistently lower than those from equivalent magnitude-distance binned events in Oklahoma, especially at frequencies greater than $\sim 3.3 \mathrm{~Hz}$. Regional differences due to source effects may vary with both magnitude and frequency, while those due to site effects should vary with frequency only. Thus, we may be seeing regional differences in both source and site effects at small magnitudes, while at larger magnitudes we observe some regional differences in site effects.

Due to the strong magnitude-dependence of the residuals, we posit that the lower ground motion amplitudes at high frequencies from induced events in Alberta is due to a lower stress parameter for those events, when compared to the events in Oklahoma.

Potential factors that could explain this disparity include differences in injection method, or more likely, differences in event depth. In Alberta, larger magnitude events $(\mathbf{M}>4)$ tend to have better resolved depths of approximately 4-5 km. These larger magnitude, deeper events tend to match the Oklahoma spectral shapes and amplitudes more closely. Although the depths for smaller-magnitude events are less well-resolved, hydraulic fracturing operations are more inclined to induce smaller earthquakes at around $2 \mathrm{~km}$ depth (Schultz et al., 2014; Schultz et al., 2015; Schultz et al., 2016). Events induced by wastewater injection in Oklahoma occur more commonly at depths associated with 
disposal formations and the upper basement (approximately 2-5 km; Keranen et al., 2014).

The potential for regional discrepancies due to site effects should also be explored. Different average regional site effects would likely translate as amplification of horizontal ground motions at a different frequency in each region. At the time that this study was submitted, there were no known characterizations of site effects in Alberta, and very little information on site response in Oklahoma. Recent studies (Farrugia et al., 2017 submitted manuscript and Novakovic et al., 2017 submitted manuscript) have performed preliminary site characterizations in Alberta and Oklahoma respectively. Farrugia et al. (2017, submitted manuscript) used several verified methods to determine onedimensional shear-wave velocity profiles at several sites in Alberta. These profiles were used to determine the site classifications, which they note to range from NEHRP classes C to D, with D being the predominant class. From Table 1, it can be seen that site classes C and D correspond with soft rock/firm soil and soft soil, respectively. Novakovic et al. (2017, submitted manuscript) used a generalized inversion to develop a region-specific GMPE from ground motion observations in Oklahoma. This method seemed to show that site amplification on average in Oklahoma is minimal relative to a $\mathrm{B} / \mathrm{C}$ site condition. These results would suggest that ground motions in Alberta might tend to be amplified more than those in Oklahoma based on their site geologies. However, both studies also show that site class is variable and can be very different from one site to the next, even in the same geographic region. It is beyond the scope of this study to further explore the effect of regional differences in site effects between Alberta and Oklahoma, however they should be noted. 
There does not appear to be a trend in the Alberta-Oklahoma residuals with $\mathrm{R}_{\text {hypo, }}$ (within any magnitude range) suggesting that our attenuation and path functions are applicable in both Alberta and Oklahoma. A useful result of this study is that for magnitudes greater than approximately $\mathbf{M} 3.8$, induced events in Alberta and Oklahoma exhibit comparable ground motion amplitudes and spectral shapes (except for some possible regional site effects). This leads us to conclude that in future studies of ground motions and seismic hazard from induced events in Alberta, ground-motion databases for events of $\mathbf{M}>\sim 3.8$ can be supplemented using the Oklahoma database, which has a denser seismic network and a richer catalog of events in terms of magnitude and nearhypocentral distance distribution.

We also determined that high-frequency ground motions from Alberta events are weak compared to those from natural events in CENA, represented by Yenier and Atkinson (2015; YA15 $\left.{ }_{\mathrm{CENA}}\right)$, for magnitudes $\mathbf{M}<3.5$, but are consistent with YA15 ${ }_{\mathrm{CENA}}$ predictions for greater magnitudes. This confirms that the YA15 ${ }_{\mathrm{CENA}} \mathrm{GMPE}$ is an appropriate proxy ground motion model for induced events in Alberta, when modeling the motions for magnitudes greater than $\mathbf{M} 3.5$.

Finally, we determined through graphical comparisons and residual analyses that ground motions from induced events are well modeled by the two GMPEs considered as potential induced-event model proxies, Atkinson (2015; A15) and Abrahamson et al., (2014; ASK14). This is in agreement with similar findings of Atkinson and Assatourians (2017), who state that these are appropriate proxy GMPEs for predicting median ground motions from moderate induced events in CENA. The YA15 CENA GMPE is also a good proxy GMPE, provided that a shallow focal depth is specified. 


\section{Future Studies}

The work presented in this thesis could be expanded upon in a number of ways. The use of other methods to determine the stress parameter for an event, such as spectral matching to a Brune $(1970 ; 1971)$ point source model, would allow for a more nuanced calculation of the stress parameters associated with induced seismic events in Alberta. Further analysis of Alberta stress parameters, specifically how the depth of the event as well as the mechanism for earthquake triggering affects the stress parameter would help to illuminate the controlling factors on the behaviour of induced events. Additionally, recent studies on site conditions in Alberta could be incorporated into the YA15 $\mathrm{AB}, \mathrm{A} 15$, and ASK14 models to better constrain the models to represent the Alberta database. Induced seismicity GMPEs should be developed using the dense Oklahoma dataset through empirical regression. Some of these studies are already underway (Novakovic et al., 2017 submitted manuscript). For earthquakes with $\mathbf{M}>3.8$, these GMPEs could be used to model potential induced events in Alberta. Finally, the continued monitoring of induced earthquakes in Alberta and their ground motion characteristics is recommended. As more data becomes publicly available, models and results will need to be recalibrated and refined to better represent the ground motions observed.

\section{Final Remarks}

The results of this study improve our understanding of ground motions from induced seismicity in Alberta. It was determined that regional attenuation of ground motions in Alberta and Oklahoma are in agreement, and that discrepancies in motions between the two regions are likely due primarily to source effects that influence smaller magnitude events; this could be due to differences in injection-type (hydraulic fracturing 
vs. wastewater injection), or focal depth. Future studies of induced seismicity ground motions can take advantage of the denser and more robust Oklahoma database, as well as the ground motion prediction equations discussed to supplement that sparse Alberta database, and draw more robust conclusions on the behavior of ground motions from these events. Through a better understanding of ground motions and their controlling factors, and as rates of hydraulic fracturing and induced seismicity in Alberta continue to grow, this study in conjunction with future studies will hopefully reduce the uncertainty associated with GMPEs for induced events, and contribute to a better understanding of seismic hazard in Canada. 


\section{References for Chapter 4}

Abrahamson, N. A., W. J. Silva, and R. Kamai (2014). Summary of the Abrahamson, Silva, and Kamai NGA-West2 ground-motion relations for active crustal regions, Earthquake Spectra 30, 1025-1056.

Atkinson, G. (2015). Ground-motion prediction equation for small-to moderate events at short hypocentral distances, with application to induced seismicity hazards, Bulletin of the Seismological Society of America 105, doi: 10.1785/0120140142.

Atkinson, G., and K. Assatourians (2017). Are ground-motion models derived from natural events applicable to the estimation of expected motions for induced earthquakes? Seismological Research Letters 88, no. 2A, doi: $10.1785 / 0220160153$.

Farrugia, J. J., G. M. Atkinson, and S. Molnar (2017). Characterization of Earthquake Site Amplification in Alberta, Canada, manuscript submitted to Bulletin of the Seismological Society of America.

Novakovic, M., G. M. Atkinson, K. Assatourians (2017). Empirically-calibrated ground motion prediction equation for Oklahoma, manuscript submitted to Bulletin of the Seismological Society of America.

Schultz, R., V. Stern, and Y. J. Gu (2014). An investigation of seismicity clustered near the Cordel Field, west central Alberta, and its relation to a nearby disposal well, Journal of Geophysical Research: Solid Earth, 119, 3410-3423, doi:10.1002/2013JB010836.

Schultz, R., V. Stern, M. Novakovic, G. Atkinson, and Y. J. Gu (2015). Hydraulic fracturing and the Crooked Lake sequences: insights cleaned from regional seismic networks, Geophysical Research Letters, 42, doi: 10.1002/2015GL063455.

Schultz, R., H. Corlett, K. Haug, K. Kocon, K. MacCormack, V. Stern, and T. Shipman (2016), Linking fossil reefs with earthquakes: Geologic insight to where induced seismicity occurs in Alberta, Geophysical Research Letters, 43, 2534-2542, doi:10.1002/2015GL067514.

Yenier, E., and G. Atkinson (2015). Regionally adjustable generic ground-motion prediction equation based on equivalent point-source simulations: application to Central and Eastern North America, Bulletin of the Seismological Society of America 105, 1989-2009. 


\section{Electronic Supplement Information}

I provide through an electronic supplement submitted with the electronic version of this thesis a table containing the 5\% damped pseudospectral accelerations at 28 frequencies from 0.1 to $50 \mathrm{~Hz}$ for Alberta seismic events utilized in our analysis. The caption for this table is below.

Table S1. Horizontal-and vertical-component $5 \%$ damped PSA $\left(\mathrm{cm} / \mathrm{s}^{2}\right)$ calculated at 28 frequencies for each of 25 seismic events recorded in Alberta. Table data included are: event number, hypocentral distance $(\mathrm{km})$, moment magnitude $(\boldsymbol{M})$, event date and location, station name, sample rate, component recorded ( $\mathrm{HH} 1, \mathrm{HH} 2, \mathrm{HHZ}$ representing two horizontal and one vertical component, respectively), station location and PSA calculated from 0.1 to $50 \mathrm{~Hz}$, as well as $P G A$, in $\mathrm{cm} / \mathrm{s}^{2}$ and $P G V(\mathrm{~cm} / \mathrm{s})$. 


\section{Appendix A. Vertical Ground Motions - Supplementary Figures}

I provide through this appendix figures that illustrate vertical-component response spectra from 25 study events $(\mathbf{M}>3)$ in Alberta (not shown in the main body of work) compared to the benchmarks (Oklahoma average binned ground motions and two California GMPES: Atkinson 2015 [A15] and Abrahamson et al., 2014 [ASK14]).
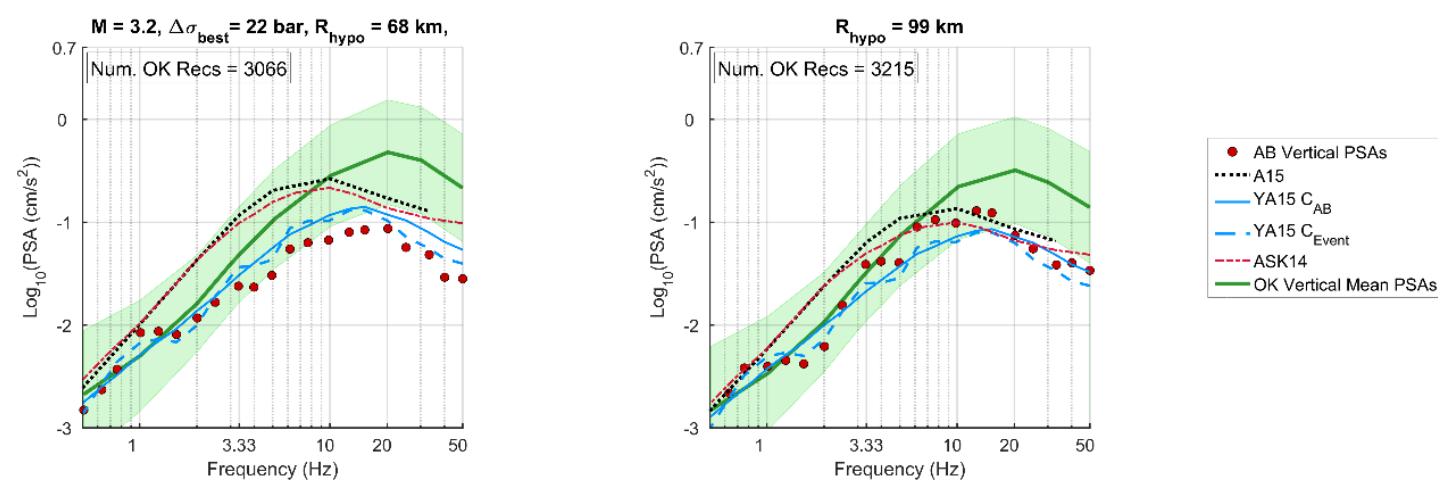

Figure A1. Vertical-component 5\% damped Alberta PSAs (circles) for M 3.2 event in Alberta. The average binned vertical-component Oklahoma PSA for equivalent magnitude-distance range is plotted along with \pm 1 standard deviation around the mean (shaded region). YA15AB and YA15event are represented by light solid and dashed lines. California GMPEs A15 (black dotted) and ASK14 (dot-dashed) are shown.
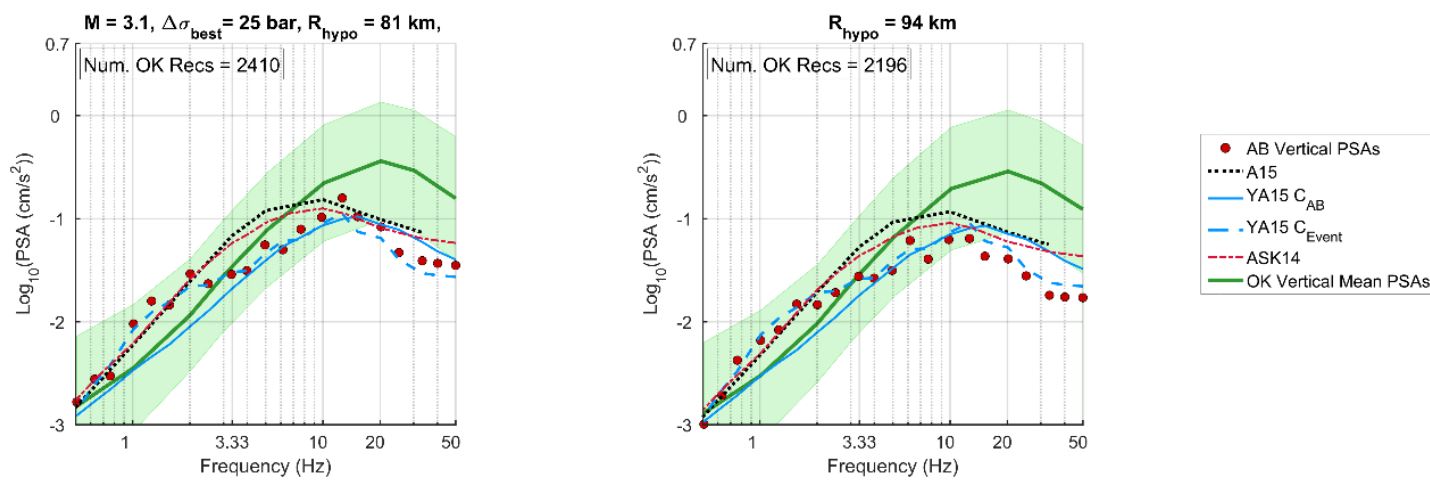

Figure A2. Vertical-component PSAs for M 3.1 event in Alberta. See Figure A1 caption for graphical description. 

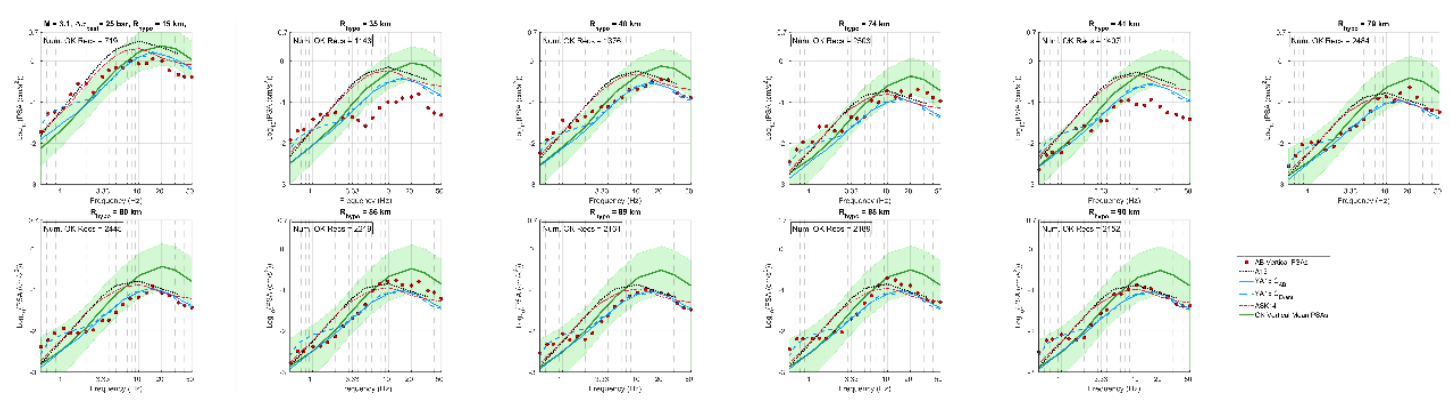

Figure A3. Vertical-component PSAs for M 3.1 event in Alberta. See Figure A1 caption for graphical description.
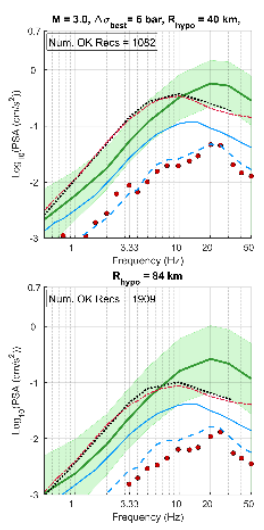
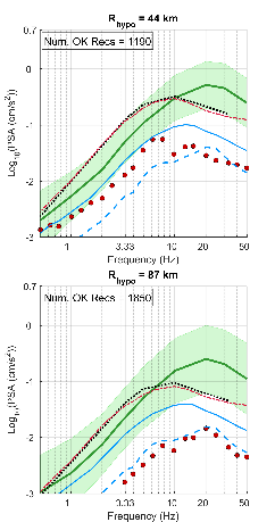
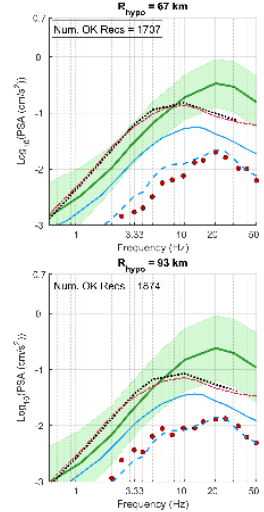
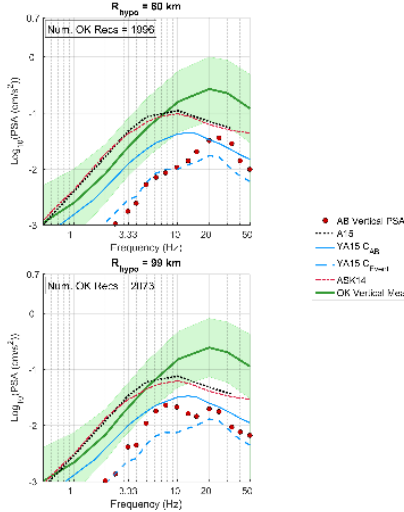

Figure A4. Vertical-component PSAs for M 3.0 event in Alberta. See Figure A1 caption for graphical description.
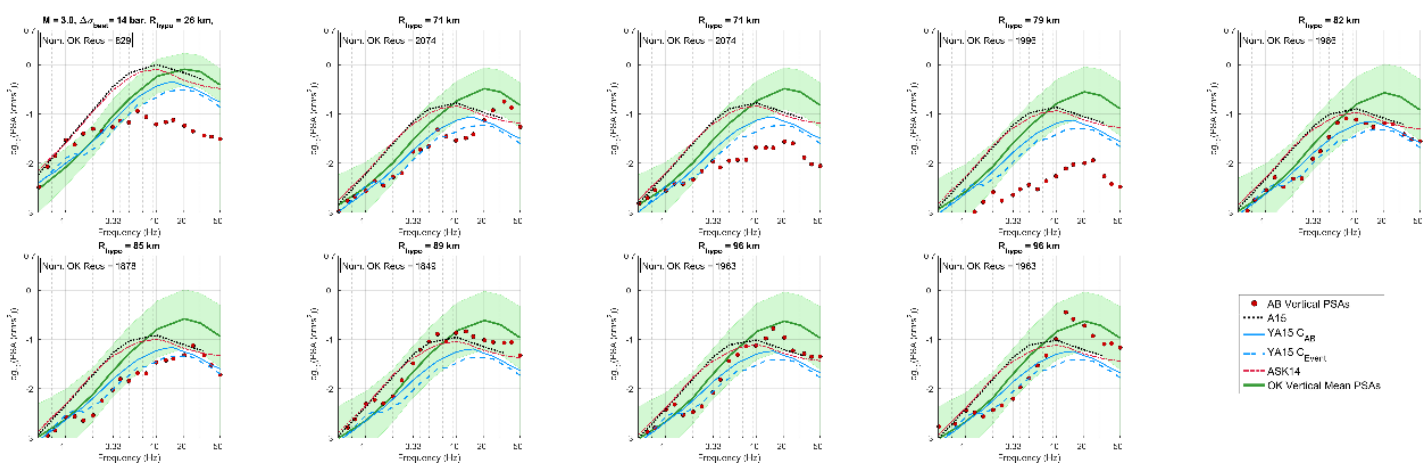

Figure A5. Vertical-component PSAs for M 3.0 event in Alberta. See Figure Al caption for graphical description. 

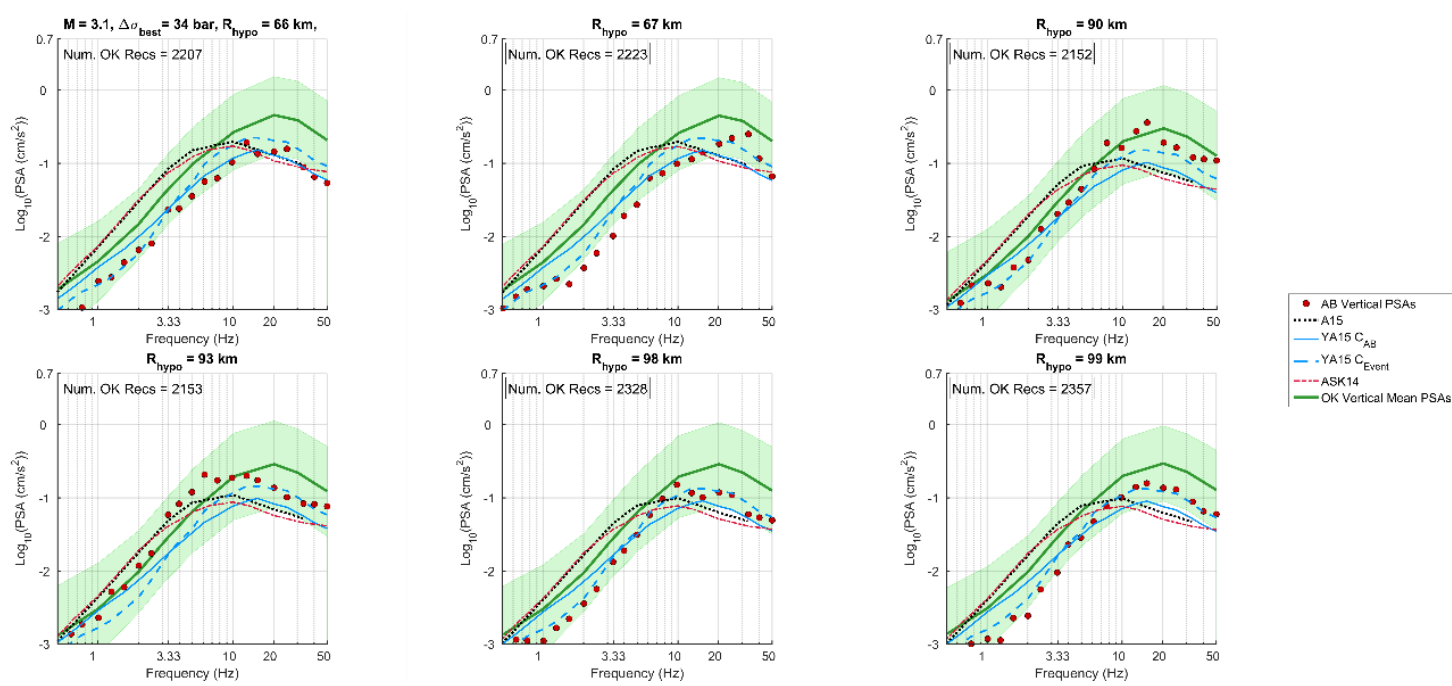

Figure A6. Vertical-component PSAs for M 3.1 event in Alberta. See Figure Al caption for graphical description. 

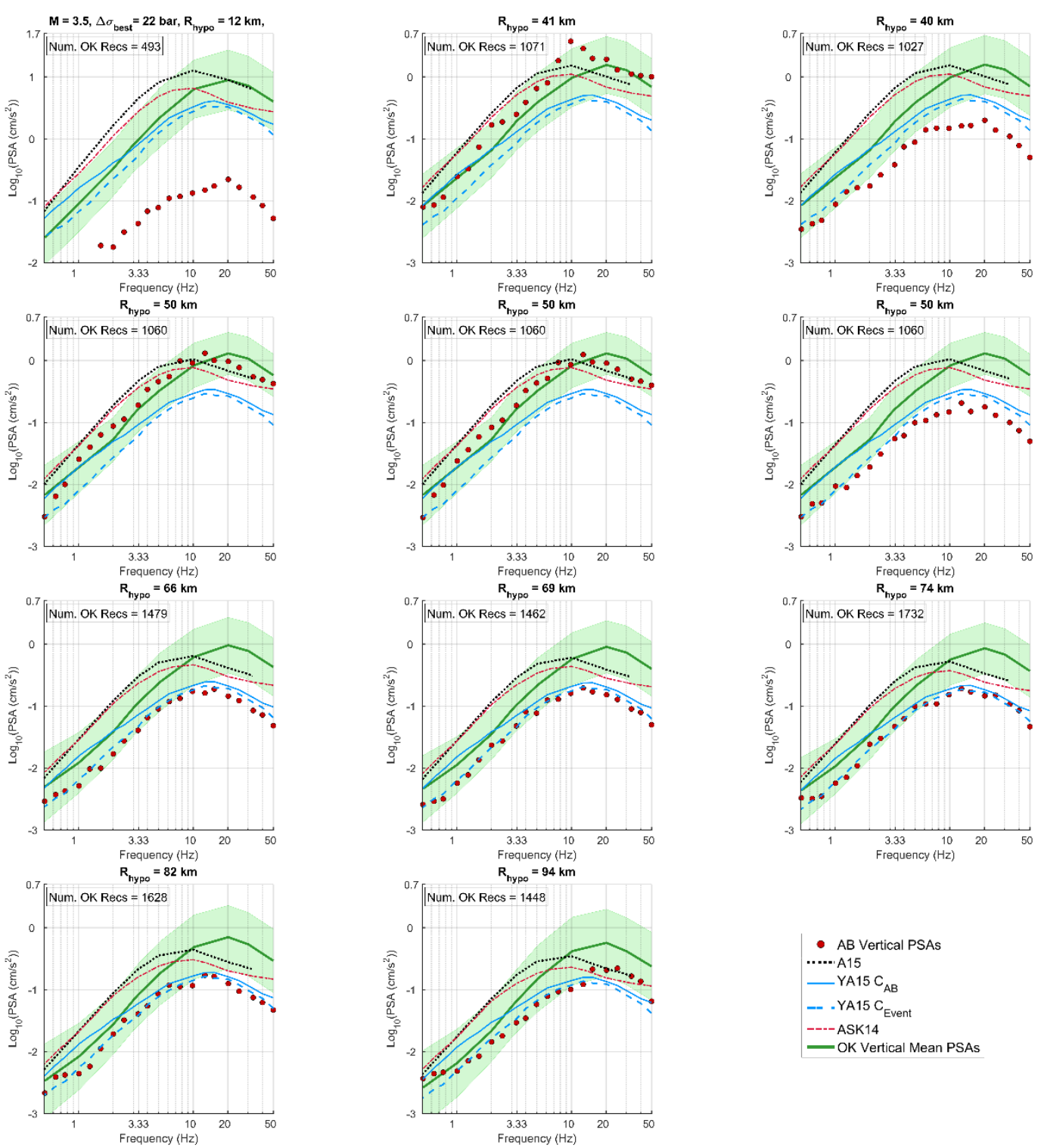

Figure A7. Vertical-component PSAs for M 3.5 event in Alberta. See Figure Al caption for graphical description.
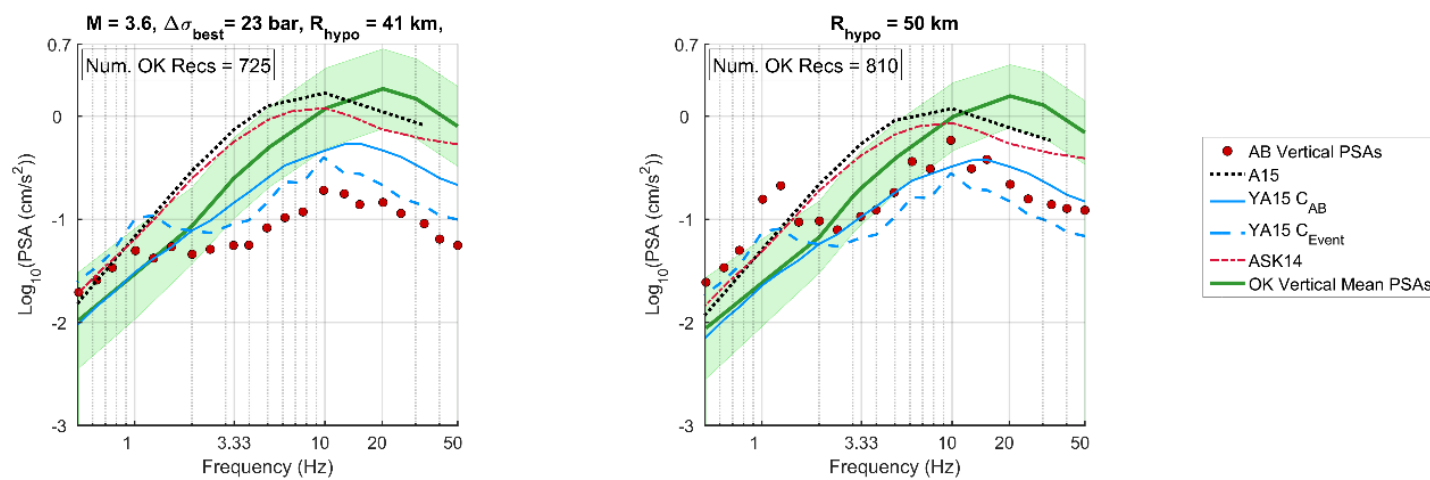
Figure A8. Vertical-component PSAs for M 3.6 event in Alberta. See Figure A1 caption for graphical description.
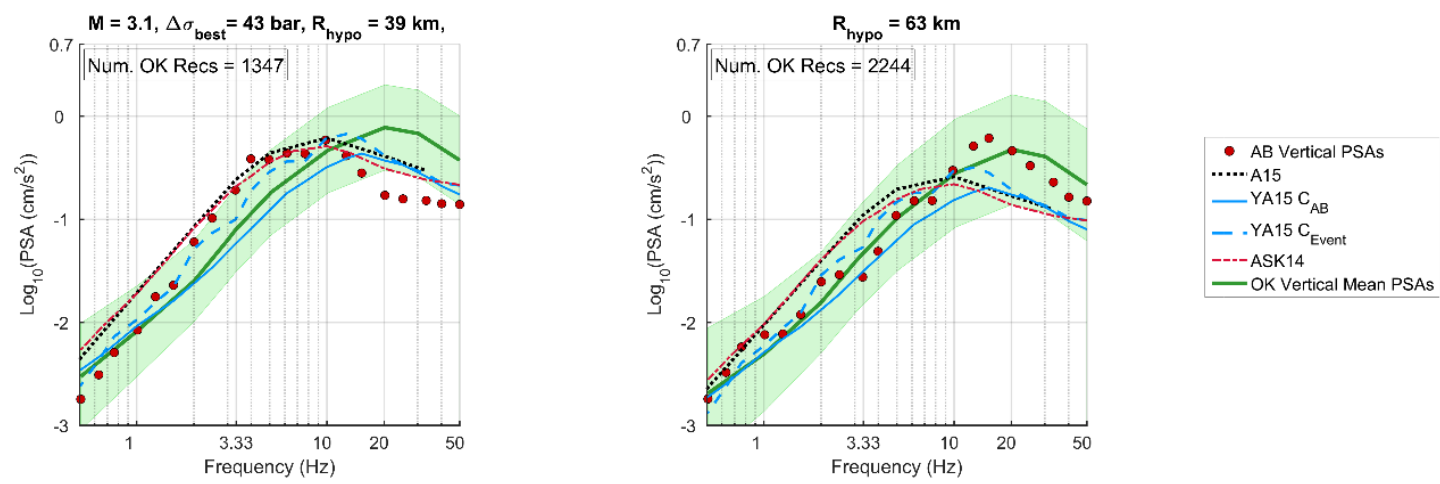

Figure A9. Vertical-component PSAs for M 3.1 event in Alberta. See Figure A1 caption for graphical description.
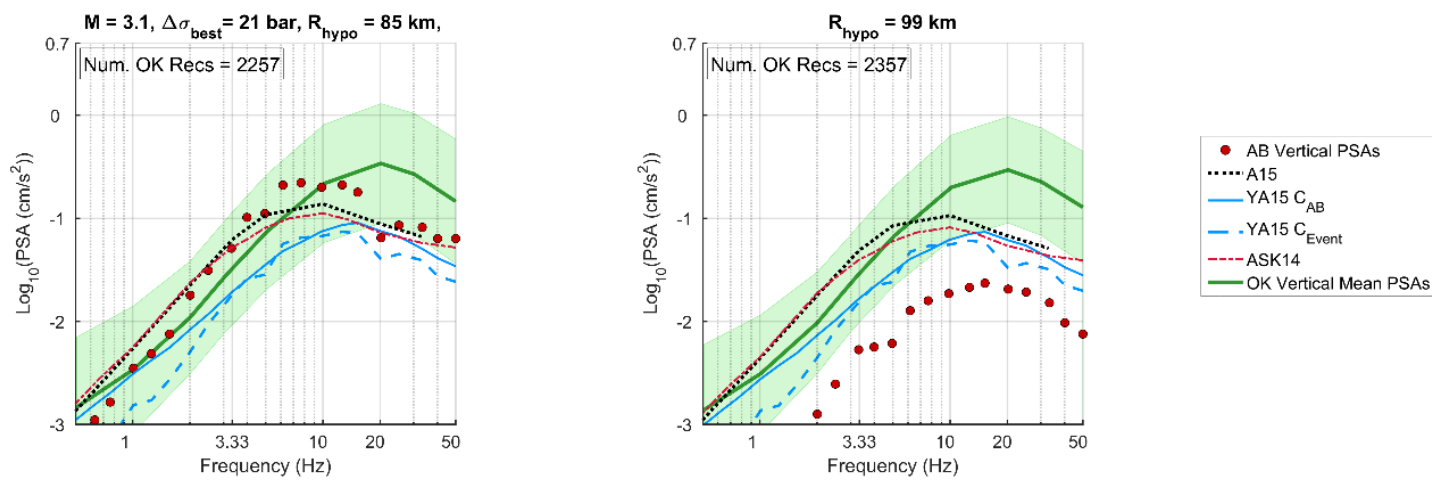

Figure A10. Vertical-component PSAs for M 3.1 event in Alberta. See Figure A1 caption for graphical description.
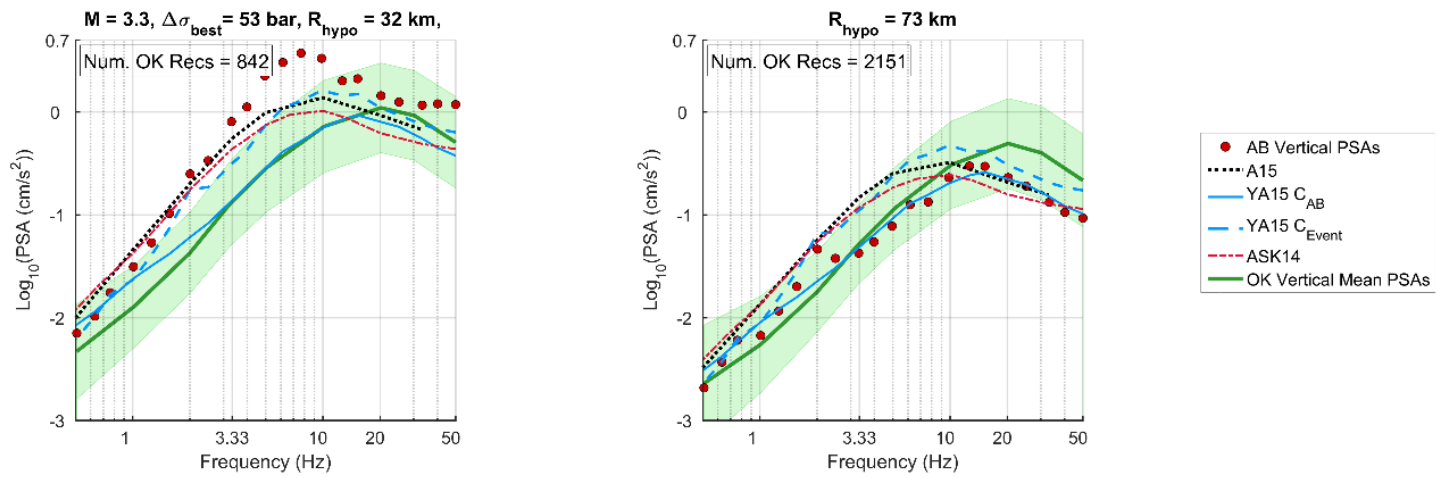

Figure A11. Vertical-component PSAs for M 3.3 event in Alberta. See Figure A1 caption for graphical description. 

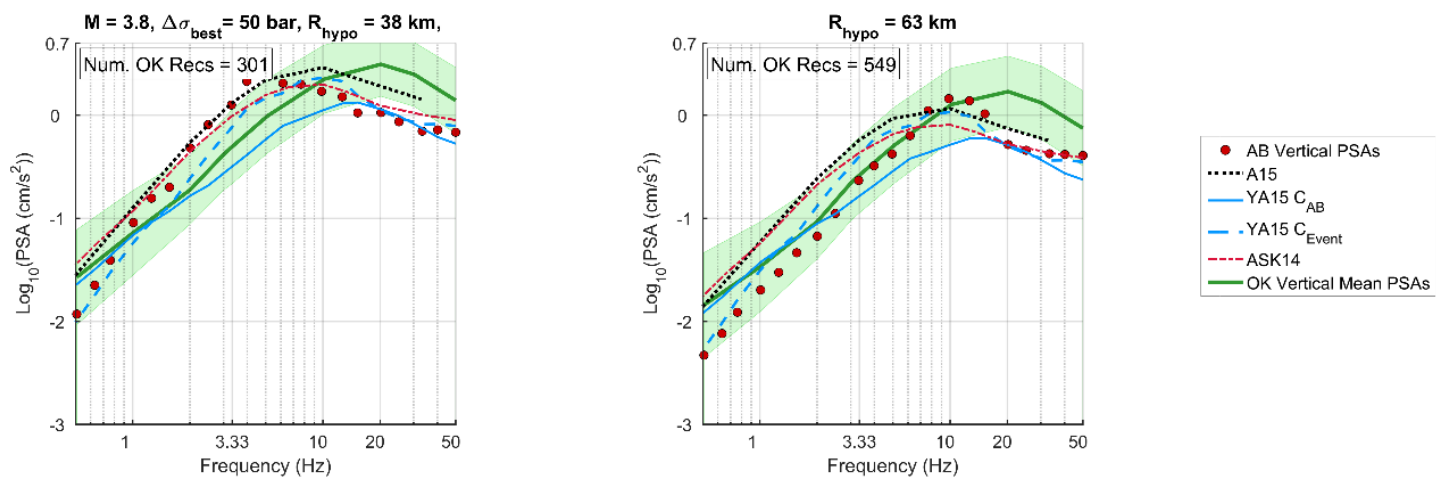

Figure A12. Vertical-component PSAs for M 3.8 event in Alberta. See Figure Al caption for graphical description.
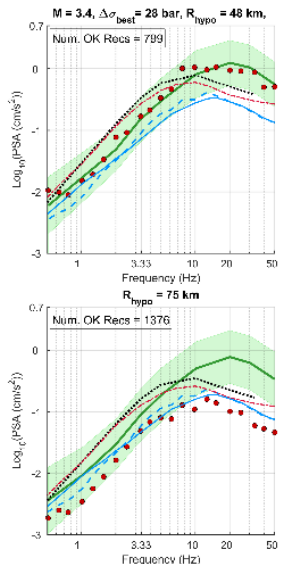
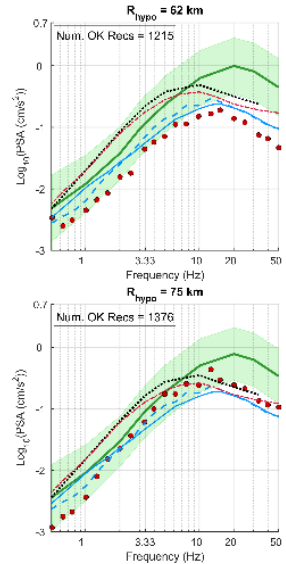
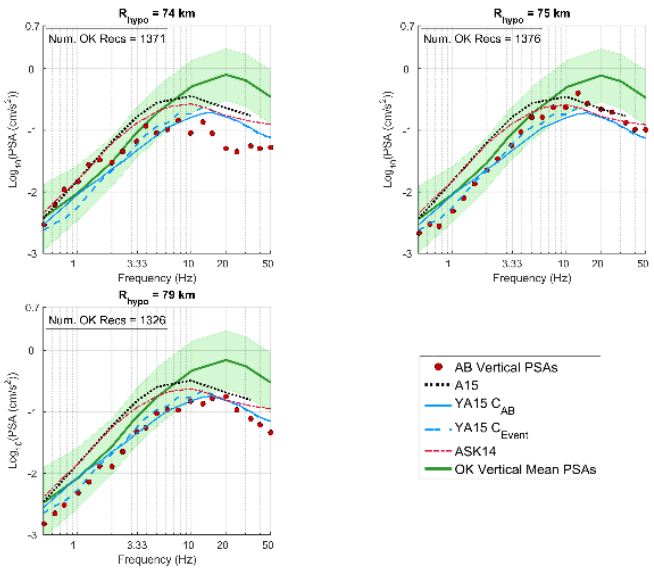

- AB Verlicap
-....A15
YA15C

- YA15 $\mathrm{C}_{\text {AB }}$

--.-ASK14

--ASK14

Figure A13. Vertical-component PSAs for M 3.4 event in Alberta. See Figure A1 caption for graphical description.
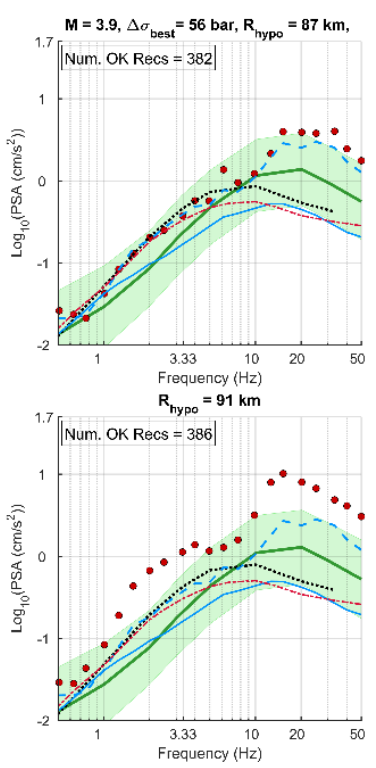
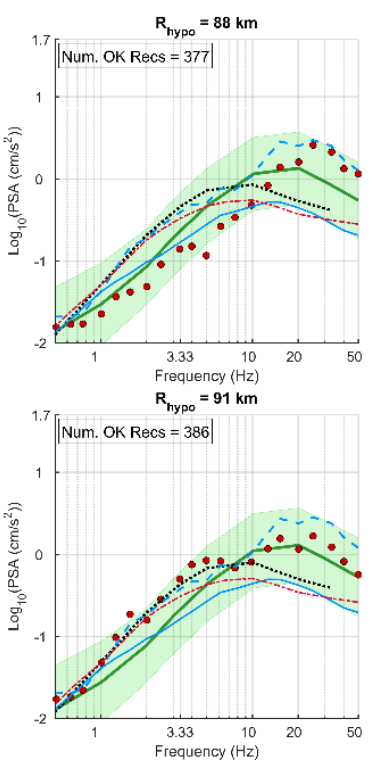
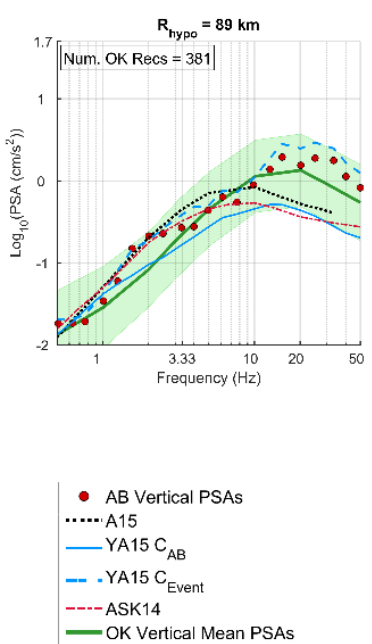

Figure A14. Vertical-component PSAs for M 3.9 event in Alberta. See Figure A1 caption for graphical description. 

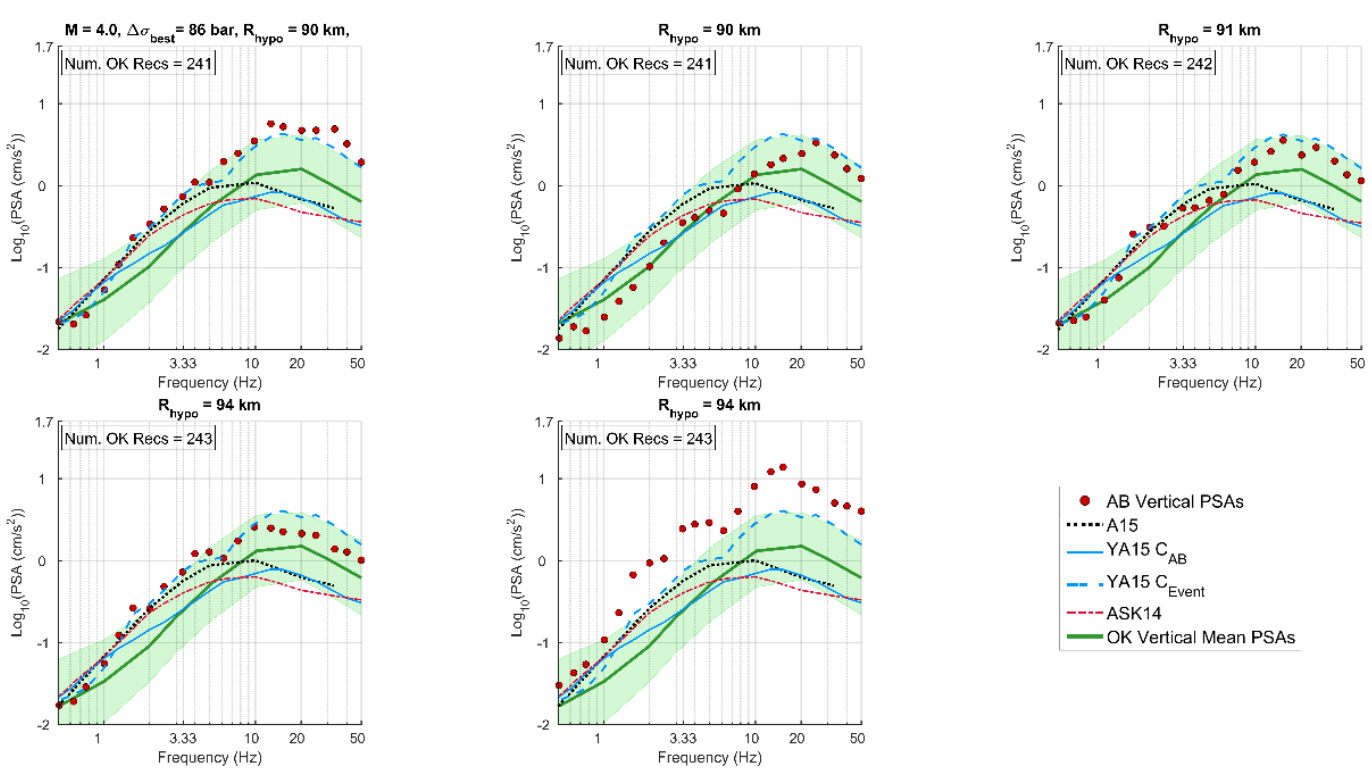

Figure A15. Vertical-component PSAs for M 4.0 event in Alberta. See Figure Al caption for graphical description.
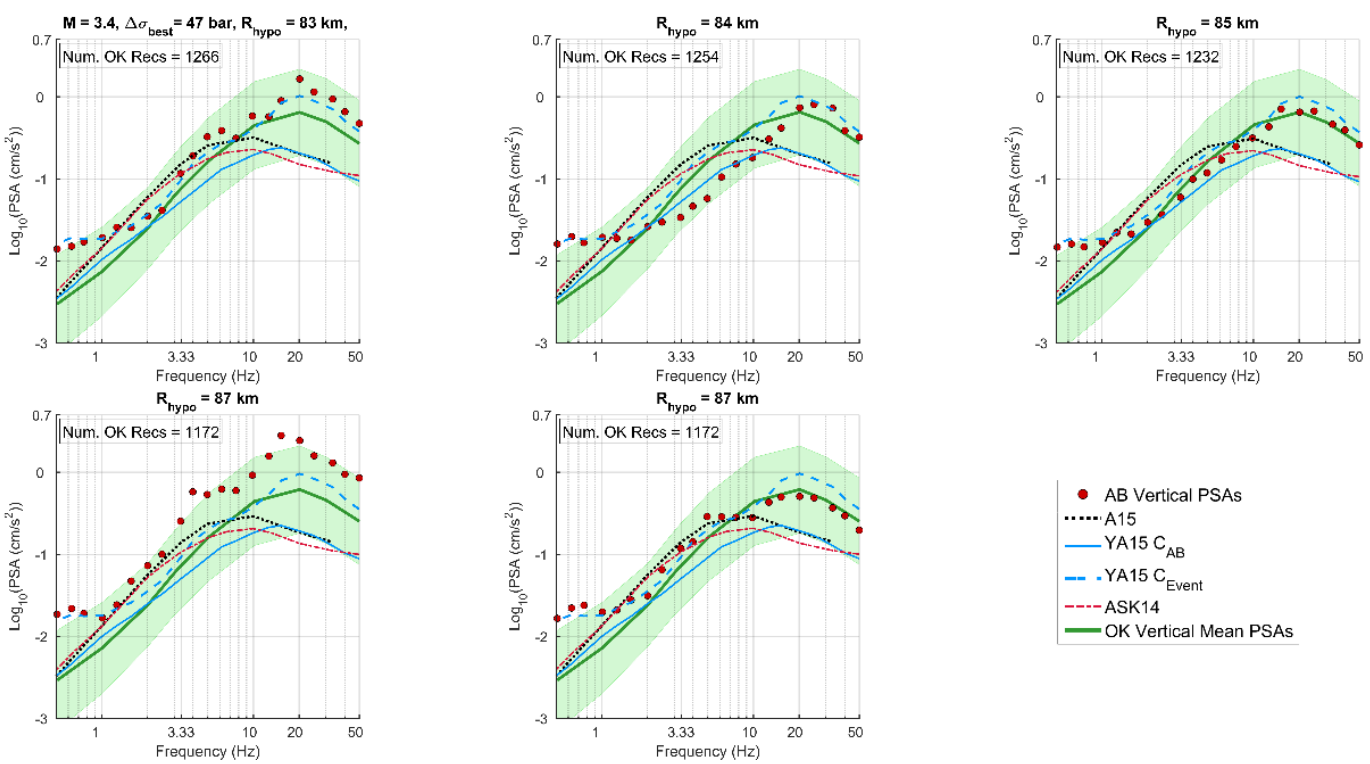

Figure A16. Vertical-component PSAs for M 3.4 event in Alberta. See Figure A1 caption for graphical description. 

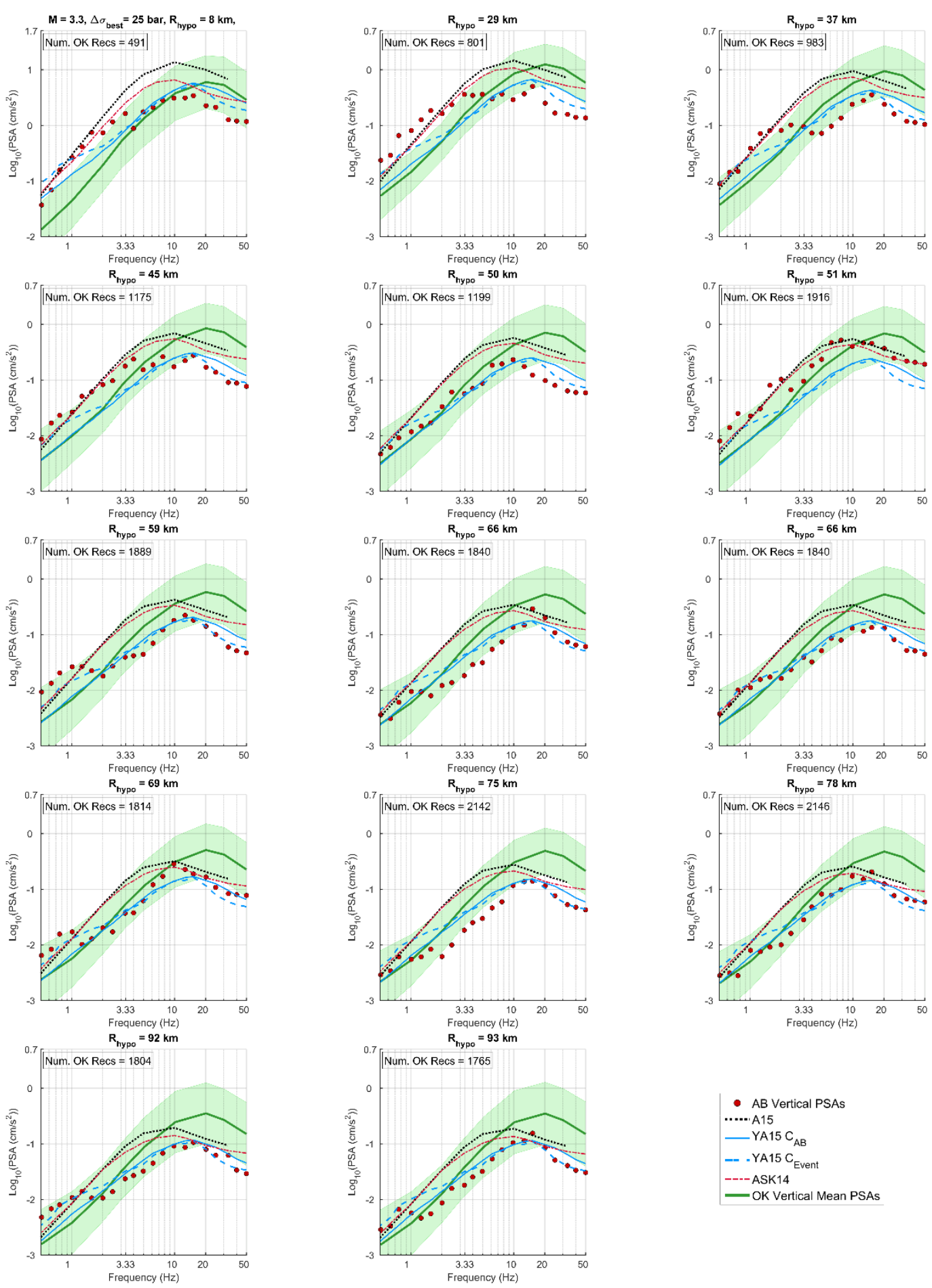

Figure A17. Vertical-component PSAs for M 3.3 event in Alberta. See Figure Al caption for graphical description. 

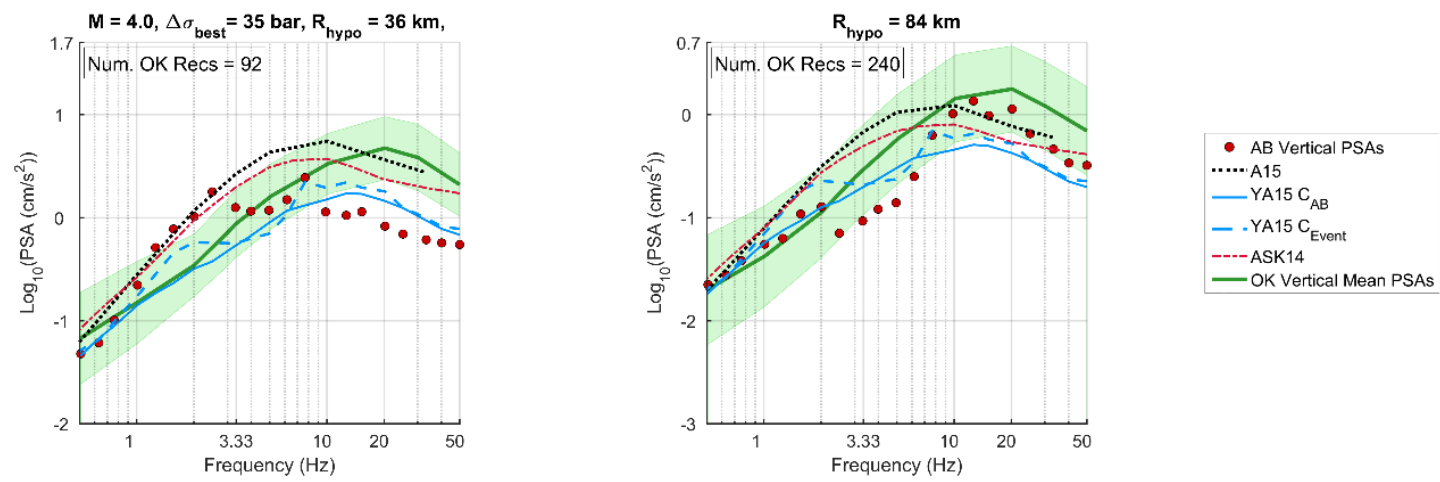

Figure A18. Vertical-component PSAs for M 4.0 event in Alberta. See Figure Al caption for graphical description.
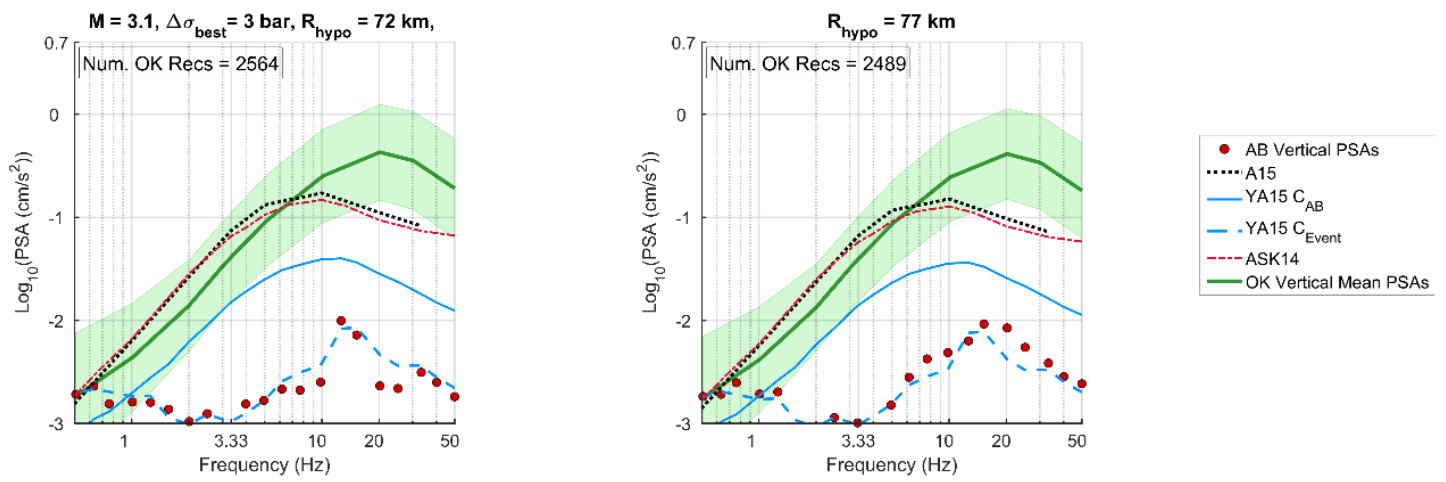

Figure A19. Vertical-component PSAs for M 3.1 event in Alberta. See Figure A1 caption for graphical description.
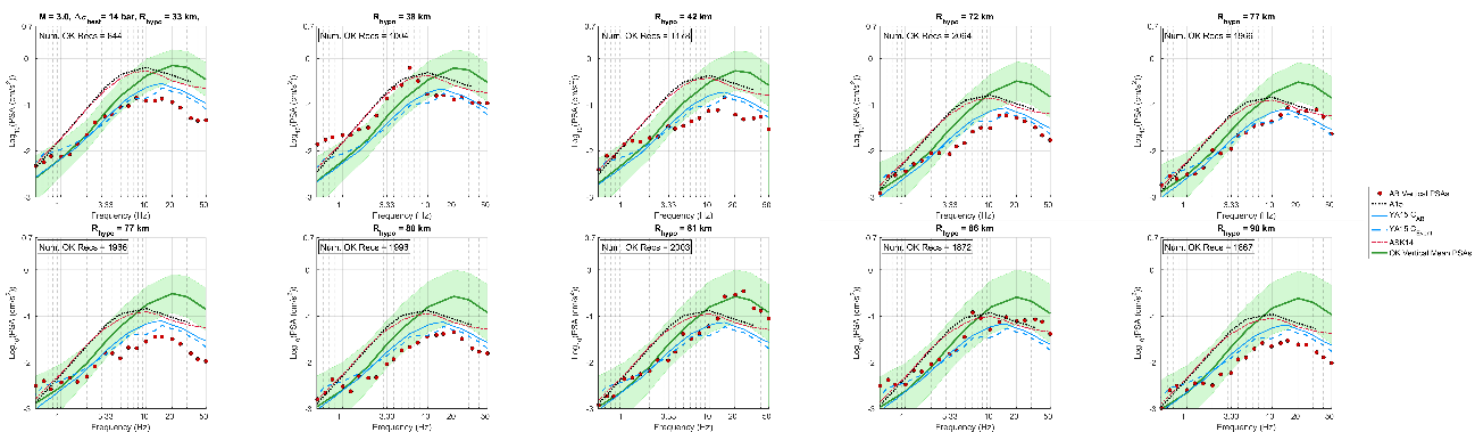

Figure A20. Vertical-component PSAs for M 3.0 event in Alberta. See Figure Al caption for graphical description. 

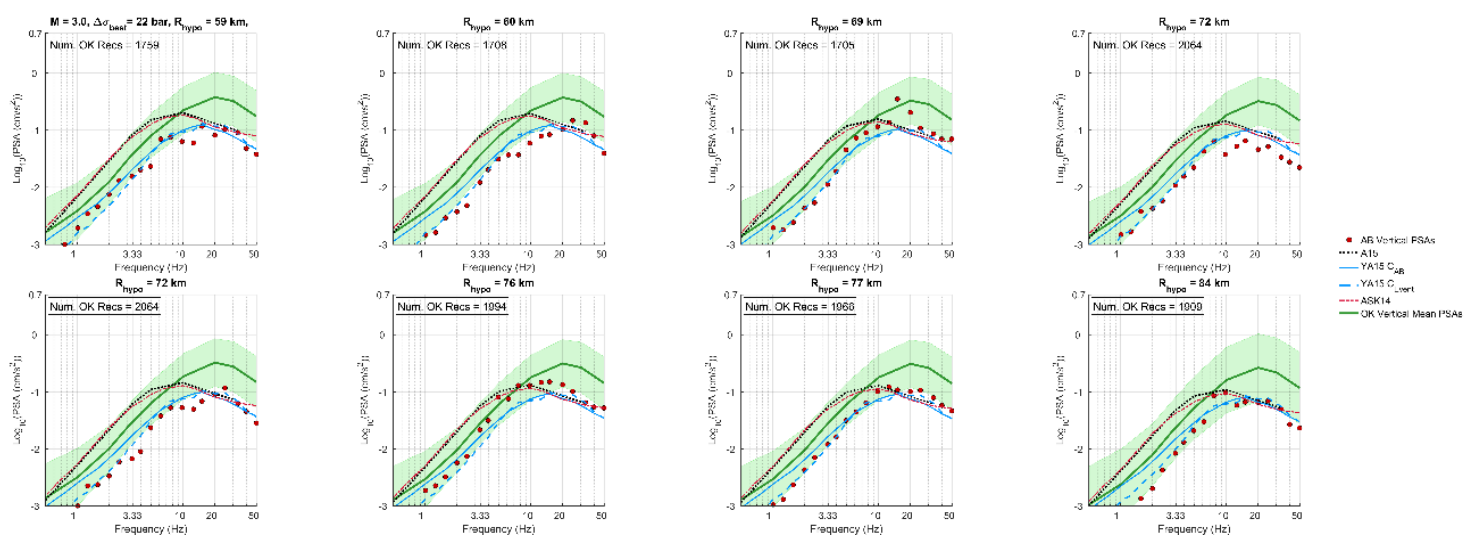

Figure A21. Vertical-component PSAs for M 3.0 event in Alberta. See Figure A1 caption for graphical description.
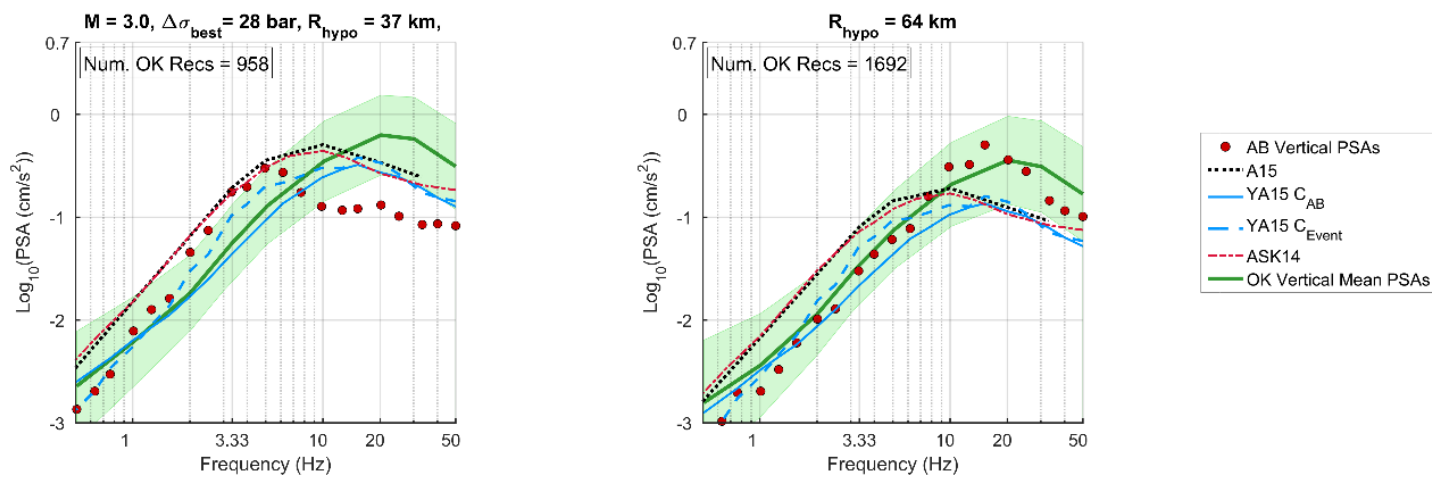

Figure A22. Vertical-component PSAs for M 3.0 event in Alberta. See Figure A1 caption for graphical description.
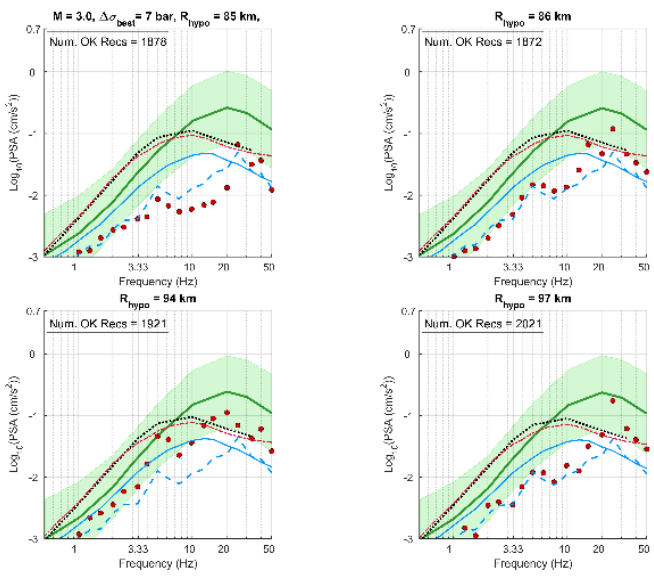
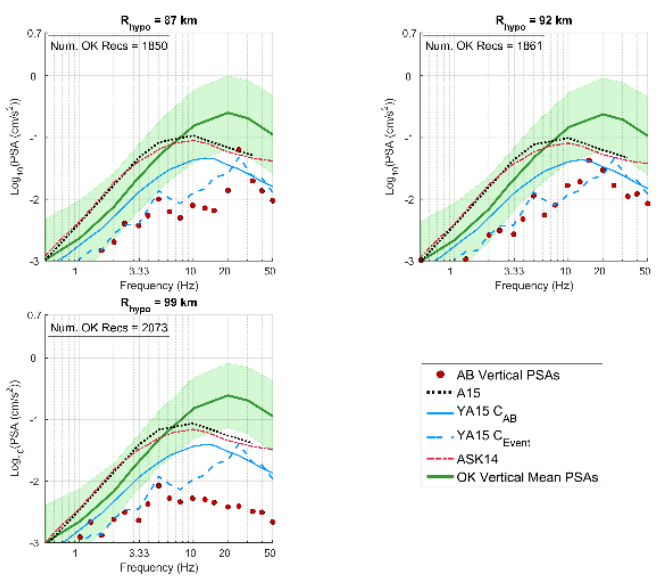

Figure A23. Vertical-component PSAs for M 3.0 event in Alberta. See Figure A1 caption for graphical description. 

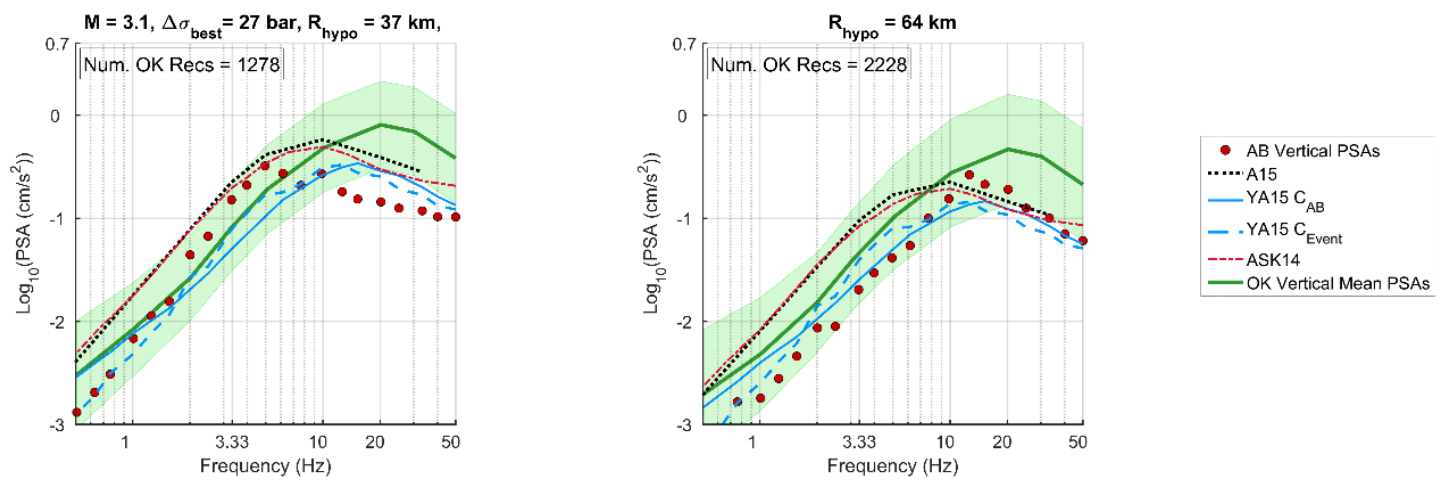

Figure A24. Vertical-component PSAs for M 3.1 event in Alberta. See Figure A1 caption for graphical description.
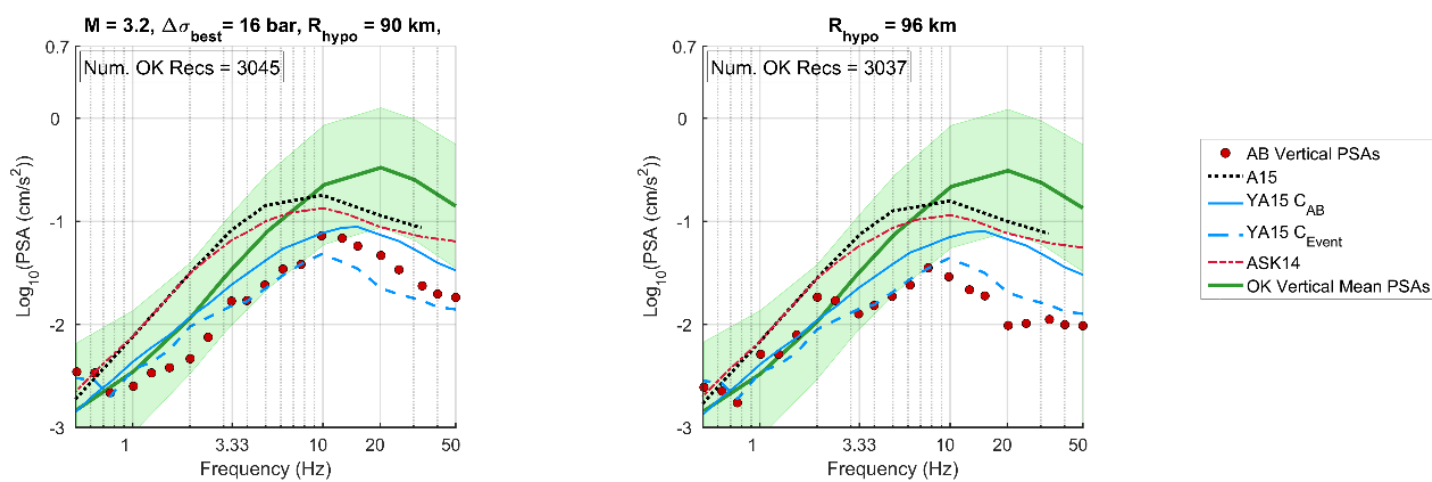

Figure A25. Vertical-component PSAs for M 3.2 event in Alberta. See Figure A1 caption for graphical description. 


\section{Appendix B. Horizontal Ground Motions - Supplementary Figures}

I provide through this appendix figures that illustrate vertical-component response spectra from 25 study events $(\mathbf{M}>3)$ in Alberta (not shown in the main body of work) compared to the benchmarks (Oklahoma average binned ground motions and two California GMPES: Atkinson 2015 [A15] and Abrahamson et al., 2014 [ASK14]).
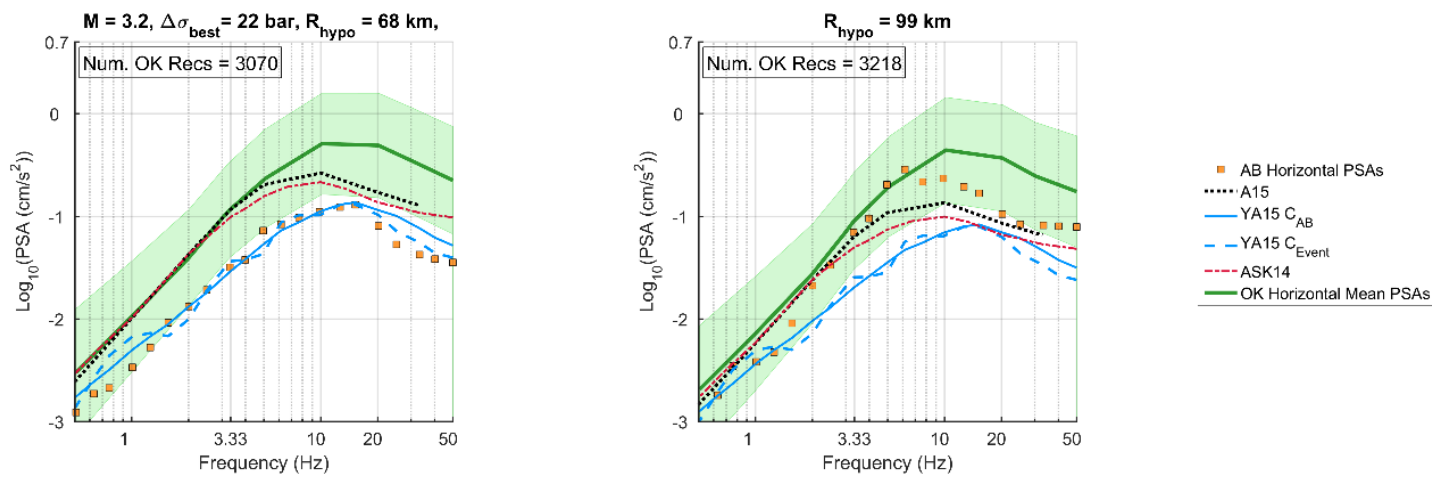

Figure B1. Horizontal-component 5\% damped Alberta PSAs (squares) for M 3.2 event in Alberta. The average binned horizontal-component Oklahoma PSA for equivalent magnitude-distance range is plotted along with \pm 1 standard deviation around the mean (shaded region). YA15 $5_{A B}$ and $Y A 15_{\text {event }}$ are represented by light solid and dashed lines. California GMPEs A15 (black dotted) and ASK14 (dot-dashed) are shown.
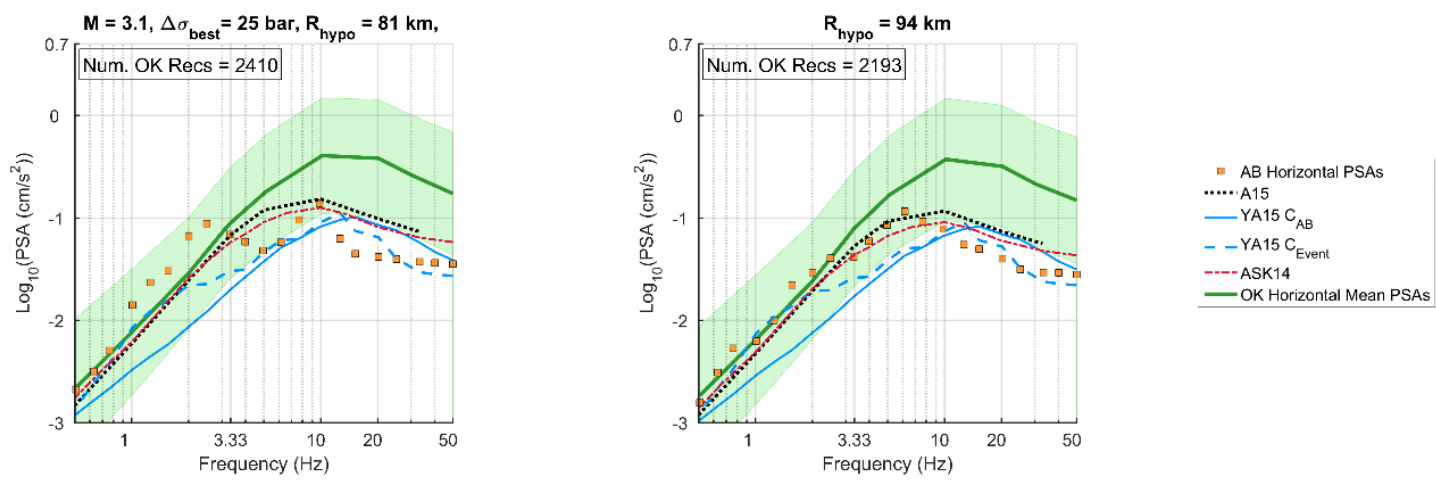

Figure B2. Horizontal-component PSAs for M 3.1 event in Alberta. See Figure B1 caption for graphical description. 

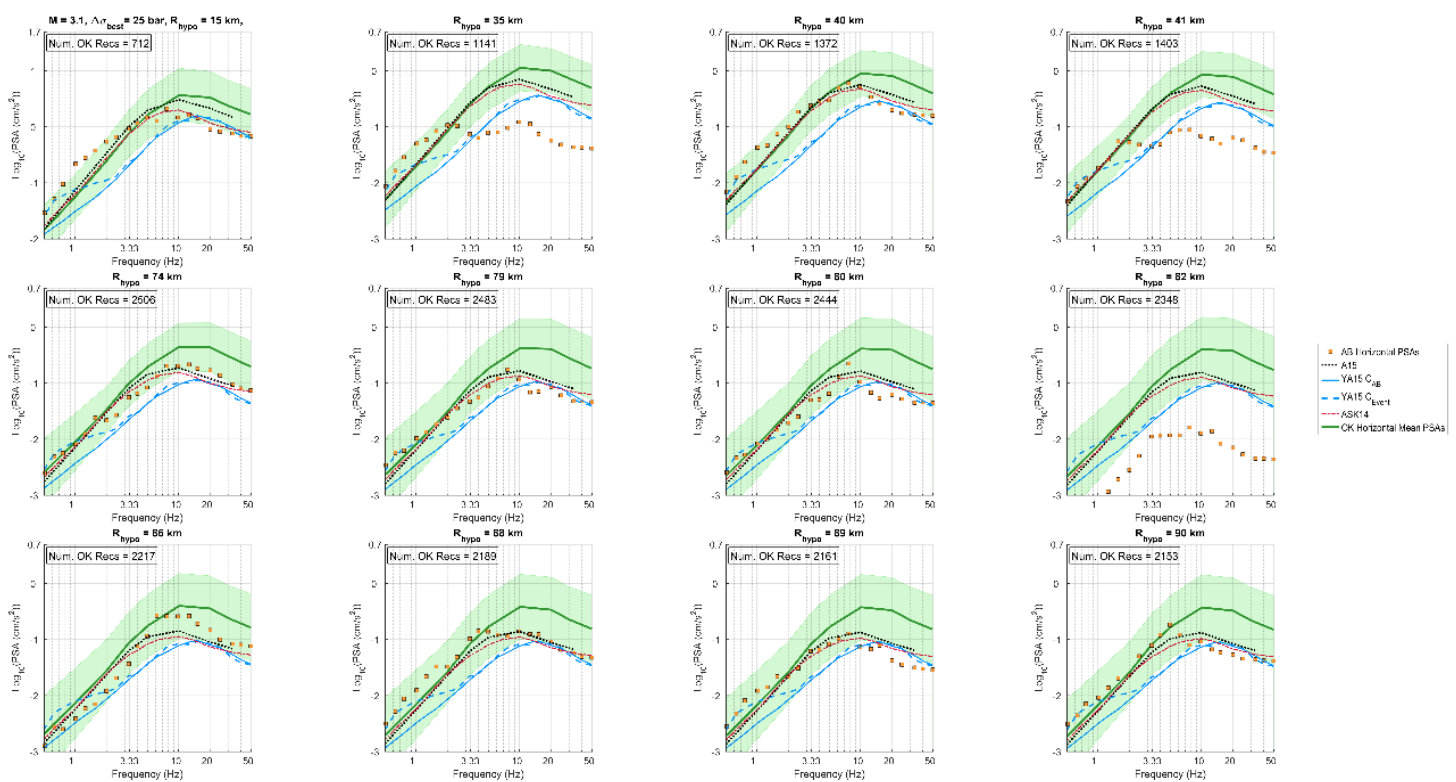

Figure B3. Horizontal-component PSAs for M 3.1 event in Alberta. See Figure B1 caption for graphical description.
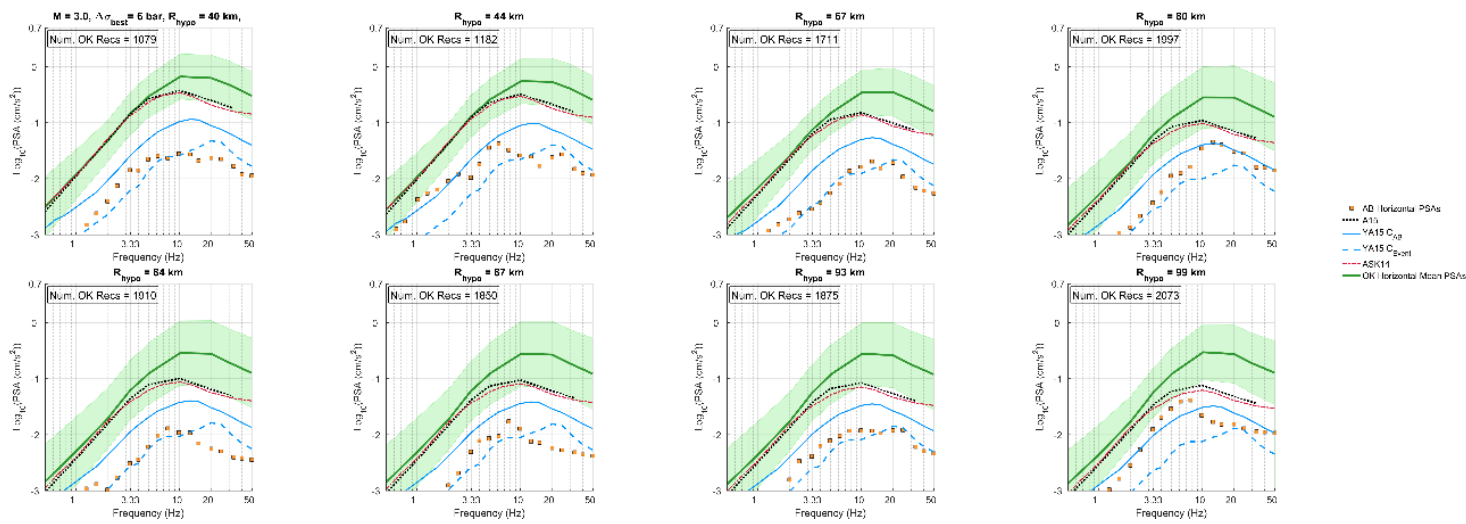

Figure B4. Horizontal-component PSAs for M 3.0 event in Alberta. See Figure B1 caption for graphical description.

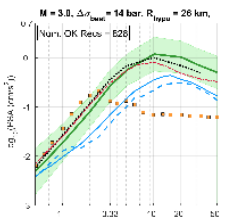

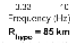

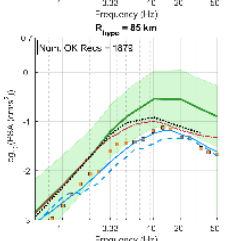

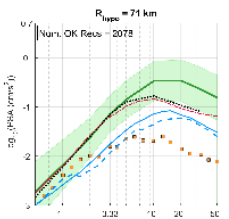

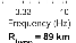

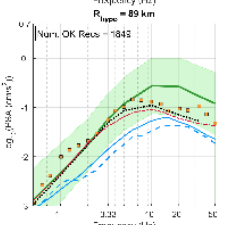

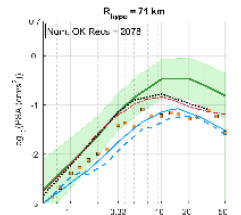

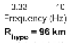

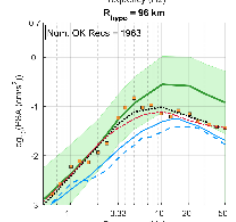

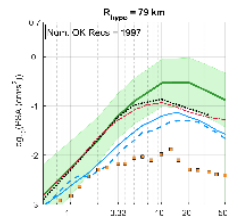

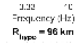

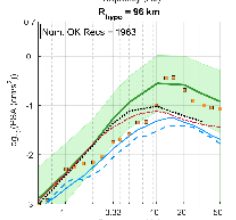

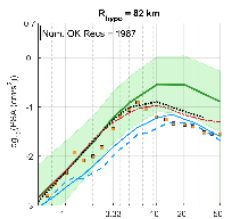

as $x$ is

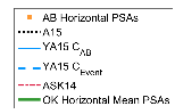

Figure B5. Horizontal-component PSAs for M 3.0 event in Alberta. See Figure B1 caption for graphical description. 

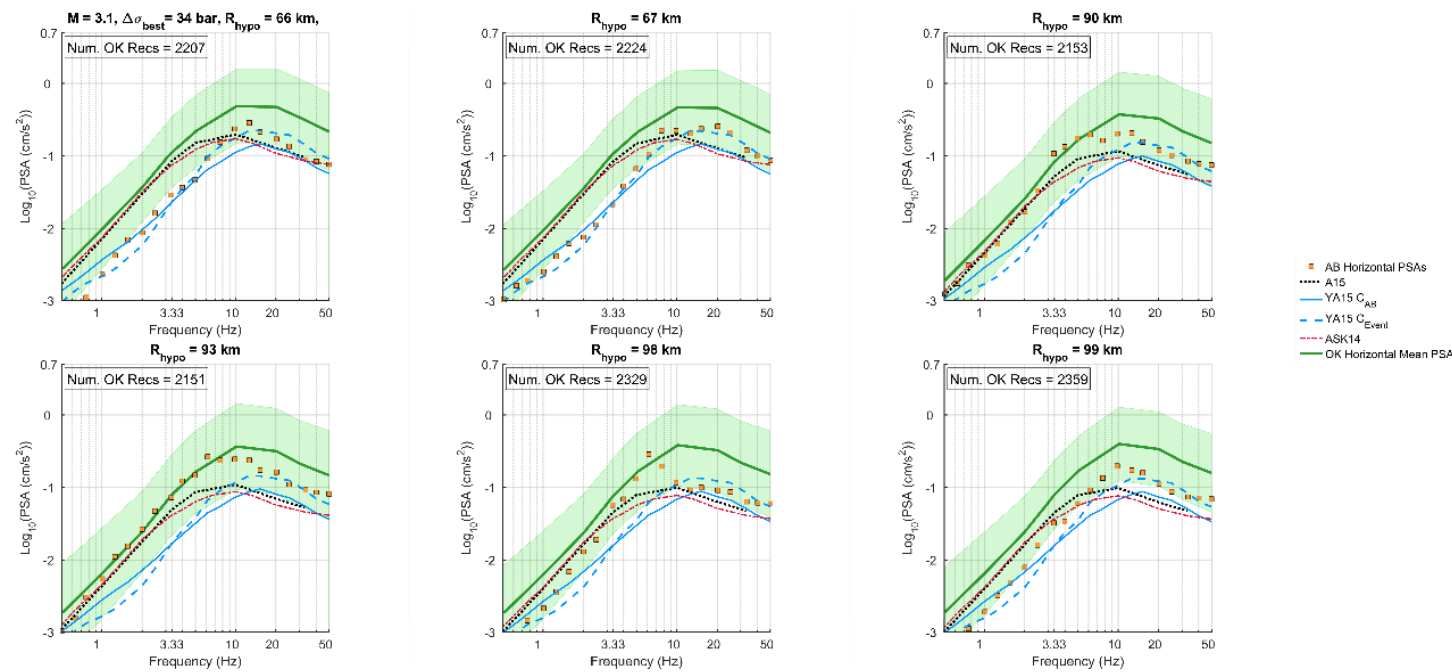

Figure B6. Horizontal-component PSAs for M 3.1 event in Alberta. See Figure B1 caption for graphical description.
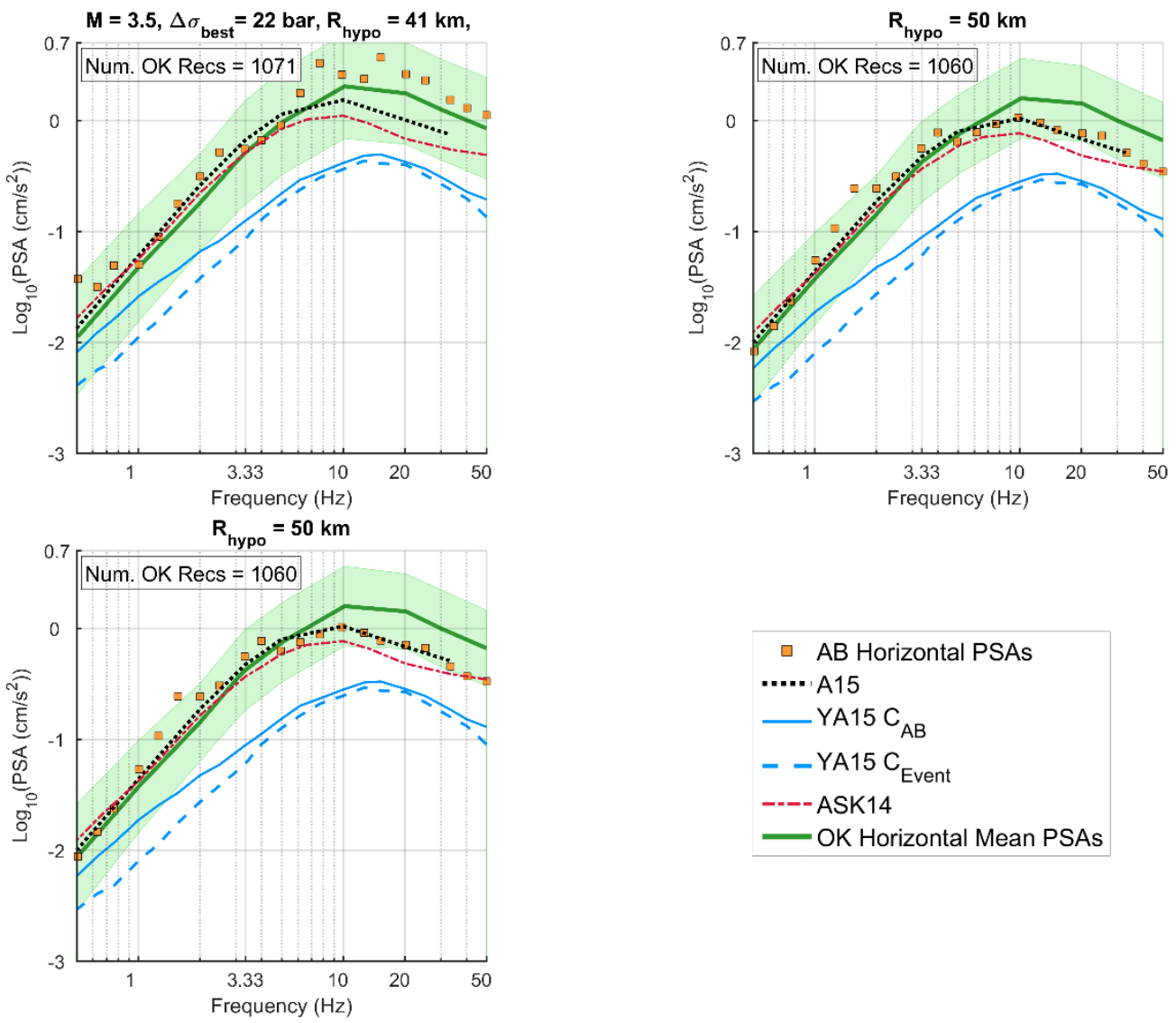

$\square \quad$ AB Horizontal PSAs

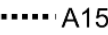

YA15 $\mathrm{C}_{\mathrm{AB}}$

- - YA15 C Event

----ASK14

OK Horizontal Mean PSAs

Figure B7 Horizontal-component PSAs for M 3.5 event in Alberta. See Figure B1 caption for graphical description. 

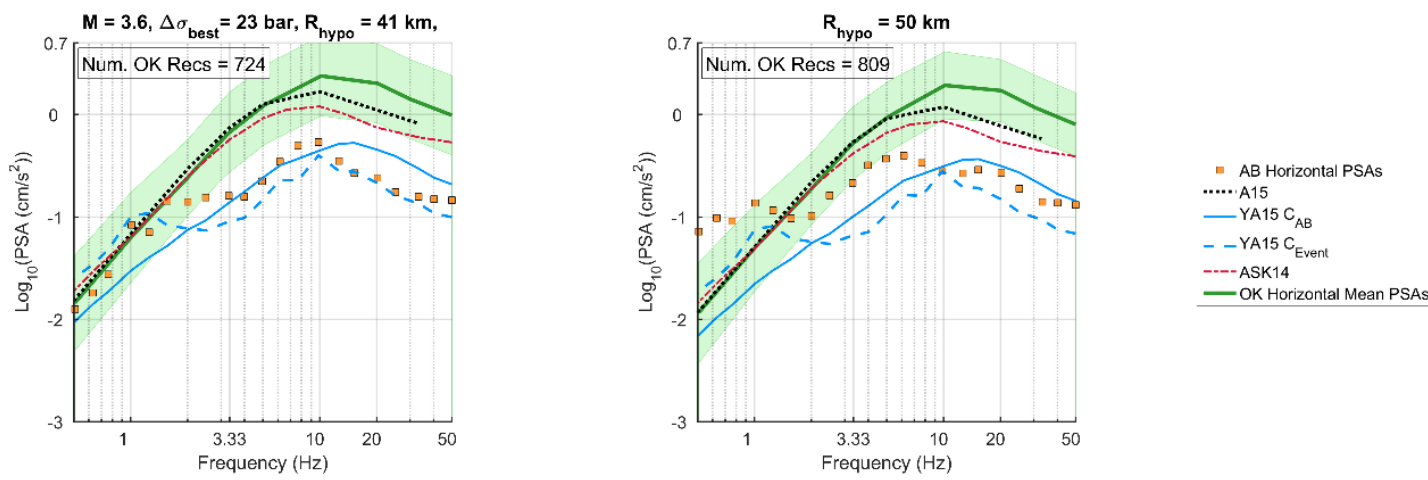

Figure B8. Horizontal-component PSAs for M 3.6 event in Alberta. See Figure B1 caption for graphical description.
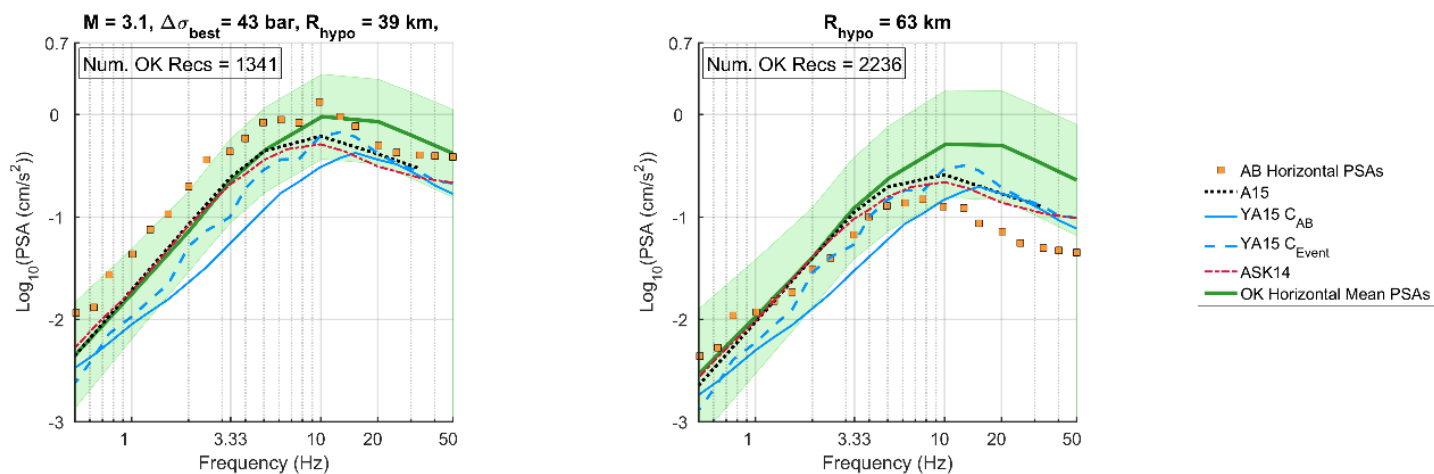

Figure B9. Horizontal-component PSAs for M 3.1 event in Alberta. See Figure B1 caption for graphical description.
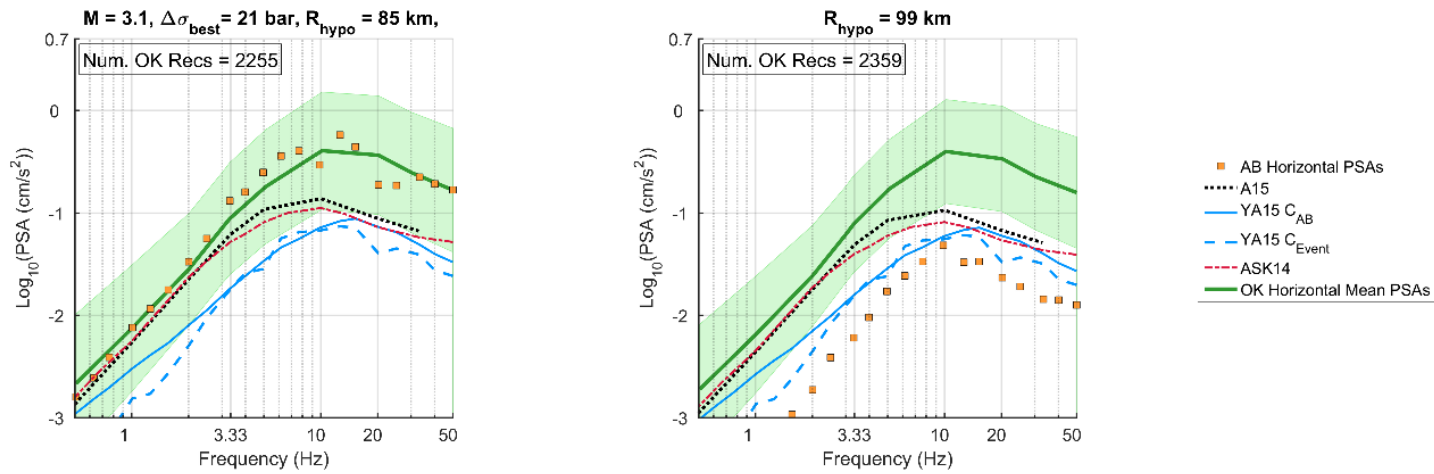

Figure B10. Horizontal-component PSAs for M 3.1 event in Alberta. See Figure B1 caption for graphical description. 

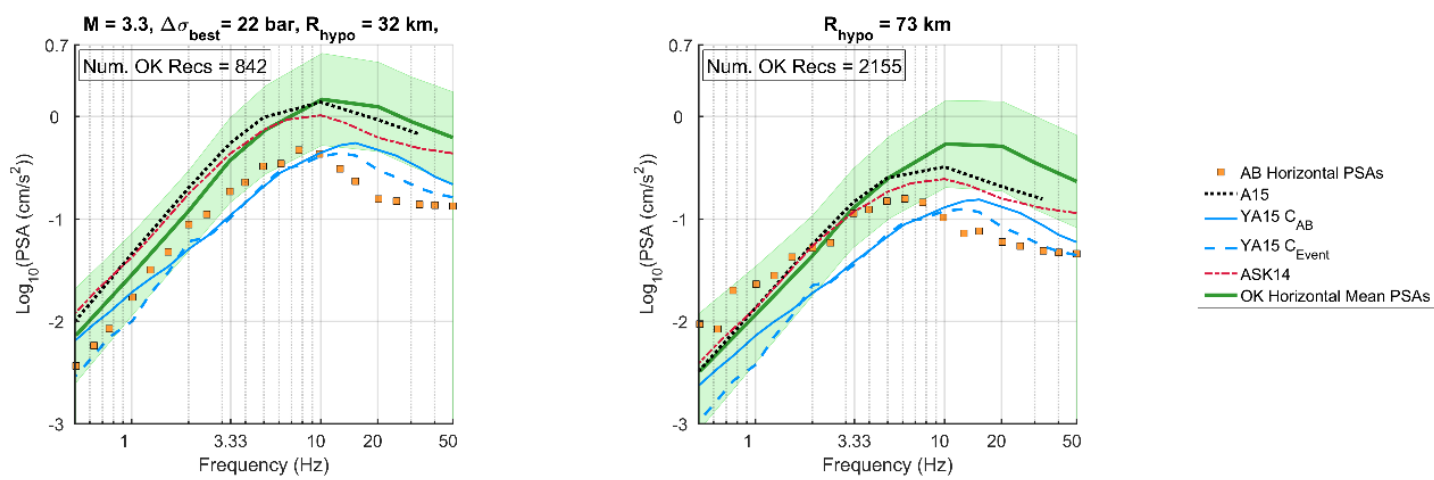

Figure B11. Horizontal-component PSAs for M 3.3 event in Alberta. See Figure B1 caption for graphical description.
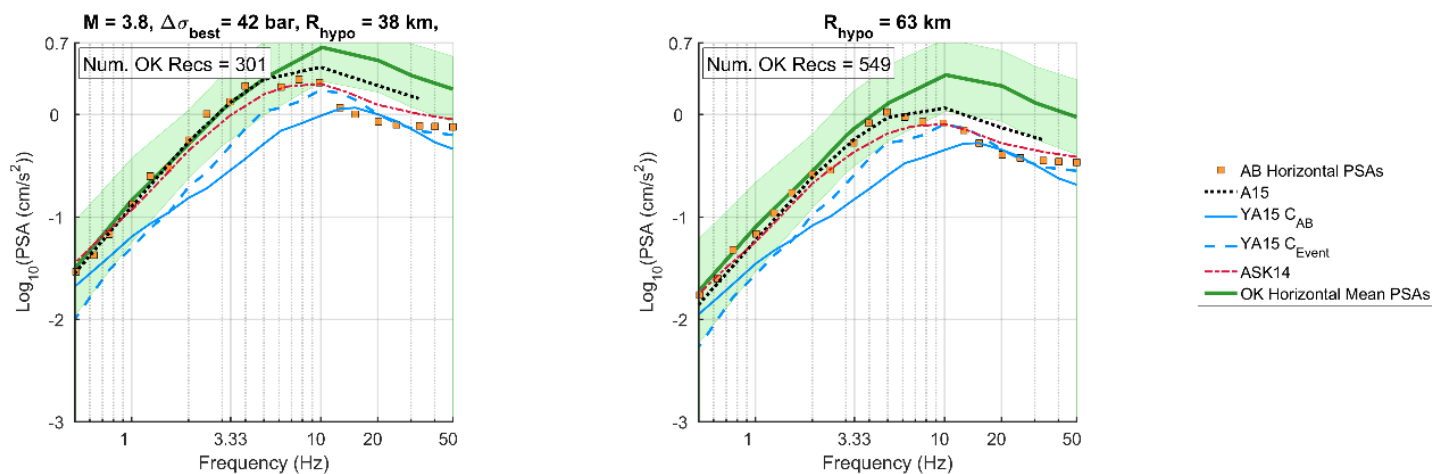

Figure B12. Horizontal-component PSAs for M 3.8 event in Alberta. See Figure B1 caption for graphical description. 

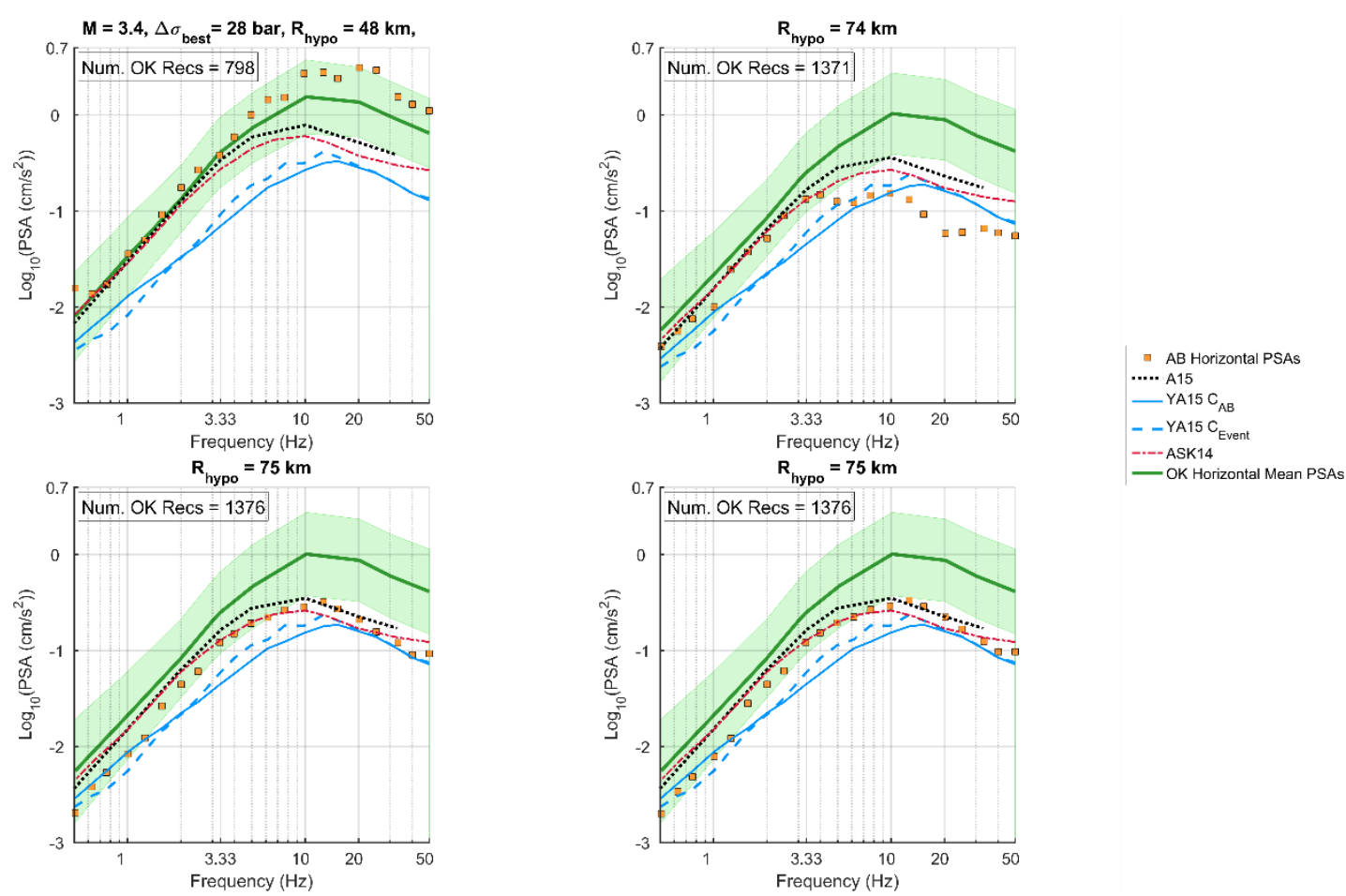

Figure B13. Horizontal-component PSAs for M 3.4 event in Alberta. See Figure B1 caption for graphical description.
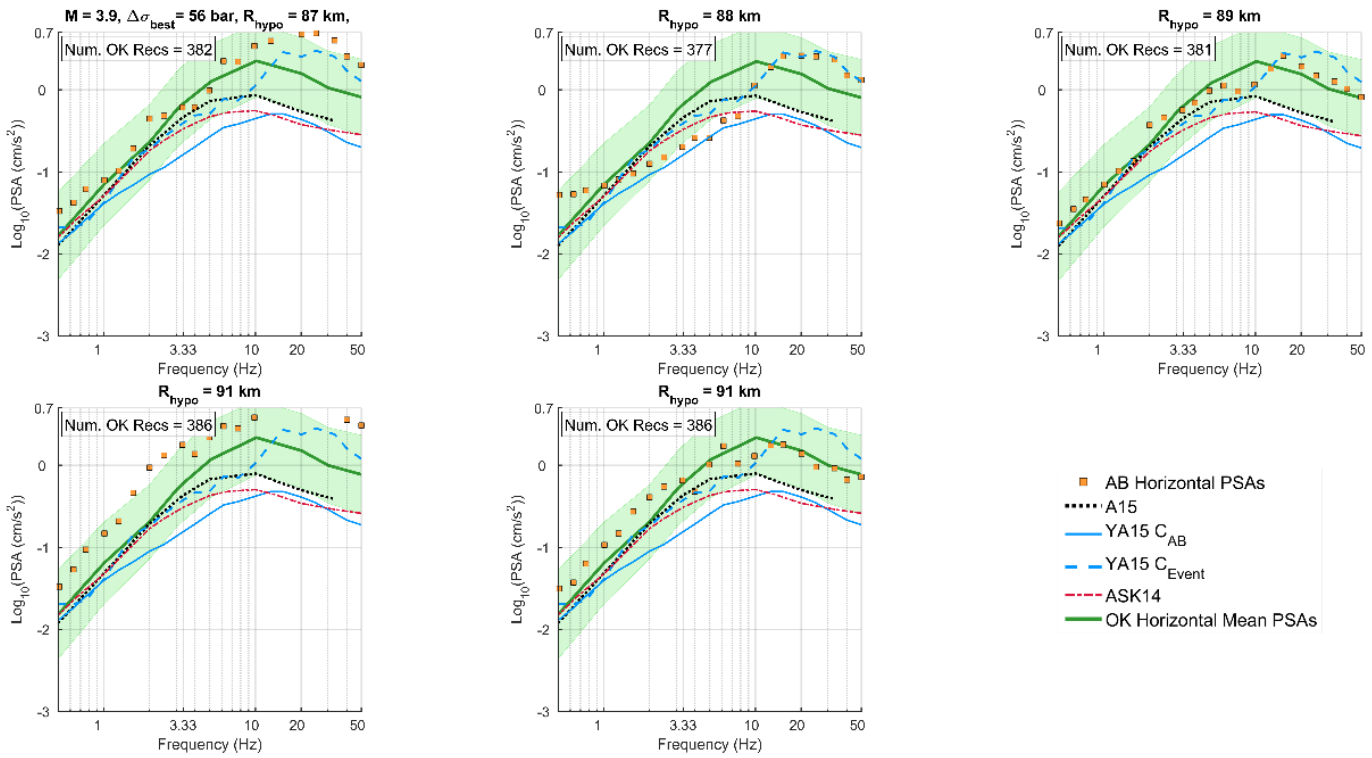

Figure B14. Horizontal-component PSAs for M 3.9 event in Alberta. See Figure B1 caption for graphical description. 

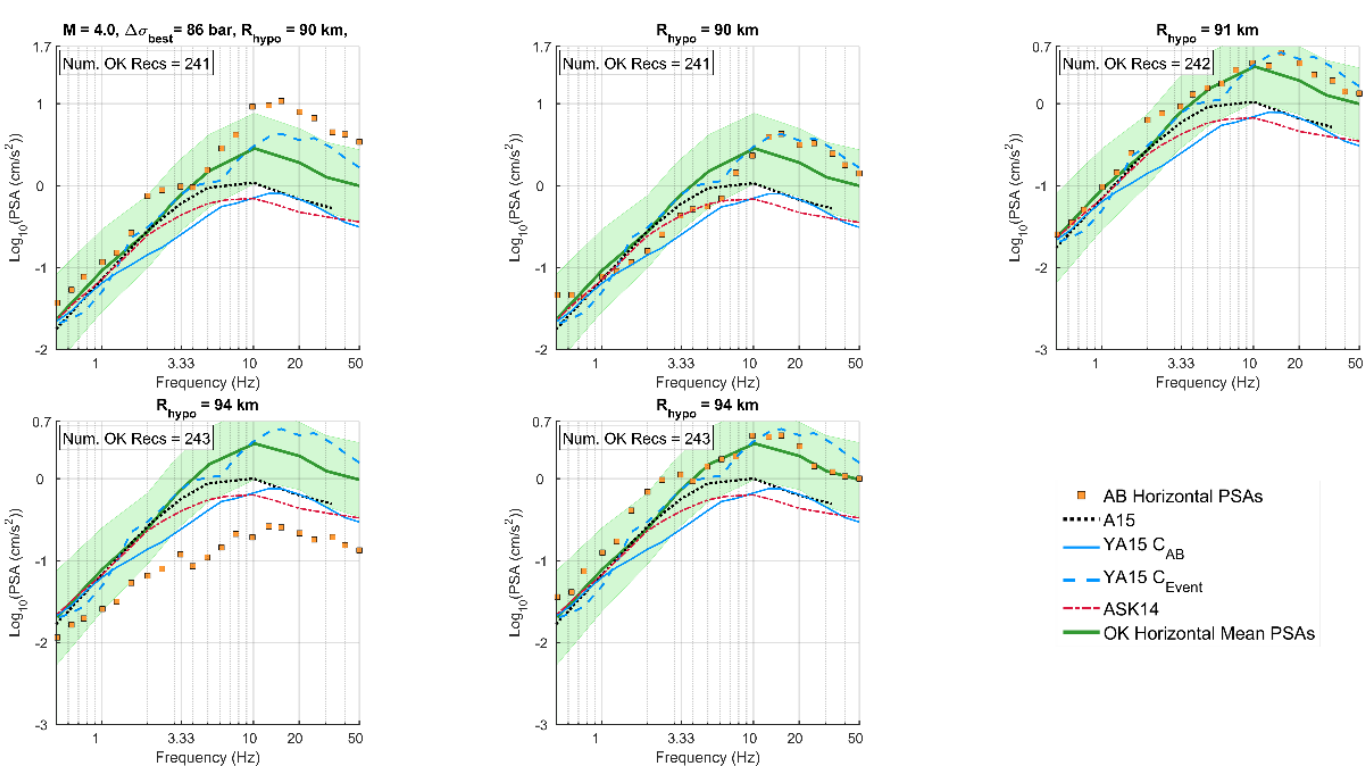

Figure B15. Horizontal-component PSAs for M 4.0 event in Alberta. See Figure B1 caption for graphical description.
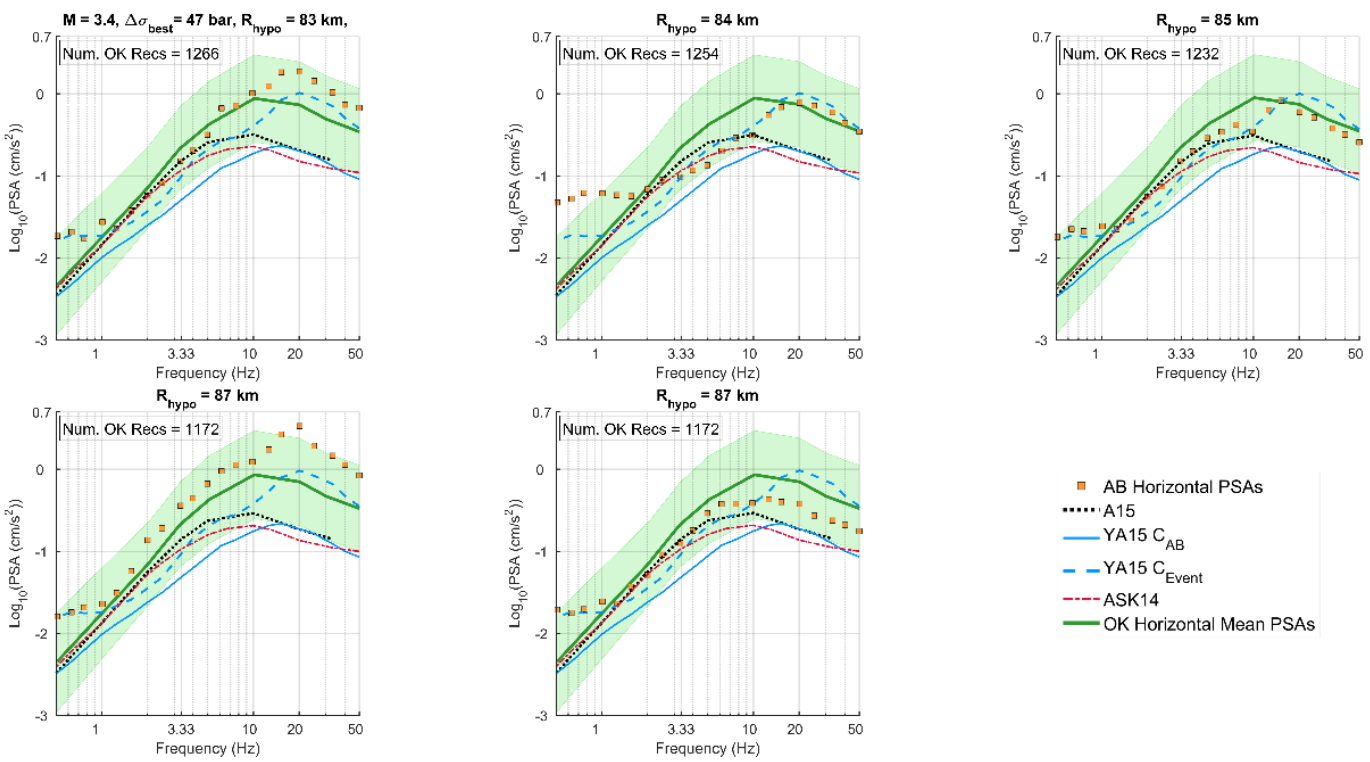

Figure B16. Horizontal-component PSAs for M 3.4 event in Alberta. See Figure B1 caption for graphical description. 

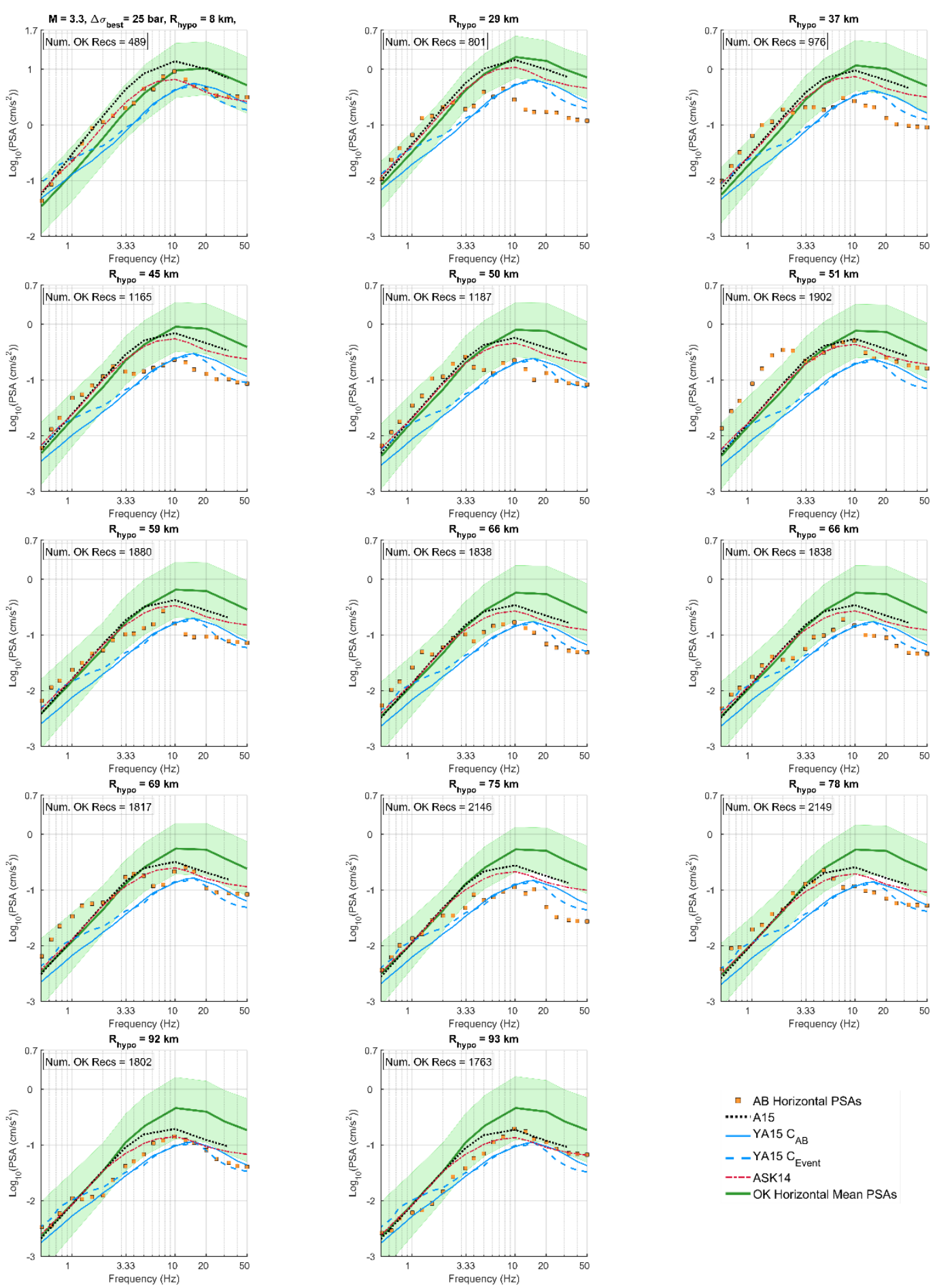

Figure B17. Horizontal-component PSAs for M 3.3 event in Alberta. See Figure B1 caption for graphical description. 

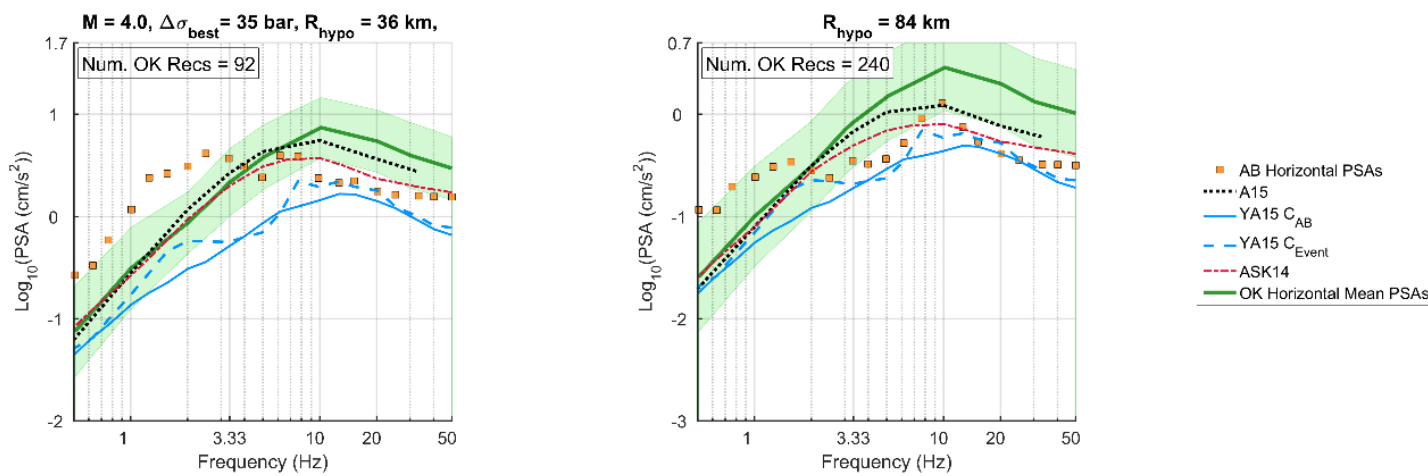

Figure B18. Horizontal-component PSAs for M 4.0 event in Alberta. See Figure B1 caption for graphical description.
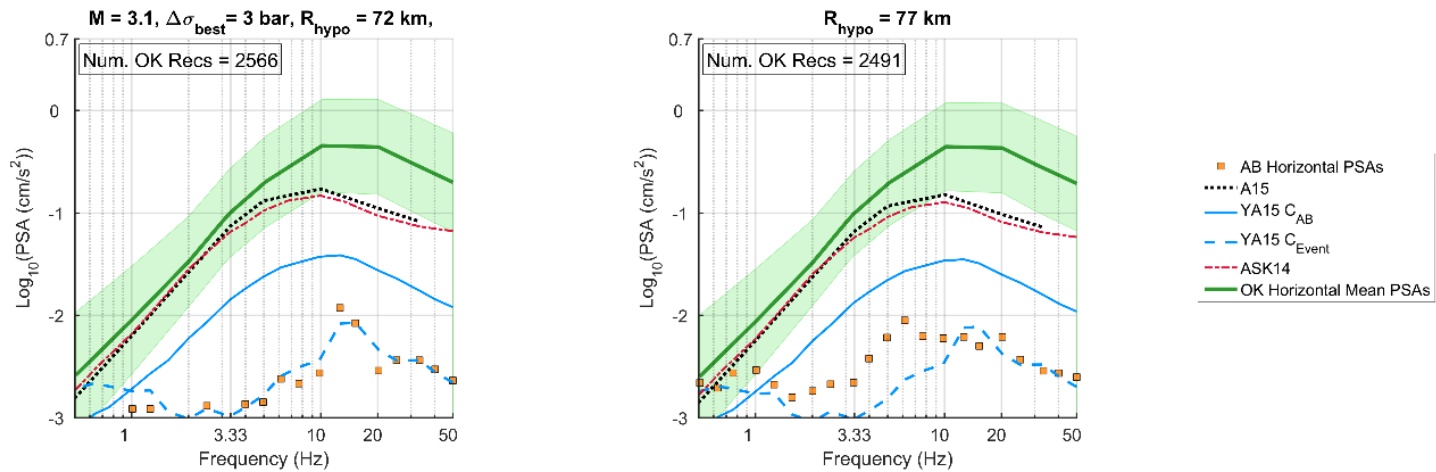

Figure B19. Horizontal-component PSAs for M 3.1 event in Alberta. See Figure B1 caption for graphical description.
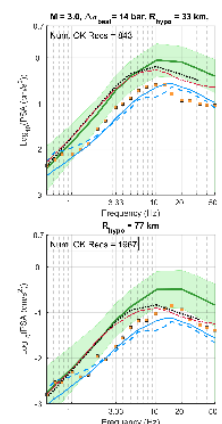
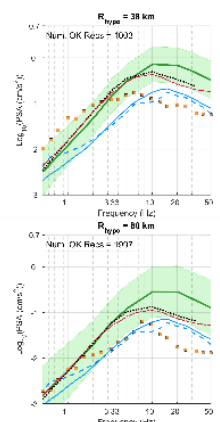
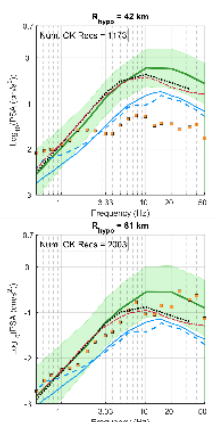

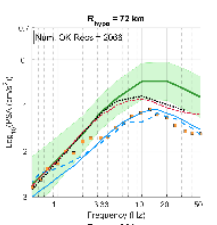

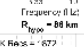

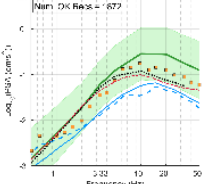

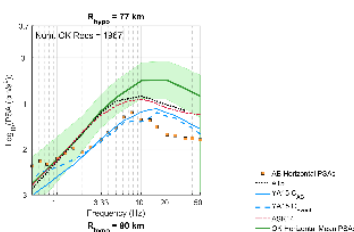

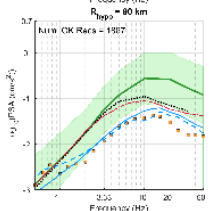

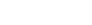

Figure B20. Horizontal-component PSAs for M 3.0 event in Alberta. See Figure B1 caption for graphical description. 

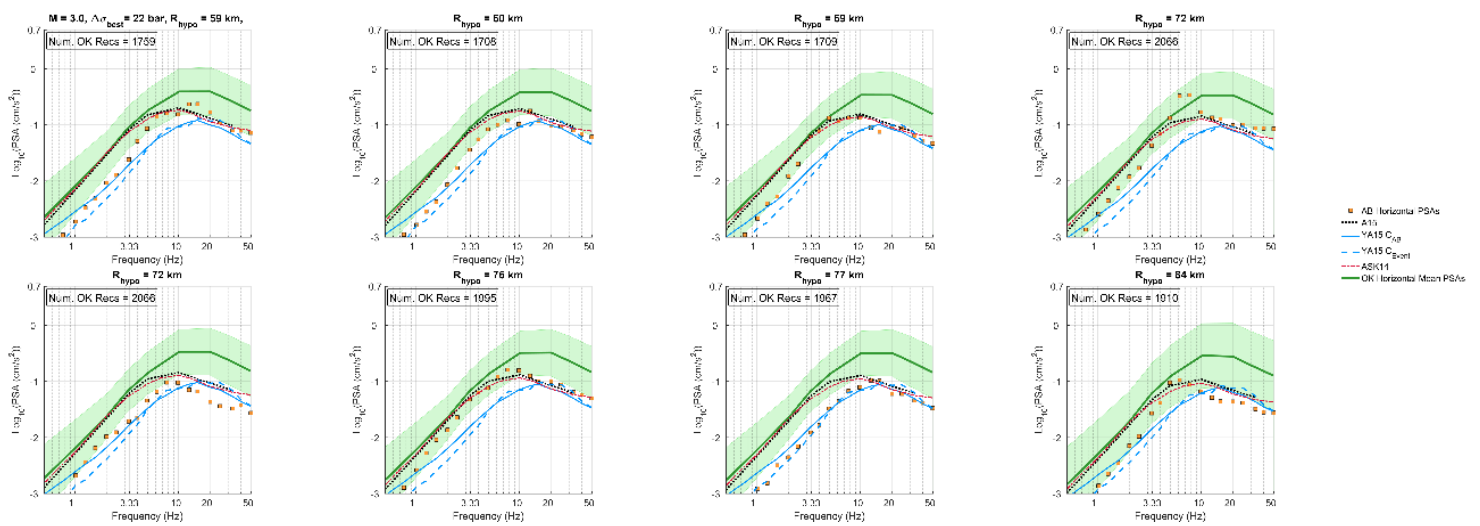

Figure B21. Horizontal-component PSAs for M 3.0 event in Alberta. See Figure B1 caption for graphical description.
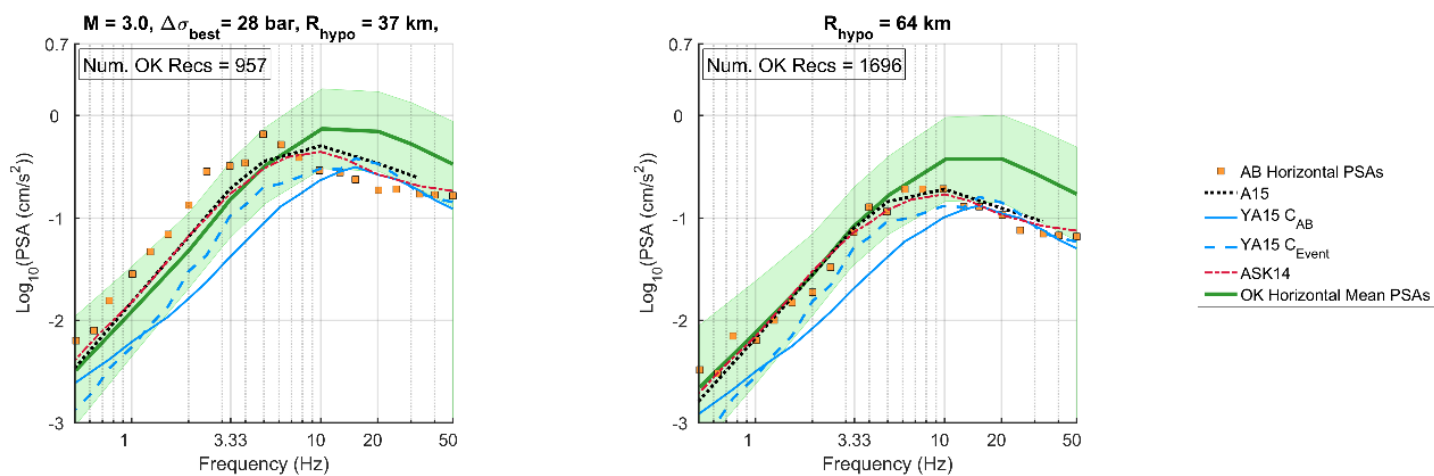

Figure B22. Horizontal-component PSAs for M 3.0 event in Alberta. See Figure B1 caption for graphical description.
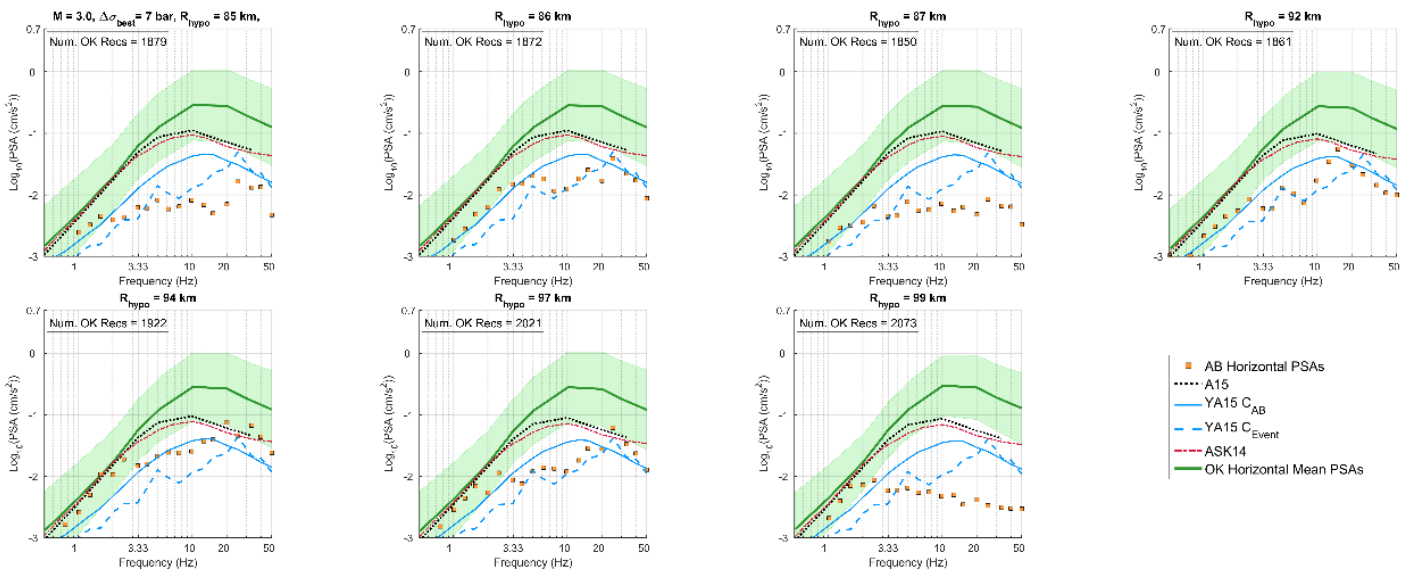

Figure B23. Horizontal-component PSAs for M 3.0 event in Alberta. See Figure B1 caption for graphical description. 

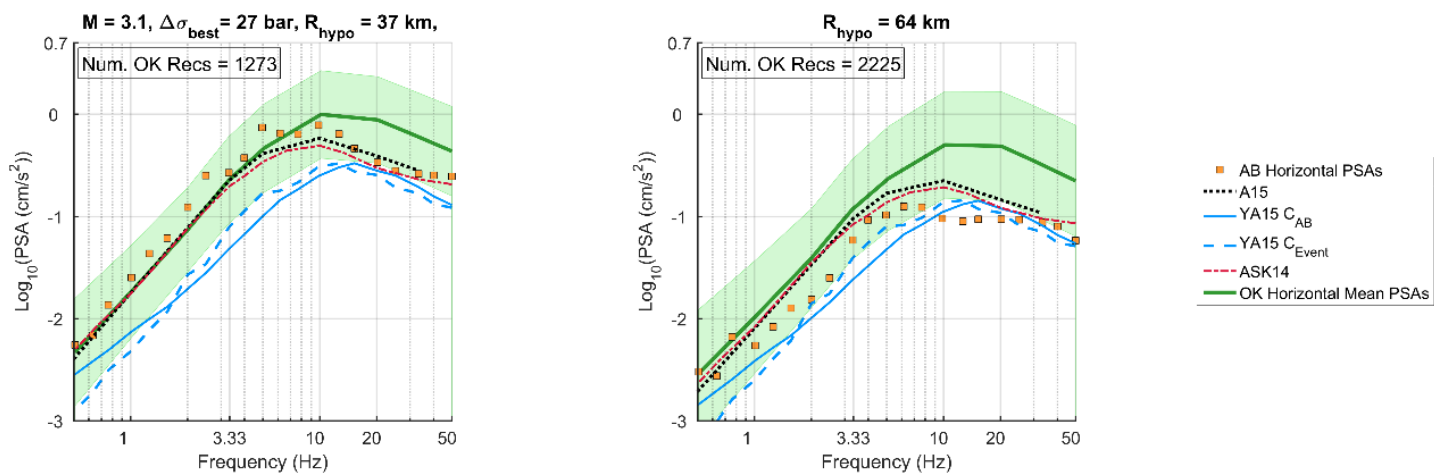

Figure B24. Horizontal-component PSAs for M 3.1 event in Alberta. See Figure B1 caption for graphical description.
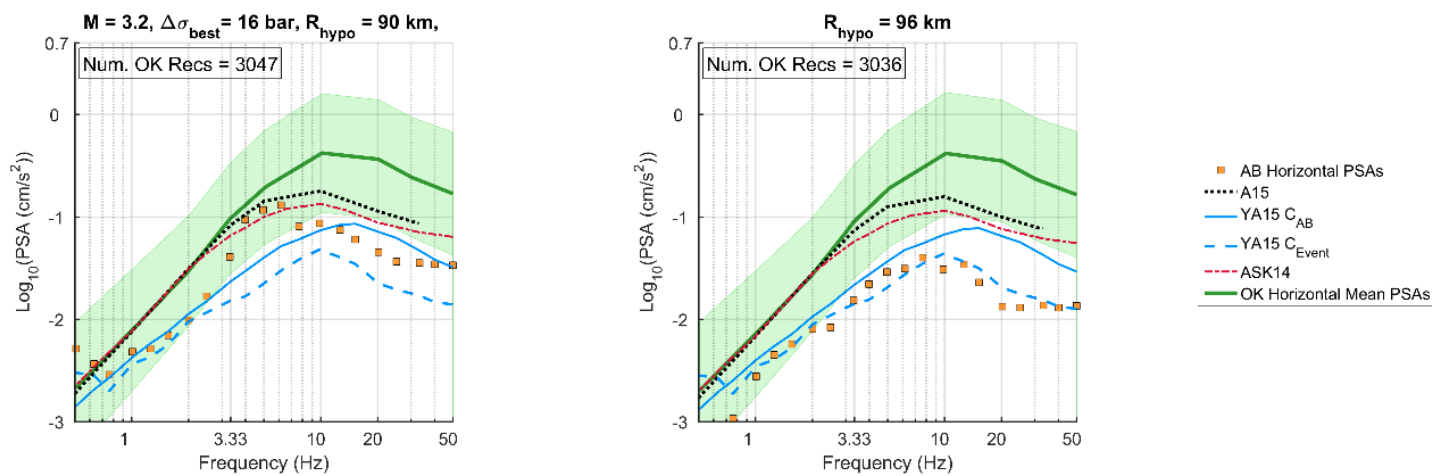

Figure B25. Horizontal-component PSAs for M 3.2 event in Alberta. See Figure B1 caption for graphical description. 


\section{Appendix C. Residuals - Supplementary Figures}

I provide through this appendix average log (base 10) residuals with magnitude for horizontal-component Alberta PSAs with respect to three benchmark GMPEs (A15, ASK14 and Yenier and Atkinson, 2015 calculated for Central and Eastern North America [YA15 ${ }_{\text {CENA }}$ ). We also provide plots illustrating the log (base 10) residuals with hypocentral distance calculated for each vertical- and horizontal-component record between Alberta and the benchmarks.
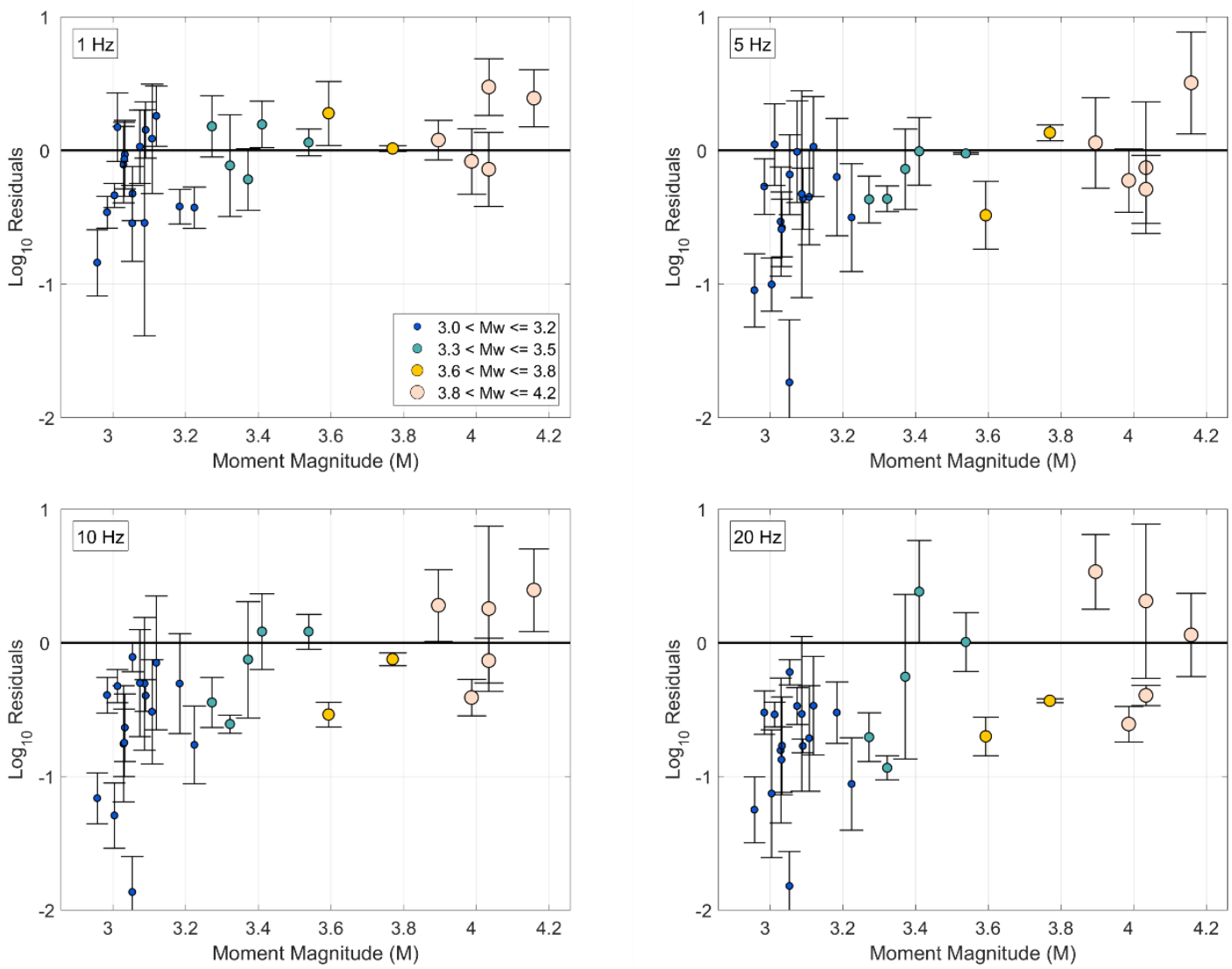

Figure C1. Average $\log _{10}$ residuals versus magnitude for horizontal-component Alberta PSAs (all records) with respect to PSA predicted by A15 at 1, 5, 10, and $20 \mathrm{~Hz}$. Marker sizes indicate magnitude bins of Alberta events. Error bars denote the standard deviation of the residuals for each event. 

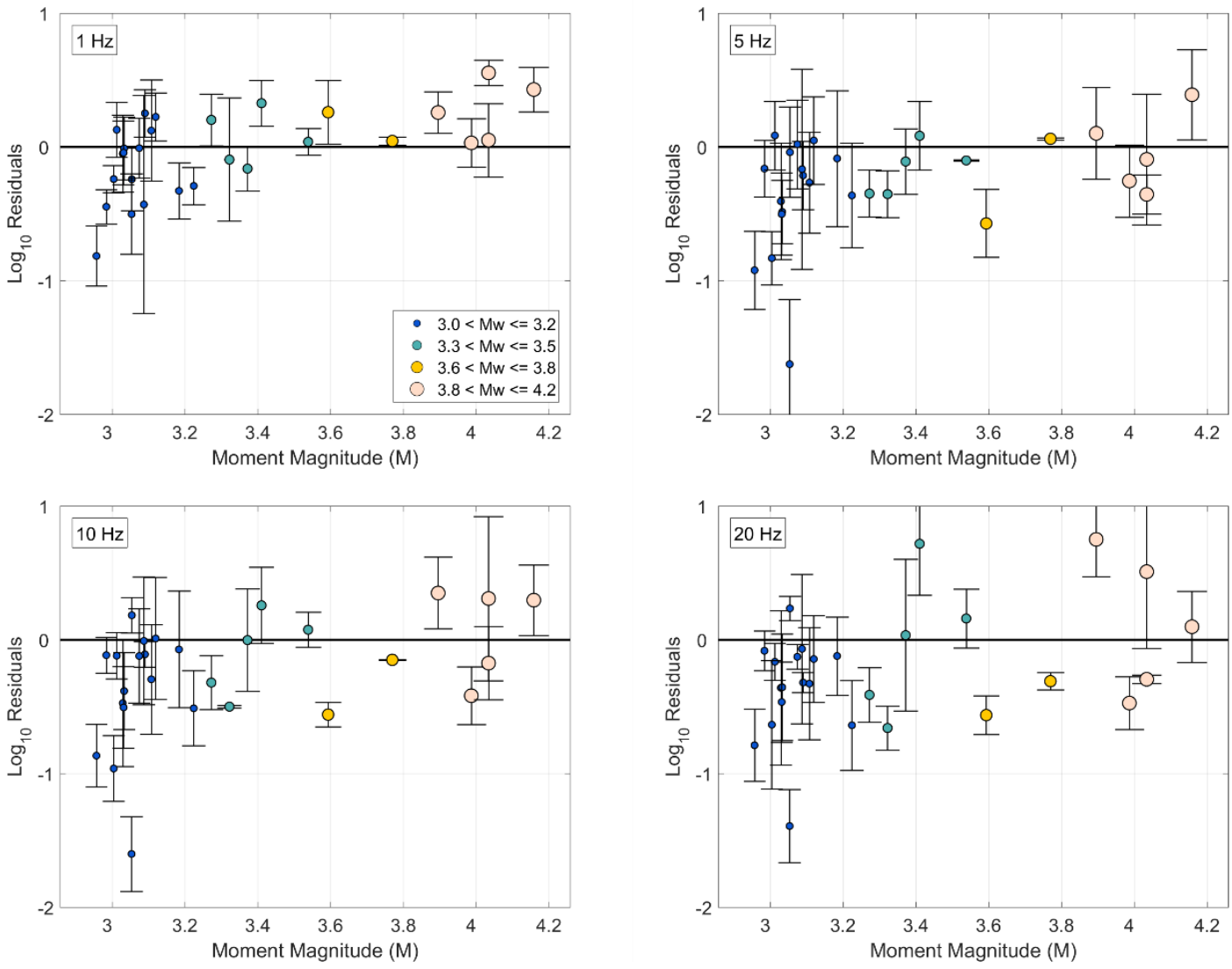

Figure C2. Average $\log _{10}$ residuals versus magnitude for horizontal-component Alberta PSAs (all records) with respect to PSA predicted by YA15 $5_{\text {CENA }}($ focal depth $=2 \mathrm{~km})$ at 1 , 5, 10, and $20 \mathrm{~Hz}$. Marker sizes indicate magnitude bins of Alberta events. Error bars denote the standard deviation of the residuals for each event. 

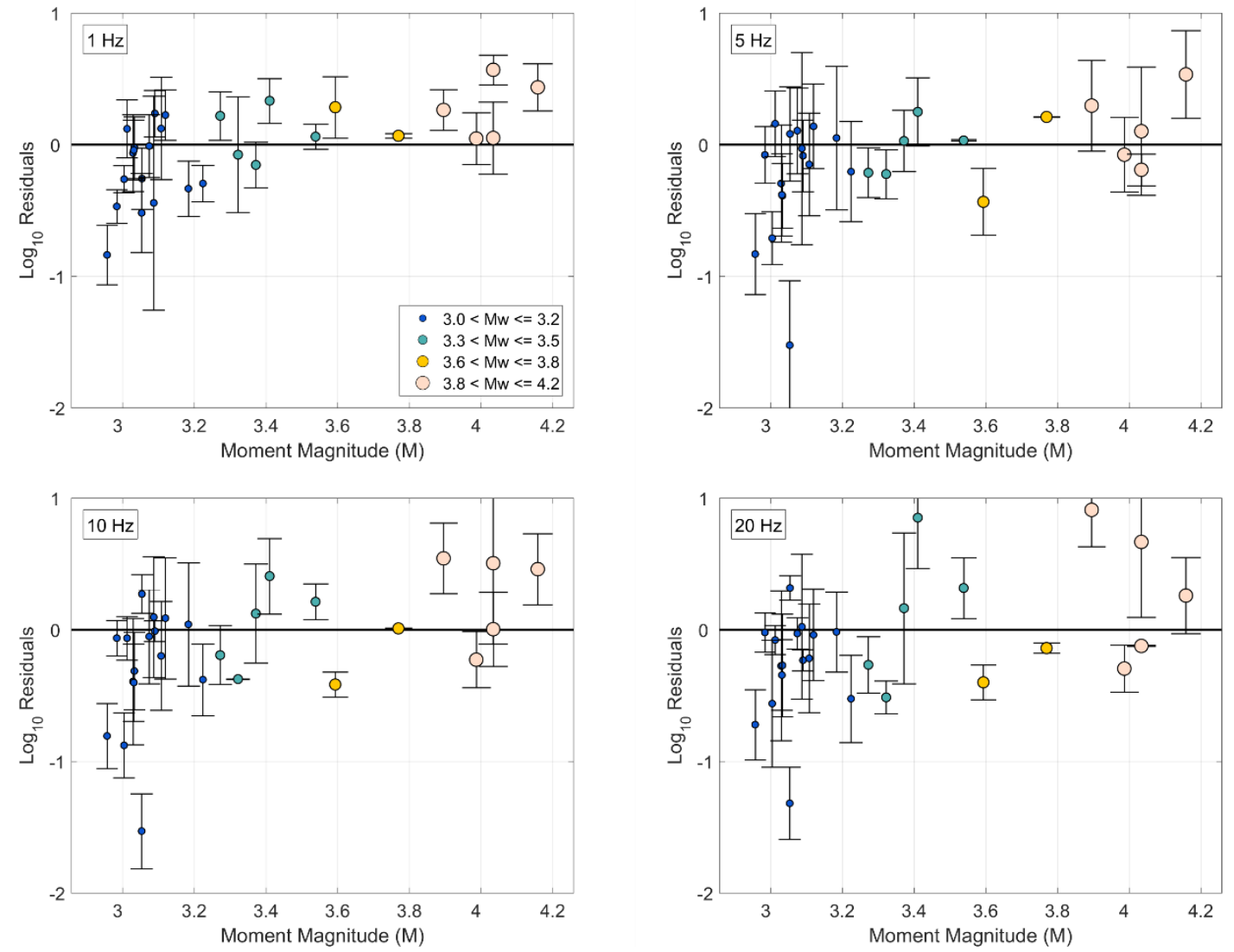

Figure C3. Average $\log _{10}$ residuals versus magnitude for horizontal-component Alberta PSAs (all records) with respect to PSA predicted by ASK14 at 1, 5, 10, and $20 \mathrm{~Hz}$. Marker sizes indicate magnitude bins of Alberta events. Error bars denote the standard deviation of the residuals for each event. 

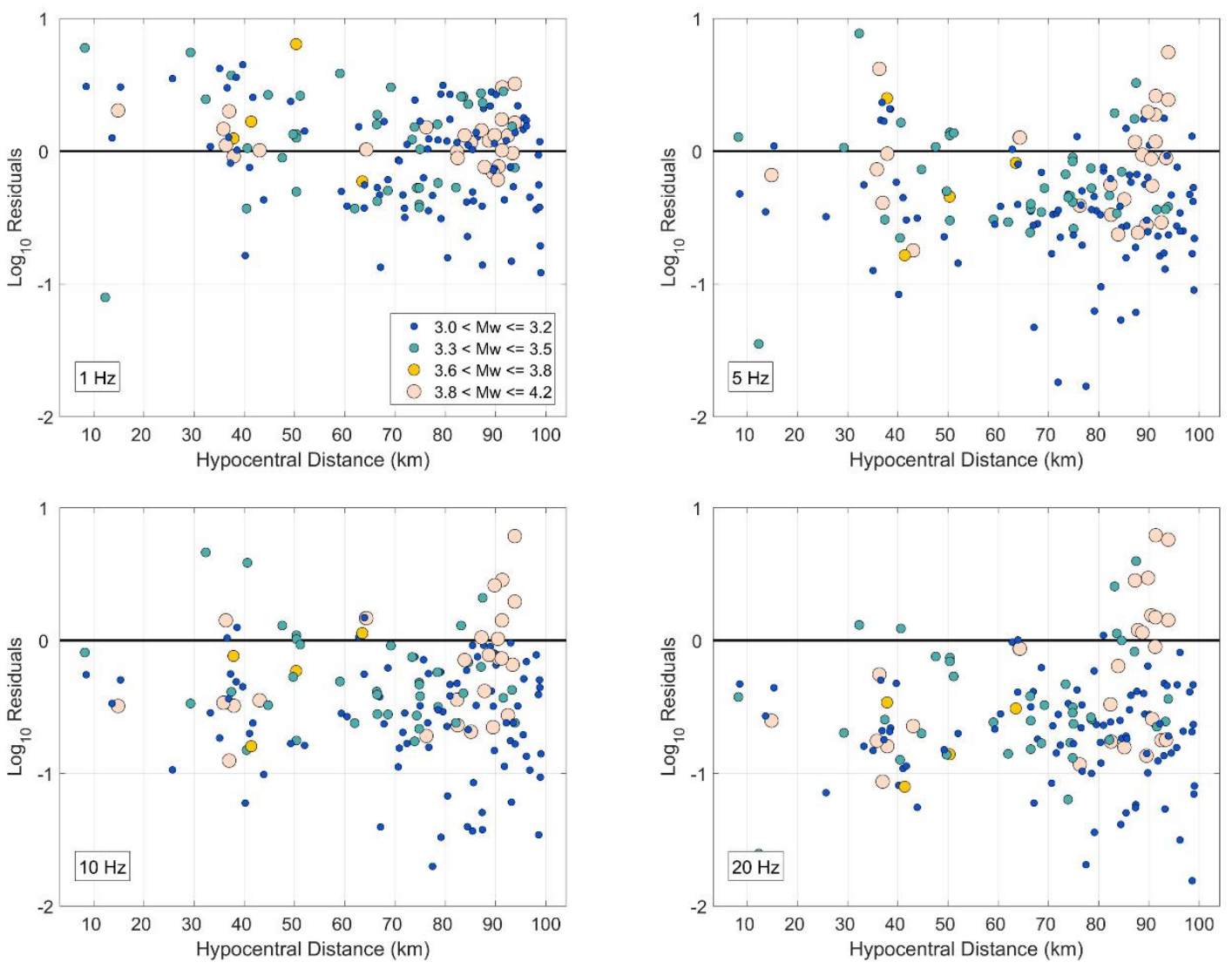

Figure C4. Log (base 10) residuals versus hypocentral distance for vertical-component Alberta PSAs (all records) with respect to Oklahoma binned-average vertical-component PSAs at 1, 5, 10, and $20 \mathrm{~Hz}$. Marker sizes indicate magnitude bins of Alberta events. 

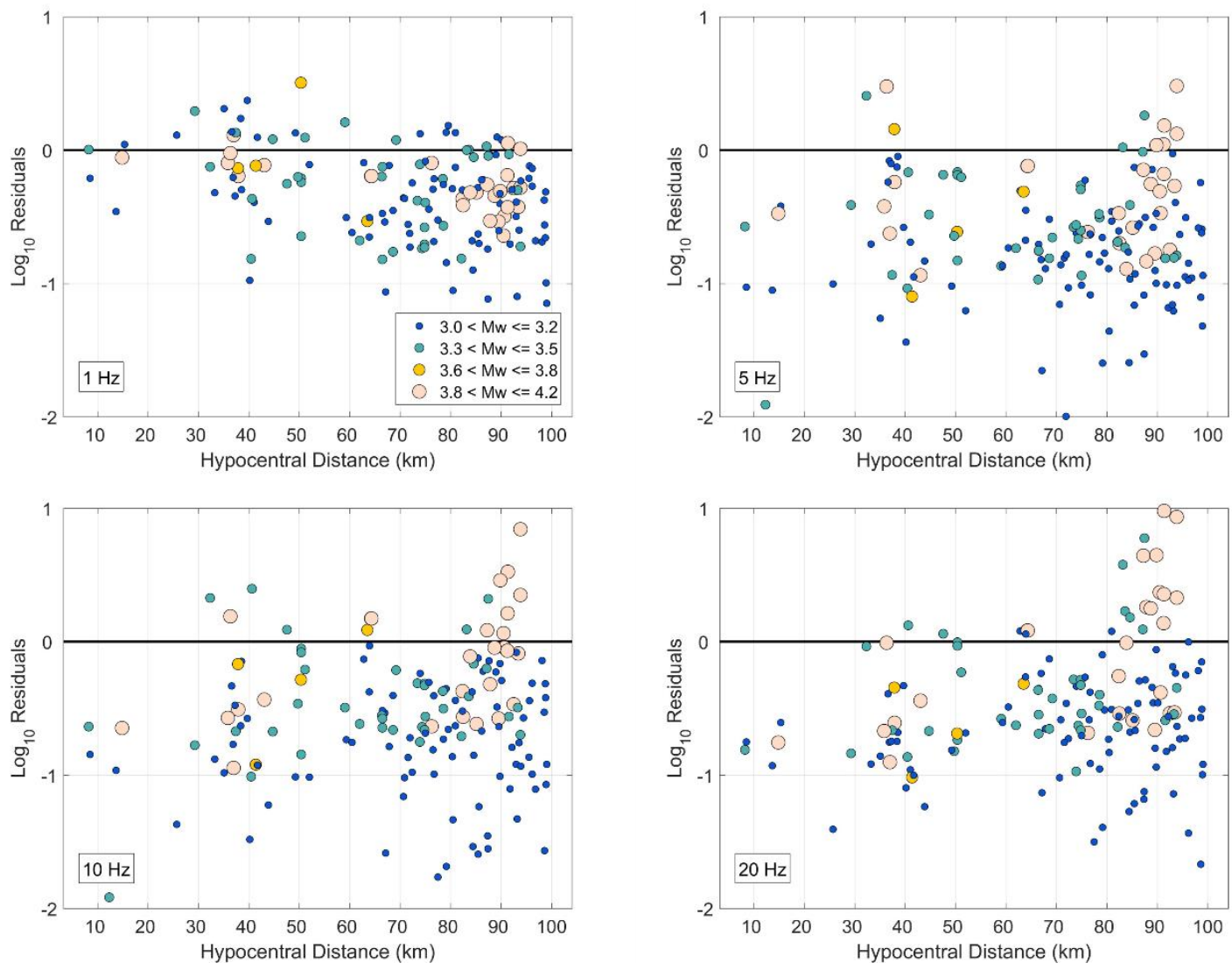

Figure C5. Log (base 10) residuals versus hypocentral distance for vertical-component Alberta PSAs (all records) with respect PSA predicted by A15 at 1, 5, 10, and $20 \mathrm{~Hz}$. Marker sizes indicate magnitude bins of Alberta events. 

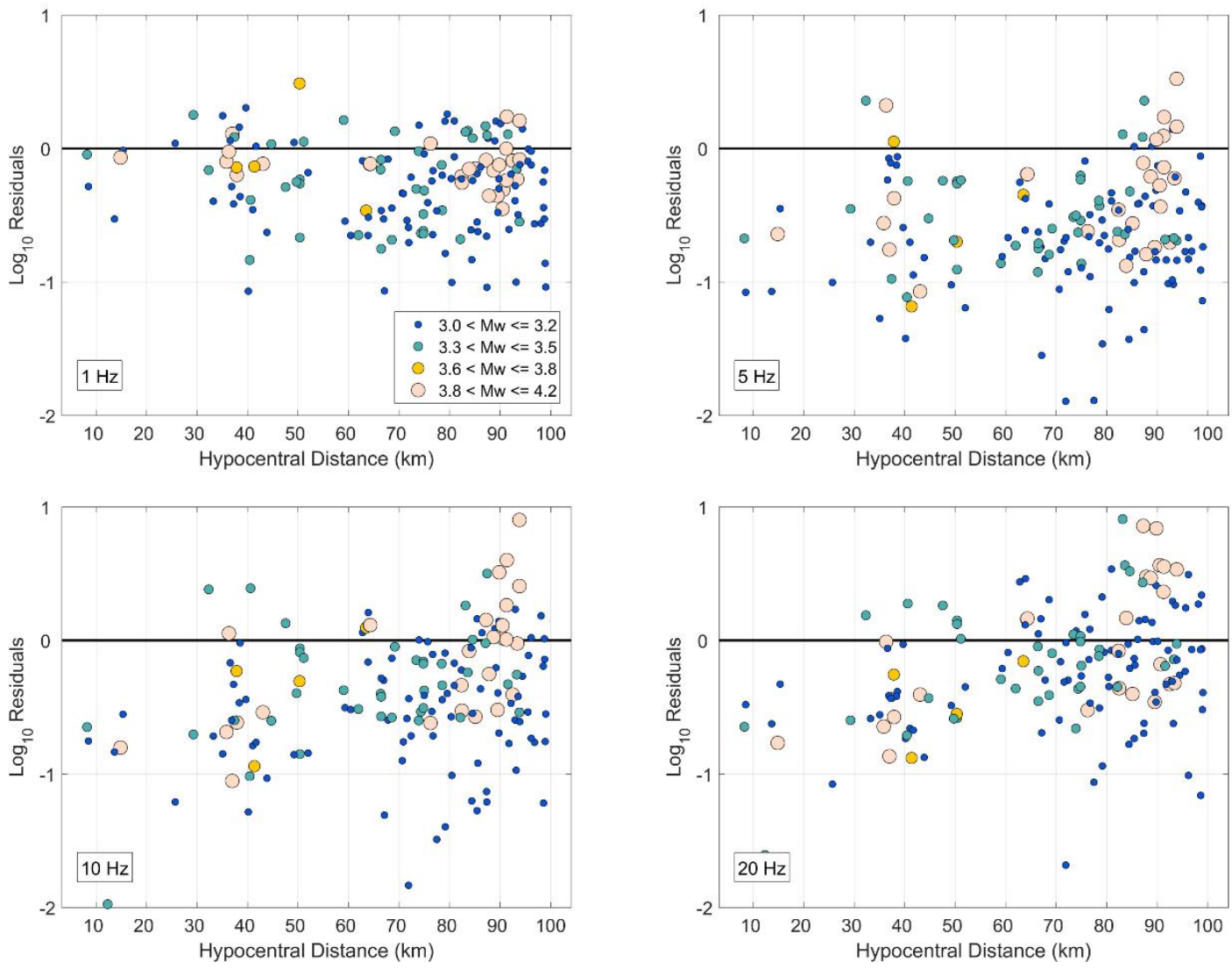

Figure C6. Log (base 10) residuals versus hypocentral distance for vertical-component Alberta PSAs (all records) with respect to PSA predicted by YA15 ${ }_{\text {CENA }}$ (focal depth $=$ $2 \mathrm{~km}$ ) at 1, 5, 10, and $20 \mathrm{~Hz}$. Marker sizes indicate magnitude bins of Alberta events. 

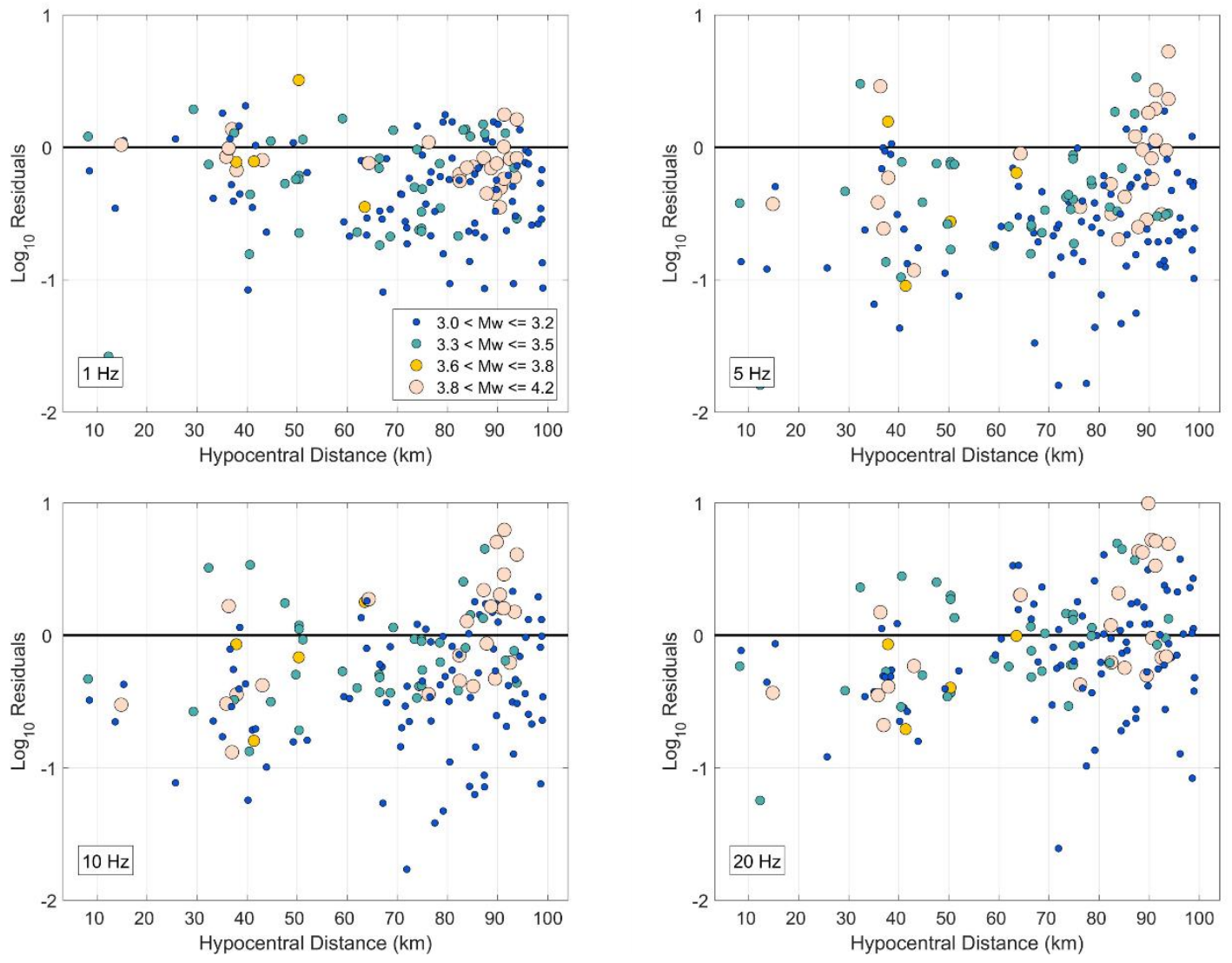

Figure C7. Log (base 10) residuals versus hypocentral distance for vertical-component Alberta PSAs (all records) with respect to PSA predicted by ASK14 (with depth to rupture modification for induced events) at 1, 5, 10, and $20 \mathrm{~Hz}$. Marker sizes indicate magnitude bins of Alberta events. 

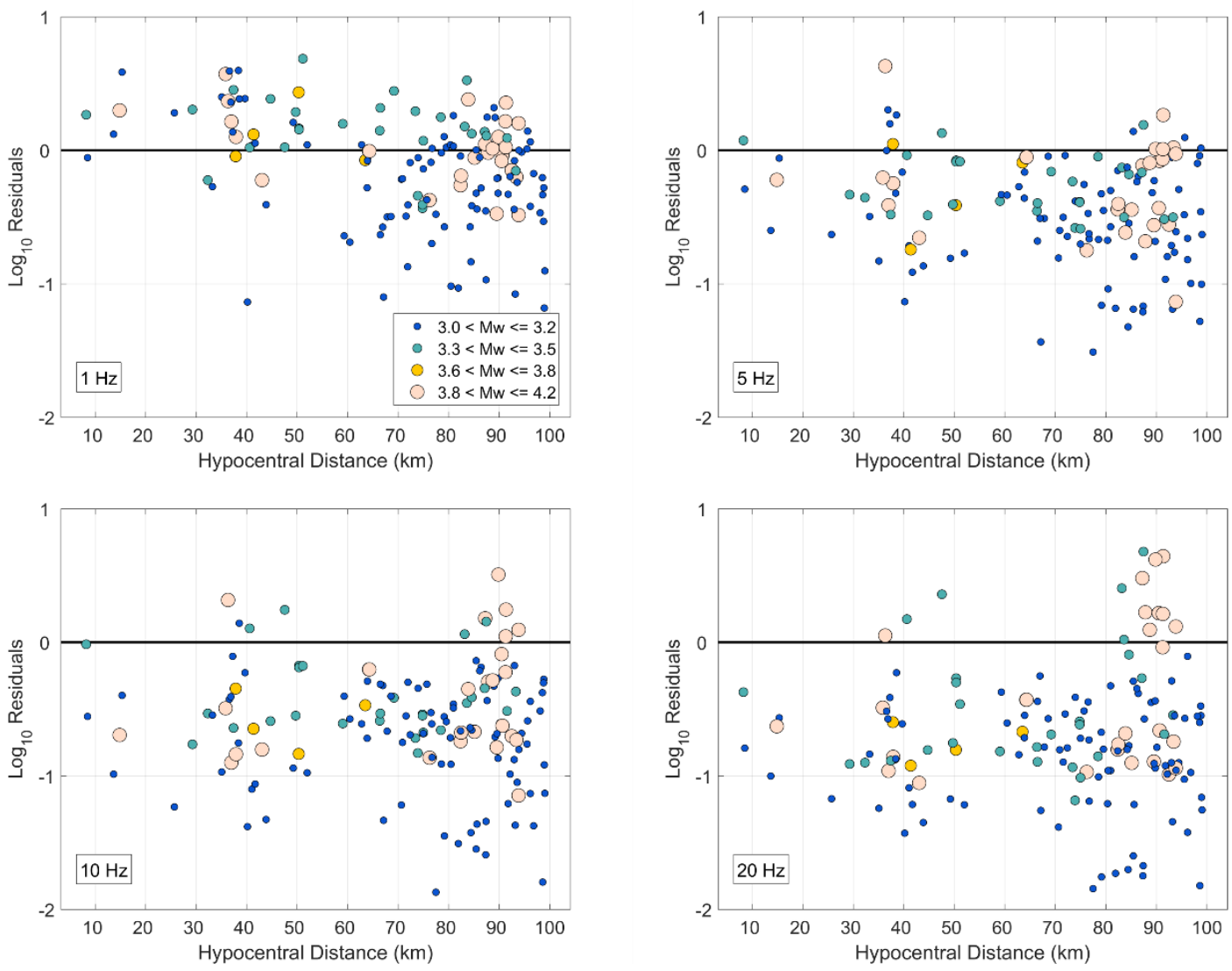

Figure C8. Log (base 10) residuals versus hypocentral distance for horizontalcomponent Alberta PSAs (all records) with respect to Oklahoma binned-average horizontal-component PSAs at 1, 5, 10, and $20 \mathrm{~Hz}$. Marker sizes indicate magnitude bins of Alberta events. 

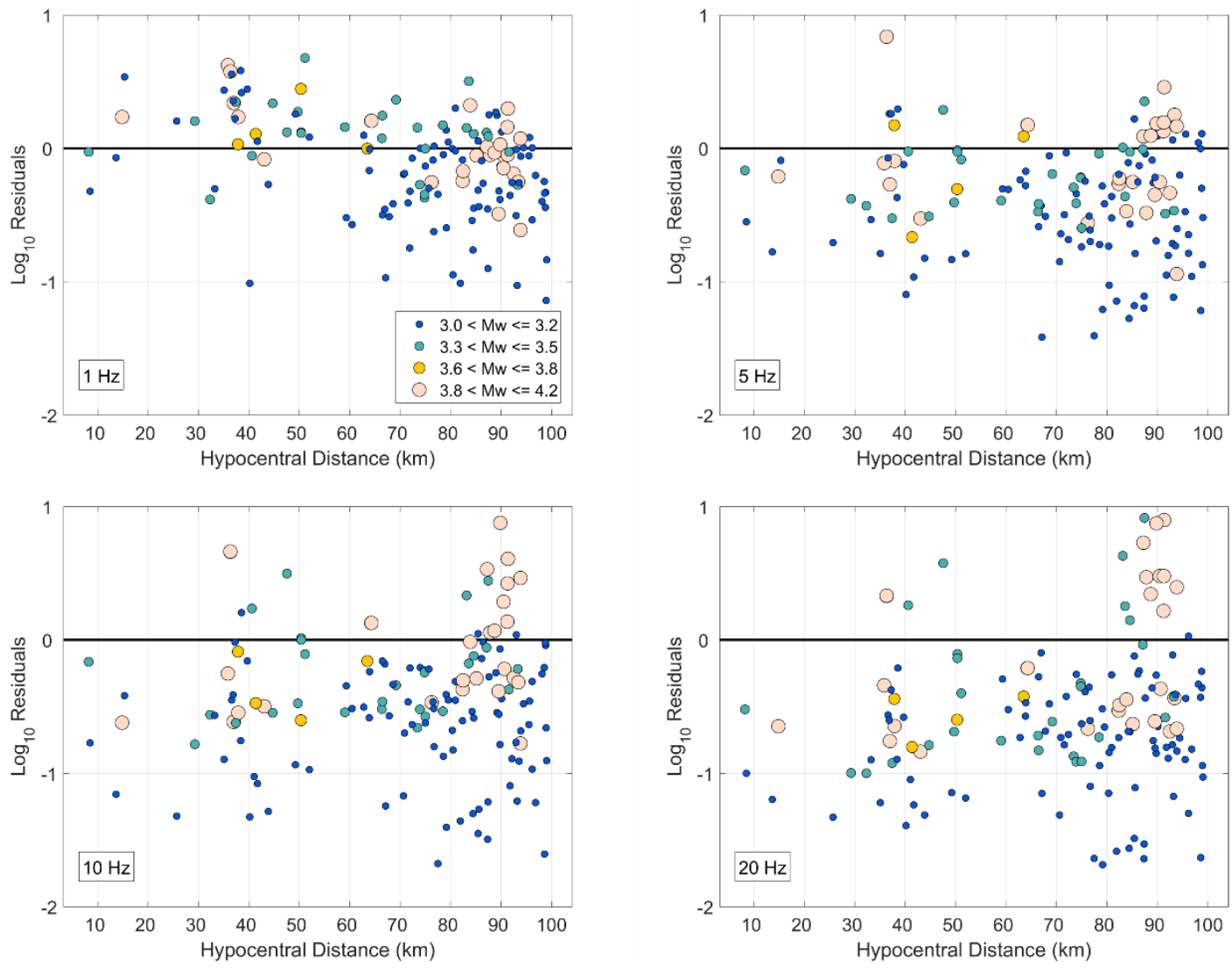

Figure C9. Log (base 10) residuals versus hypocentral distance for horizontalcomponent Alberta PSAs (all records) with respect PSA predicted by A15 at 1, 5, 10, and $20 \mathrm{~Hz}$. Marker sizes indicate magnitude bins of Alberta events. 

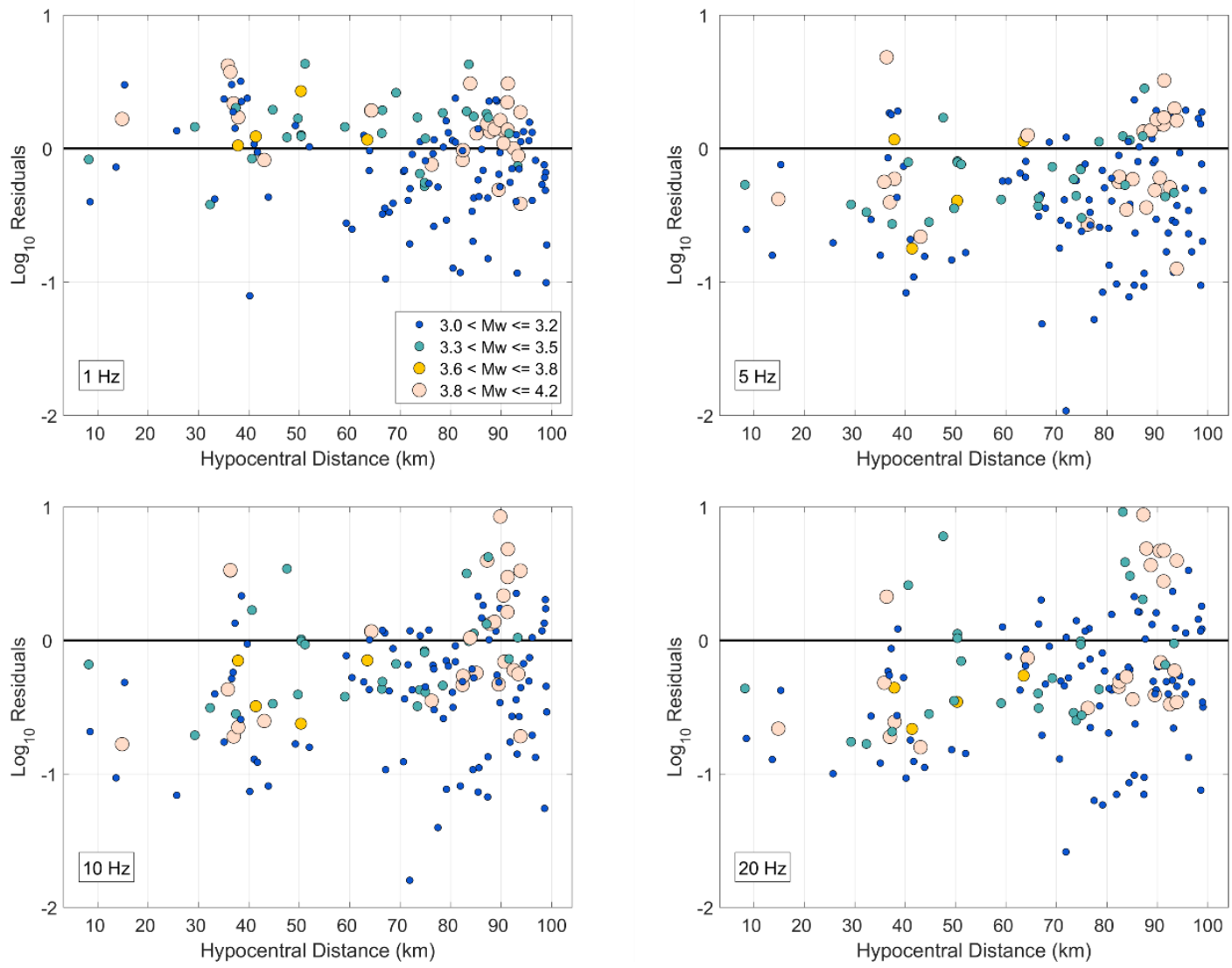

Figure C10. Log (base 10) residuals versus hypocentral distance for vertical-component Alberta PSAs (all records) with respect to PSA predicted by YA15 ${ }_{\text {CENA }}$ (focal depth $=$ $2 \mathrm{~km}$ ) at 1, 5, 10, and $20 \mathrm{~Hz}$. Marker sizes indicate magnitude bins of Alberta events. 

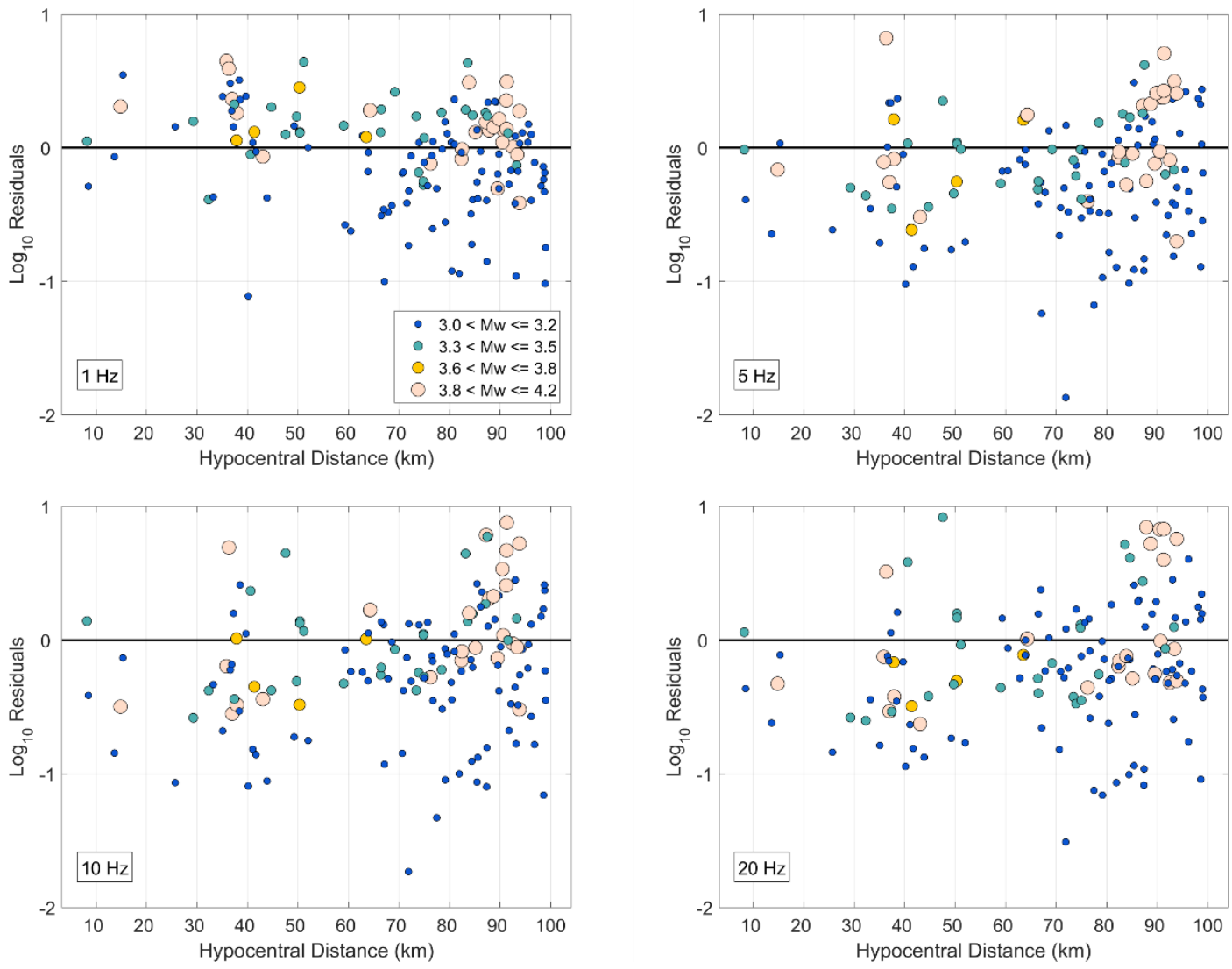

Figure C11. Log (base 10) residuals versus hypocentral distance for horizontalcomponent Alberta PSAs (all records) with respect to PSA predicted by ASK14 (with depth to rupture modification for induced events) at 1, 5, 10, and $20 \mathrm{~Hz}$. Marker sizes indicate magnitude bins of Alberta events. 


\section{Curriculum Vitae - Krista Kaski}

Name:

Post-Secondary Education and Degrees:

\section{Honours and Awards:}

Related Work Experience:

Publications:

Kaski, K. M. and G. M. Atkinson (2017). A Comparison of Ground Motion Characteristics from Induced Seismic Events in Alberta with those in Oklahoma, Seismological Research Letters, 88, no. 6, 1570-1585.
Krista M. Kaski

University of Western Ontario

London, Ontario, Canada

2010-2015 Honors B.Sc. Geophysics

University of Western Ontario

London, Ontario, Canada

2015-2017 M.Sc. Geophysics

Western Scholarship for Excellence 2010

Geophysics Scholarship for Excellence 2011, 2012, 2014,

J.P. Bickell Mining Foundation Scholarship 2011, 2012, 2014

Western Gold Medal

2015

Charles M. Carmichael Prize

2015

NSERC Undergraduate Student Research Award

2015

NSERC Canada Graduate Scholarship Master's (CGS-M)

2016-2017

Geophysics Travel Scholarship

2017

Research Assistant The University of Western Ontario 2015-2017

Teaching Assistant The University of Western Ontario 2015-2017

Geophysical Field Work Assistant Natural Resources Canada 2017 